\begin{tabular}{|l|l|}
\hline $\begin{array}{l}\text { 2. To: (Receiving Organization) } \\
\text { Packaging Engineering }\end{array}$ & $\begin{array}{l}\text { 3. From: (Originating Organization) } \\
\text { Packaging Engineering }\end{array}$ \\
\hline $\begin{array}{l}\text { 5. Proj./Prog./Dept./Div.: } \\
03 E 00\end{array}$ & $\begin{array}{l}\text { 6. Design Authority/ Design Agent/Cog. } \\
\text { Engr: }\end{array}$ \\
\hline $\begin{array}{l}\text { 8. Originator Remarks: } \\
\text { The attached test report is being submitted for approval and } \\
\text { release. }\end{array}$
\end{tabular}

11. Receiver Remarks:

11A. Design Basel ine Document?
4. Related EDT No.:

NA

7. Purchase Order No.:

NA

9. Equip./Component No.:

NA

10. System/Bldg./Facility: NA

12. Major Assm. Dwg. No.: NA

13. Permit/Permit Application No.: NA

14. Required Response Date: NA

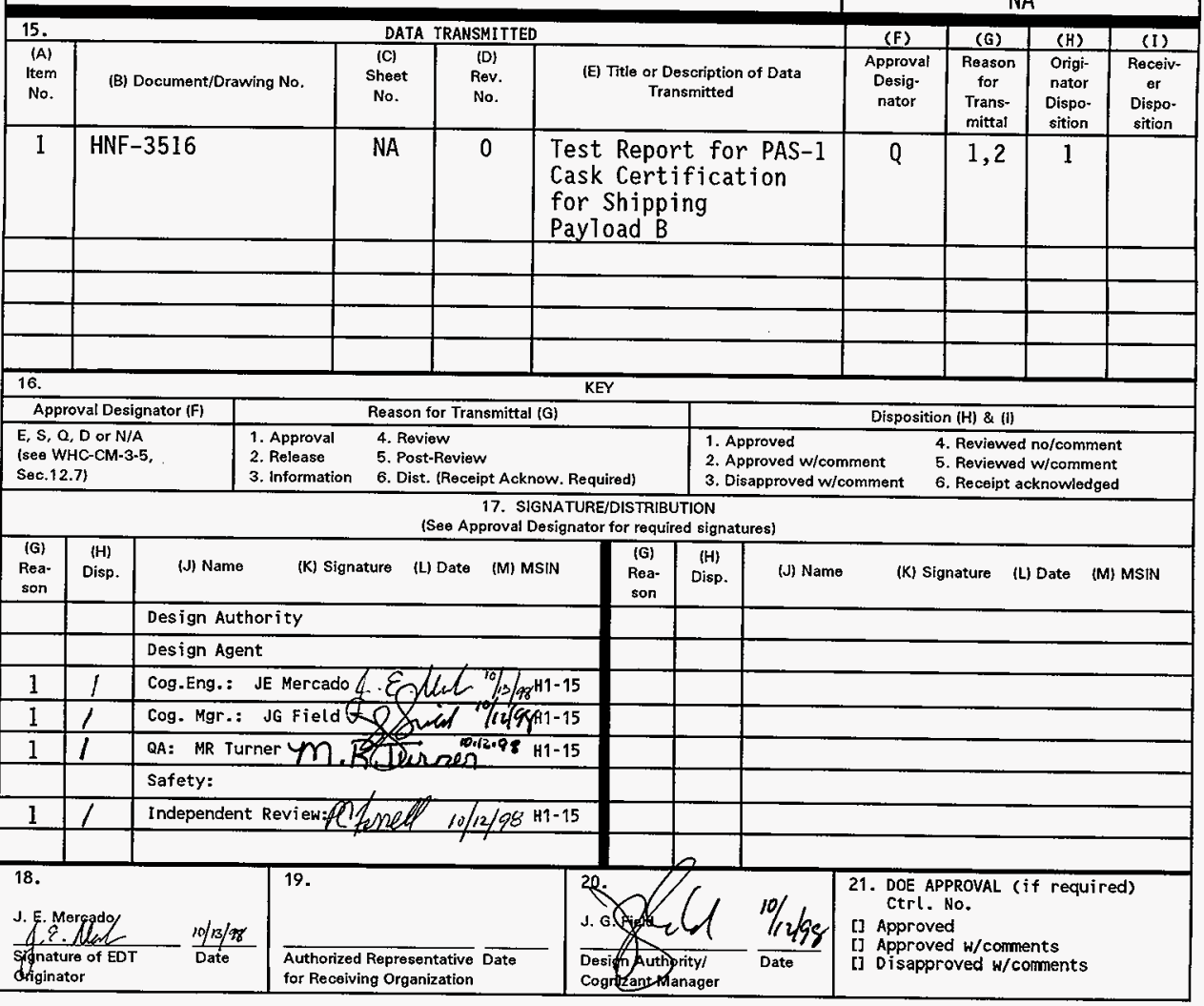




\title{
Test Report for PAS-1 Cask Certification for Shipping Payload B
}

\author{
J. E. Mercado \\ Waste Management Federal Services, Inc., Northwest Operations \\ Rich T and, Washington 99352 \\ for Fluor Daniel Hanford, Inc. \\ U.S. Department of Energy Contract DE-AC06-96RL13200 \\ EDT/ECN: EDT 622969 \\ Org Code: $03 \mathrm{E} 00$ \\ Task Order: GS080003 \\ B\&R Code: \\ UC: 513 \\ CACN: 103430 COA: EF00 \\ Project: 772031 Crosswalk: 116 \\ Tota] Pages: 156
}

Key Words: Certificate of Compliance, visual weld inspections, dimensional inspections, dye penetrant examinations, helium leak testing, pressure testing

Abstract: This test report documents the successfut inspection and testing to certify two NuPac PAS-1 casks in accordance with U.S. Department of Energy Certificate of Compliance (COC) USA/9184/B(U) . The primary and secondary containment vessels of each cask met the acceptance criteria defined in the $\mathrm{COC}$ and the test $\mathrm{plan}$.

TRADEMARK DISCLAIMER. Reference herein to any specific comercial product, process, or service by trade name, trademark, manufacturer, or otherwise, does not necessarily constitute or imply its endorsement, recommendation, or favoring by the United States Government or any agency thereof or its contractors or subcontractors.

Printed in the United States of America. To obtain copies of this document, contact: WHC/BCS Document Control Services, P.0. Box 1970, Mailstop H6-08, Richtand WA 99352, Phone (509) 372-2420; Fax (509) 376-4989.
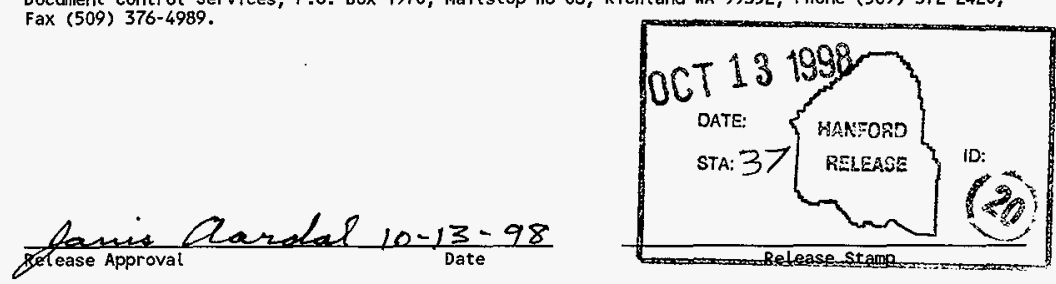

\section{Approved for Public Release}


HNF-3516, Rev. 0

This page intentionally left blank. 
HNF-3516, Rev. 0

\section{CONTENTS}

1.0 INTRODUCTION .1

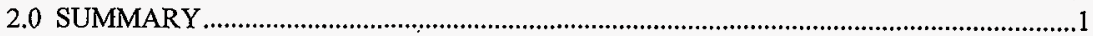

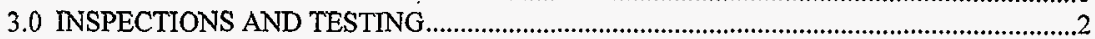

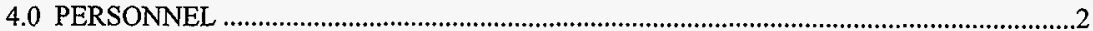

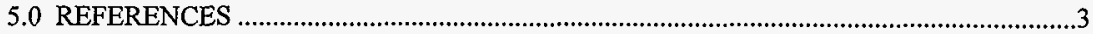

\section{APPENDICES}

A TEST REPORT FOR VISUAL WELD INSPECTIONS …............................................... A-i

B TEST REPORT FOR DIMENSIONAL INSPECTIONS ................................................... B-i

C TEST REPORT FOR DYE PENETRANT EXAMINATIONS …….................................. C-i

D TEST REPORT FOR HELIUM LEAK TESTING …........................................................

E TEST REPORT FOR PRESSURE TESTING ....................................................................... 
HNF-3516, Rev. 0

\section{LIST OF TERMS}

$\mathrm{cm}$

Cogema

DOE

in.

$\mathrm{kPa}$

L

LLNL

psig

PCV

WMNW centimeter

Cogema Engineering Corporation

U.S. Department of Energy

inch

kilopascals (gage)

liter

Lawrence Livermore National Laboratory

pounds per square inch, gage

primary containment vessel

Waste Management Federal Services, Inc., Northwest Operations 


\section{TEST REPORT FOR PAS-1 CASK CERTIFICATION FOR SHIPPING PAYLOAD B}

\subsection{INTRODUCTION}

The NuPac PAS-1 cask was required to undergo inspection and testing in order to be certified in accordance with U.S. Department of Energy (DOE) Certificate of Compliance USA/9184/B(U) (DOE 1998). The intent of the inspection and testing was to verify that pressurization of the containment vessels will not impair the performance of the cask or damage the welds. This investigation was considered necessary because the cask was not originally designed to carry a payload with the potential to pressurize the containment vessels. Payload B authorizes the transport of up to $4 \mathrm{~L}$ of liquid radioactive waste from the Hanford tank farms. This payload does have chemical and radiological properties that could result in gas generation and subsequent pressure increases inside the package.

Casks Serial Numbers 2162-026 and 2162-027 were inspected and tested in the 305 Engineering Testing Laboratory in the 300 Area at the Hanford Site. Waste Management Federal Services, Inc., Northwest Operations (WMNW), Packaging Engineering, was in charge of the testing. Numatec Hanford Corporation directed the operations in the test facility.

\subsection{SUMMARY}

The testing and inspections were conducted successfully with both the primary and secondary containment vessels of each cask meeting the acceptance criteria defined in DOE (1998) and HNF-2979, Test Plan for PAS-1 (USA/9184/B/U] DOE Serial Numbers 2162-026 and 2162-027 To Ship Payload B (Mercado 1998b). No distortion or other anomalies were observed.

A series of inspections was performed to determine the baseline condition of each vessel. These inspections included visual weld inspection, dimensional inspections, and dye penetrant examination of the primary containment vessel (PCV) welds. Both casks were subjected to a $348 \mathrm{kPa}$ gage (50-psig) pressure test, with helium leak testing taking place before and after the pressure test. 


\subsection{INSPECTIONS AND TESTING}

The tests and inspections were conducted in accordance with HNF-3355, Procedures and Acceptance Criteria for PAS-1 Cask Inspections (Mercado 1998a) and Mercado (1998b). The test and inspection reports are provided in Appendices $\mathrm{A}$ through $\mathrm{E}$. The sequence began on Wednesday, September 9, 1998, and concluded on Thursday, September 17, 1998.

Initial helium leak testing of the secondary containment vessels was unsuccessful, with both casks failing to meet the acceptance criteria. The margin of failure was small, indicating a minor problem with the sealing surfaces. The carbon steel sealing surfaces of the secondary containment vessels were polished by hand with $320-, 400$-, and 600-grit sandpaper to remove some visible scratches, and the subsequent tests met the acceptance criteria for leak-tightness.

The bottom welds of the PCVs were dressed using a 180-grit flapper wheel and a 320 blending belt. The inner weld on vessel $2162-027$ was ground in two locations approximately $1.27 \mathrm{~cm} \times 0.64 \mathrm{~cm}(0.5 \mathrm{in} .0 .25 \mathrm{in}$.) with a 160 -grit disk grinder.

The post-pressure leak test of the 2162-026 PCV was unsuccessful. Examination of the sealing surface detected a burr in the area below the o-ring, which had been scratched across the surface. The burr was removed and the surface polished with 400-grit sandpaper to remove some visible scratches. The results of the subsequent leak test were acceptable.

\subsection{PERSONNEL}

The following personnel were involved in the testing of the PAS-1:

Cognizant Engineer: J. E. Mercado (WMNW)

WMNW Packaging Engineering Manager: J. G. Field

Technical Lead, Mechanical Engineering: R. J. Smith (WMNW)

Chief Engineer, Licensing and Certification: P. C. Ferrell (WMNW)

Chief Mechanical Engineer: S. S. Shiraga (WMNW)

Engineering Testing Laboratory: P. V. Meeuwsen (Numatec Hanford Corporation)

DOE, Richland Operations Office, Traffic Manager: D. W. Claussen

DOE Certification Official: M. E. Wangler (EM-30) 
Test witnesses: $\quad$ R. Towell (Eagle Research Group)

E. W. Russell (Lawrence Livermore National Laboratory (LLNL)

J. Hovingh (LLNL)

R. S. Hafner (LLNL)

Quality Control Inspectors:

M. F. Brickey (Waste Management Federal Services of

Hanford, Inc. (WMH)

D. L. Vance (WMH)

S. C. Peterson (DE\&S Northwest, Inc.)

B. L. Smith (WMH)

Nondestructive examination:

W. D. Purdy (Cogema Engineering Corporation [Cogema])

B. L. Hopkins (Cogema)

J. K. Keve (Cogema)

W. H. Nelson (Cogema)

Technical experts: $\quad$ C. E. Graves (Fluor Daniel Northwest, Inc.)

T. A. Delucchi (Cogema).

\subsection{REFERENCES}

DOE, 1998, U.S. Department of Energy Certificate of Compliance for Radioactive Materials Packages, USA/9184/B(U), Rev. 0, U.S. Department of Energy, Washington, D.C.

Mercado, J. E., 1998a, Procedures and Acceptance Criteria for PAS-1 Cask Inspections, HNF-355, Rev. 0, prepared by Waste Management Federal Services, Inc., Northwest Operations for Fluor Daniel Hanford, Inc., Richland, Washington.

Mercado, J. E., 1998b, Test Plan for PAS-1 (USA/9184/B[U] DOE Serial Numbers 2162-026 and 2162-027 To Ship Payload B, HNF-2979, Rev. 0, prepared by Waste Management Federal Services, Inc., Northwest Operations for Fluor Daniel Hanford, Inc., Richland, Washington. 
HNF-3516, Rev. 0

This page intentionally left blank. 
HNF-3516, Rev. 0

APPENDIX A

TEST REPORT FOR VISUAL WELD INSPECTIONS 
HNF-3516, Rev. 0

This page intentionally left blank.

A-ii 
HNF-3516, Rev. 0

HNF-3355 Rev. 0

APPENDIX A: VISUAL WELD INSPECTION REPOAT.

POST PRESSuRE TEST

PAS-1 Cask Serial Number 2162-026

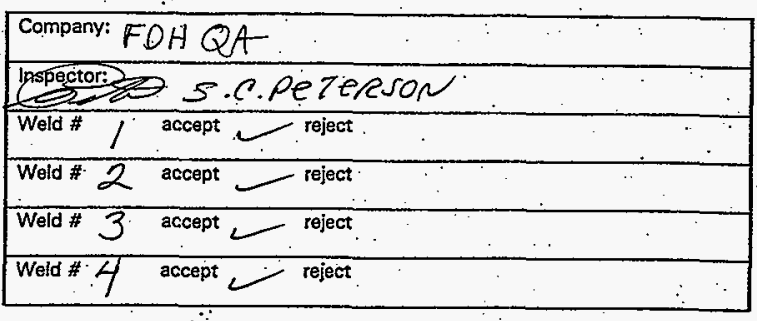

PAS-1 Cask Sprial Number 2162-027

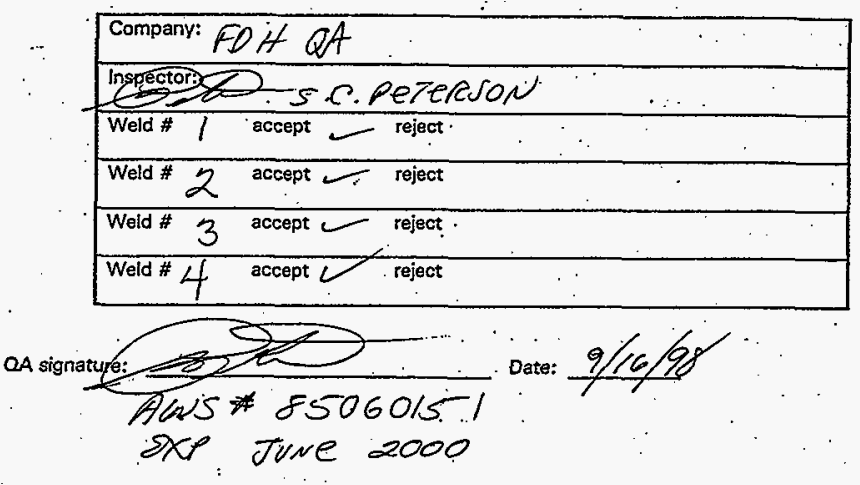


HNF-3516, Rev. 0

HNF-3355 - Rev. 0

APPENDIX A: VISUAL WELD INSPECTION REPORT.

PAS-1 Cask Serial Number 2162-026

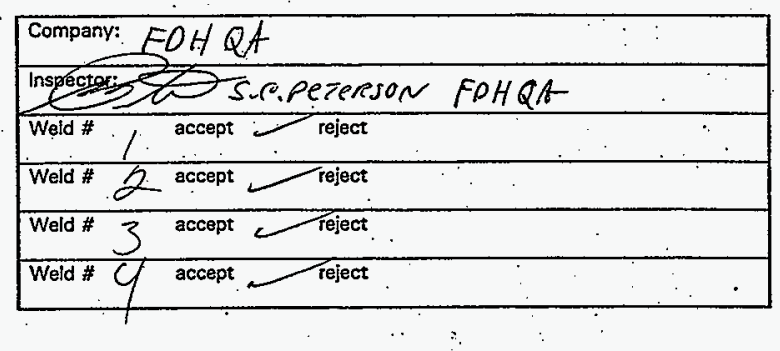

PAS-1 Cask Serial Number 2162-027

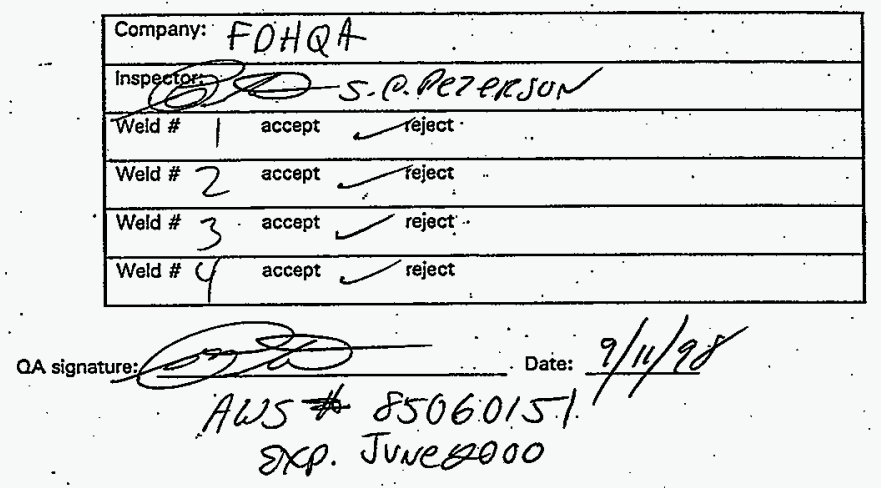


HNF-3516, Rev. 0

APPENDIX B

TEST REPORT FOR DIMENSIONAL INSPECTIONS

B-i 
HNF-3516, Rev. 0

This page intentionally left blank.

B-ii 
HNF-3516, Rev. 0

HNF-3355 Rev. 0

Table 1.

Serial number $2 / 62-26$

Initial Moasttrements and Inspoctions record all dimensions in thenes

\begin{tabular}{|c|c|c|c|}
\hline Baso & OD. & Os & రం \\
\hline Vertical iocation & Odegreas & 120-degrees & 240 decreeg \\
\hline LOP & 18.9725 & $18.963 \quad 20,353$ & $19.000 \quad 70,570$ \\
\hline center & 18.924 & 28.272 & 28.973 \\
\hline botlom & 13,922 & 19.262 & $1 / 8.981$ \\
\hline
\end{tabular}

\begin{tabular}{|c|c|c|c|c|c|c|}
\hline 나영 & It & $\mathrm{OD}$ & ID & OD & & 60 \\
\hline Vertical jocation & \multicolumn{2}{|c|}{ odegreas } & \multicolumn{2}{|c|}{120 degrees } & \multicolumn{2}{|c|}{240 degrees } \\
\hline Lop & 18.435 & 70,585 & $18: 024$ & 20.585 & 28.026 & 20.581 \\
\hline center & 18.056 & $N / t^{2}$ & 18.045 & 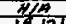 & 40039 & $A / 7$ \\
\hline
\end{tabular}

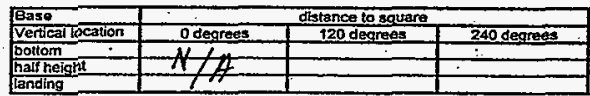
BASE NOT.. SQUARE

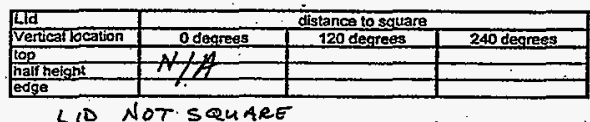

LID NOT SQUUARE

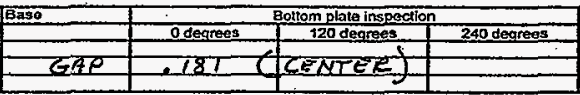

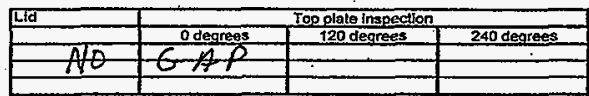

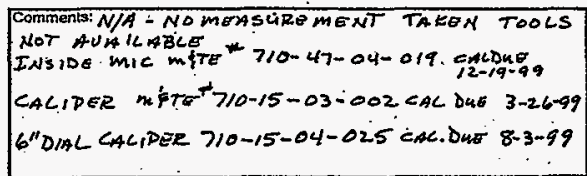

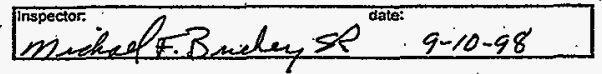


HNF-3516, Rev, 0

HNF-3355 Rev. 0

Table 2.

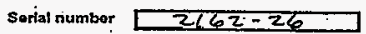

Post-test Measurements and inspections record ald dimensions in triches

\begin{tabular}{|c|c|c|c|}
\hline gaso & OD & 00 & ठర \\
\hline Vertical tocation & 0 degreas & 120 deqtees & 240 degrees \\
\hline $\begin{array}{l}\text { cop } \\
\text { cen!er } \\
\text { bottom }\end{array}$ & 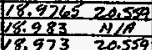 & $\begin{array}{ll}18,962 & 20551 \\
18,972 & N / 4\end{array}$ & $\begin{array}{ll}19.001 & 20.571 \\
18.952 & \mathrm{~N} / \mathrm{h}\end{array}$ \\
\hline
\end{tabular}

\begin{tabular}{|c|c|c|c|}
\hline Lid & $0 D$ & $O D$ & OD \\
\hline Vertical localion & Odegroes & 120 degrees & 240 degrees \\
\hline $\begin{array}{l}\text { Sop } \\
\text { Center } \\
\text { Dothom }\end{array}$ & $\frac{18.043520 .586}{18.056} \frac{\mathrm{N} / \mathrm{H}}{18.061}$ & $\frac{18.026-79585}{18.046-029-\frac{N 17}{19 . n 1}}$ & $\begin{array}{ll}18026 & 2058 \\
\angle 8,039 & 1 / 12 \\
18.0515 & 19.171\end{array}$ \\
\hline
\end{tabular}

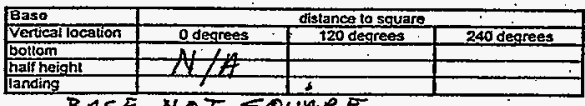

BASE NOT SQUARE.

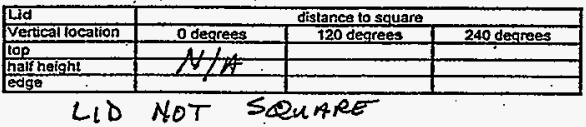

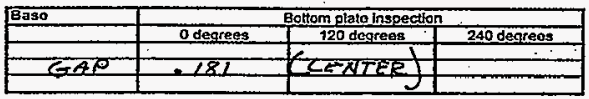

\begin{tabular}{|c|c|c|c|}
\hline प्रत् & & plate inspecti & \\
\hline & Odegrees & 120 degrees & 240 degrees \\
\hline No & $G A P$ & & \\
\hline & & & \\
\hline
\end{tabular}
Comments:N/A NO MEAS AREMEMT THKEA TOLS

FNSRD MeC. mire* $710-47-04-019$ 2AC-D DE CALCPER m iste-\#-710-15-03-002 CAC,DnF 3-26-99

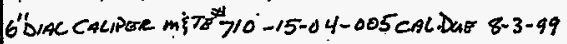

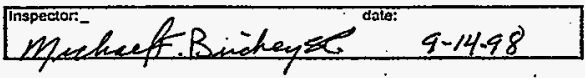




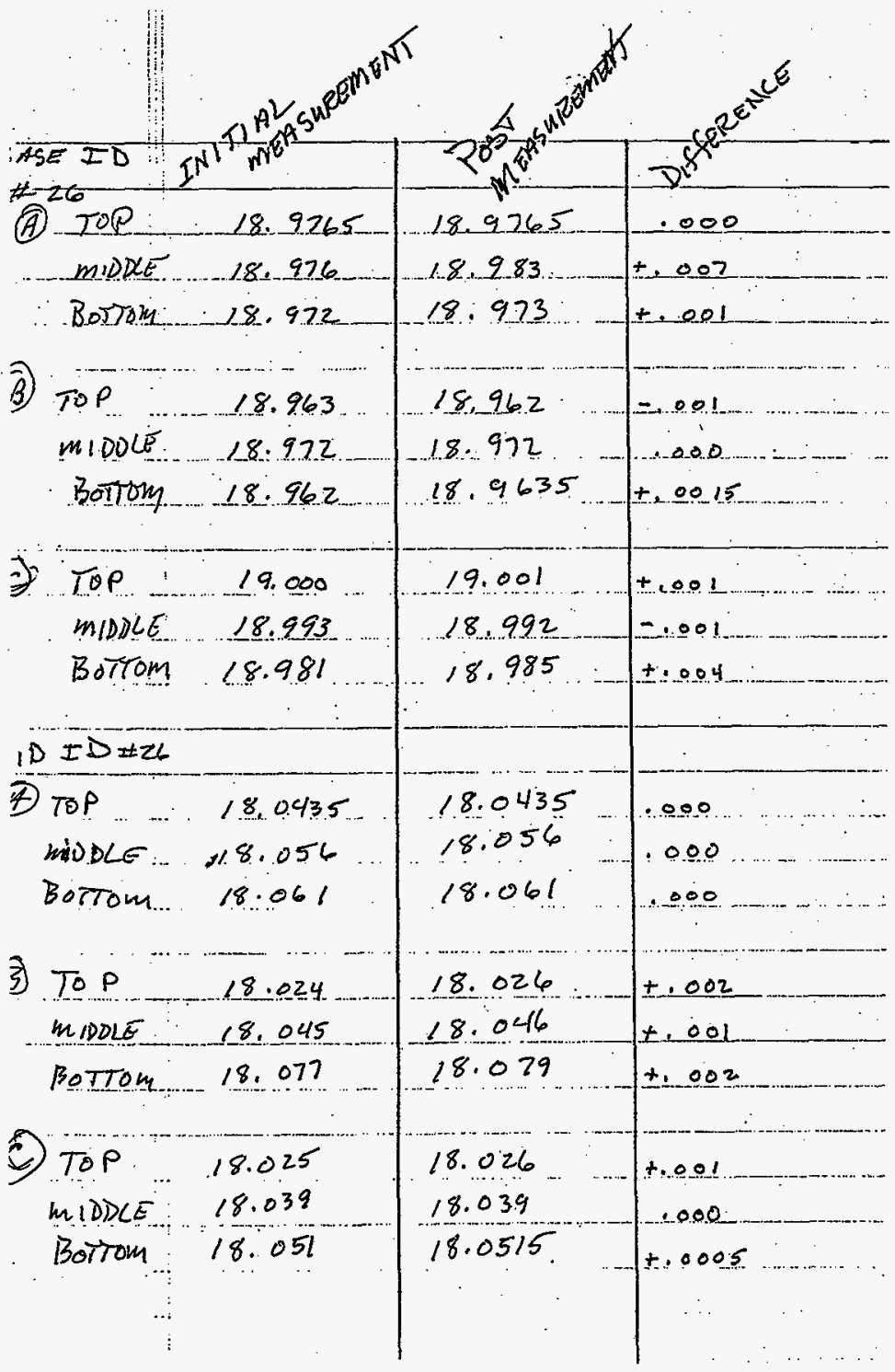




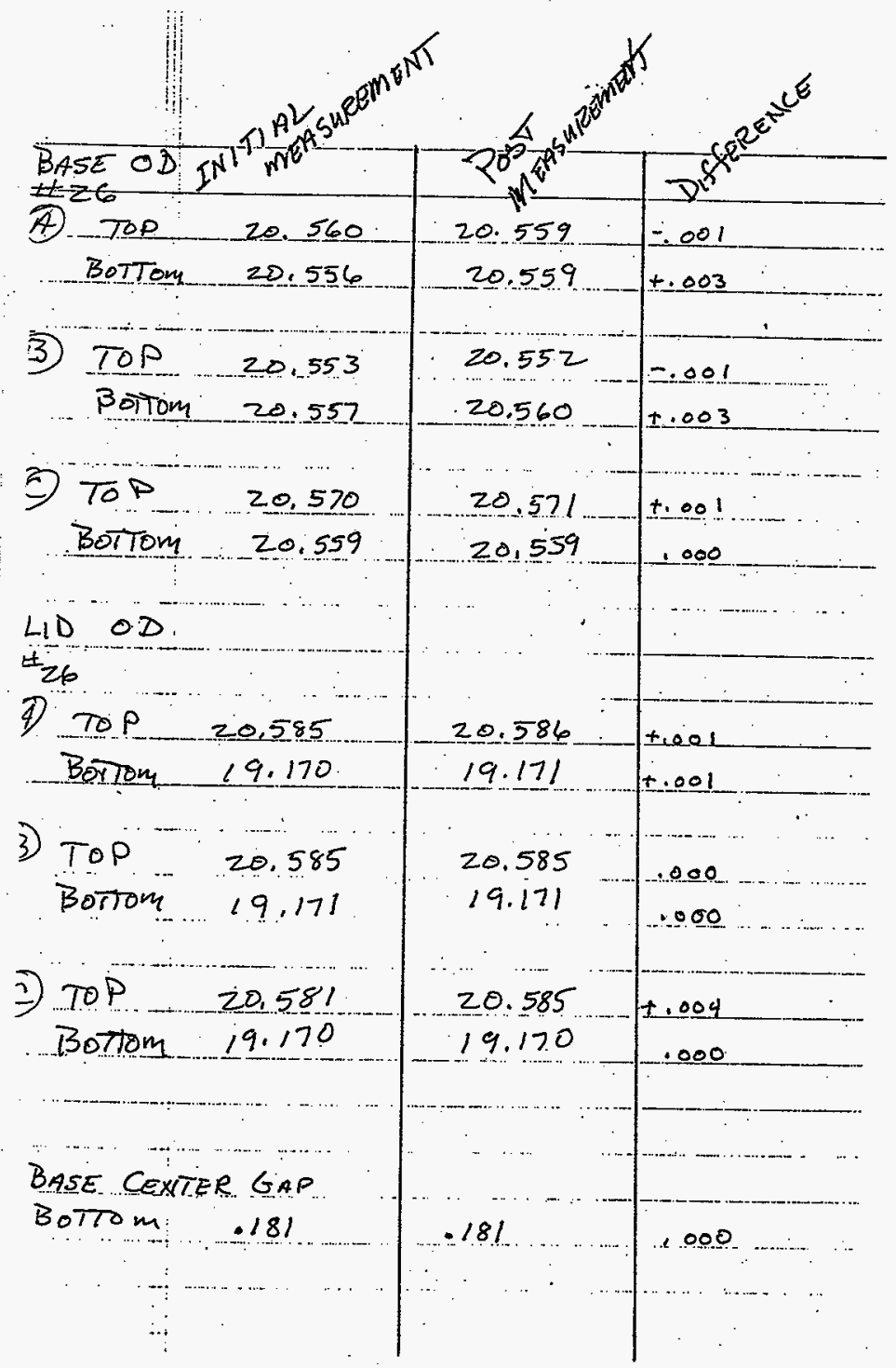


HNF-3516, Rev. 0

HNF-3355 Rev. 0

Table 1.

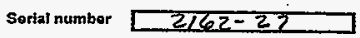

Initial Moasurements and Inspoctions record all dimensioris in inches

\begin{tabular}{|c|c|c|c|c|c|}
\hline Baso & 00 & & $\phi 0$ & T & OD \\
\hline Vertical location & o dequees & 720. & rees & 2400 & rees \\
\hline$\frac{\text { cop }}{\text { center: }}$ & $\frac{18.949}{18926} \frac{24561}{18.953} \frac{N 16}{20.519}$ & $\frac{18.994}{18.958}$ & $\frac{20,57}{N / A}$ & $\frac{9.940}{8.949}$ & $\frac{20,52}{20 / 2}$ \\
\hline
\end{tabular}

\begin{tabular}{|c|c|c|c|c|}
\hline LId & 00 & T5 & 60 & का \\
\hline vertcal location & odegrees & 120 & grees & 240 degrees \\
\hline $\begin{array}{l}\text { Lop } \\
\text { Center } \\
\text { bottom }\end{array}$ & 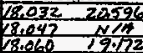 & $\frac{18.035}{18.047}$ & $\frac{\frac{20,07}{\alpha 17}}{1 \% 122}$ & 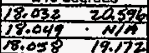 \\
\hline
\end{tabular}

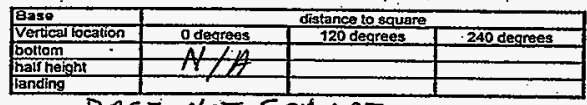

landing

BASE NOT SQÚLAE

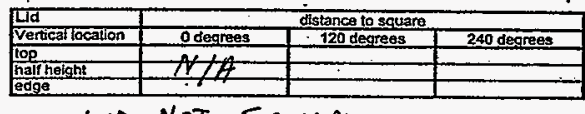

$\angle I D$ Not Seuiter

\begin{tabular}{|c|c|c|c|}
\hline Baso & \multirow{2}{*}{\multicolumn{3}{|c|}{ Bottom plate inspection }} \\
\hline & Odeqrees & & 240 dequees \\
\hline EAP & 191 & NITE & \\
\hline
\end{tabular}

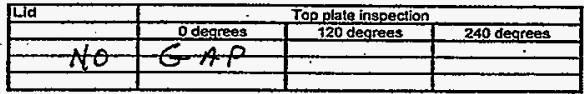

Comments: NO NLASUREMEMT TAKEX * IN'SIDE MIC-m!TE: 710-47-04-019 CAL DUE $12-19-99$

CALIPER in tTE" $710-15-03-002$ CALDUF 3-26-99 6"DIAC CALIPER MITE" $710.15-04-025$ CAL DUE 8-3-99

* ToOLS Not MUAlLABCE

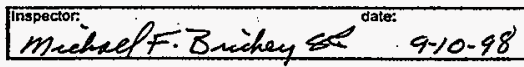


HNF-3516, Rev. 0

HNF-3355 Rev. 0

Table 2.

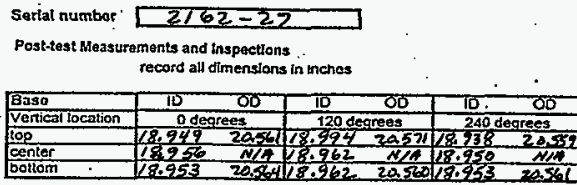

\begin{tabular}{|c|c|c|c|c|c|c|}
\hline Lid & DD & $\infty 0$ & 10 & 00 & ID & . \\
\hline Verteal location & \multicolumn{2}{|c|}{ Odeqrees } & \multicolumn{2}{|c|}{120 degrees } & \multicolumn{2}{|c|}{240 decreas } \\
\hline top & 18.032 & 20,524 & 78.036 & 29596 & 18,034 & 20,596 \\
\hline $\begin{array}{l}\text { Center } \\
\text { bottom }\end{array}$ & $\frac{180447}{180059}$ & $\frac{N / 1}{19.170}$ & $\frac{18.047}{18.057}$ & $\frac{N / 4}{19.170}$ & $\frac{18,44}{18+0575}$ & $\frac{11}{19.121}$ \\
\hline
\end{tabular}

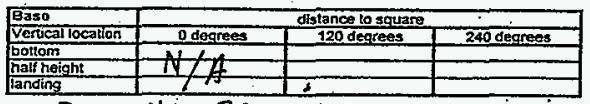

tanding

BASE NOT SQUARE

\begin{tabular}{|c|c|c|c|}
\hline Ed & \multicolumn{3}{|c|}{ distance to scuare } \\
\hline Vertcal location & 0 degrees & 120 degrees & 240 degrees \\
\hline IOP & & & \\
\hline half helght & & & \\
\hline
\end{tabular}

LID NoT SquneE

\begin{tabular}{|c|c|c|c|}
\hline Baso & \multirow{2}{*}{\multicolumn{3}{|c|}{ Sottom plate inspection }} \\
\hline & Odegrees & & 240 degrees \\
\hline EATO & 19 & $z$ & \\
\hline
\end{tabular}

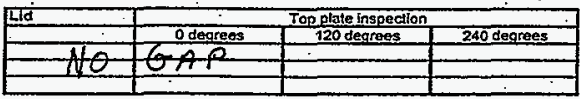

Comments: NO MEASUREMENT TAKEN $*$

INSIDE WIC - Mtre $710+47-04-019$

INSIDE WIC-MfTE CAL DHE 12-19-99

CALIPER m/TE 710-15-03-002 CALDME.3-26-49

6"DIALCACIPER M हुTE 710-15-04-025

Cul out - 8-3-49

- Tools Not AUA/2 Abla

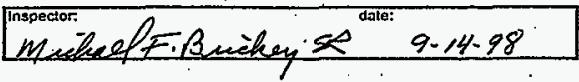

5. 
HNF-3516, Rev. 0

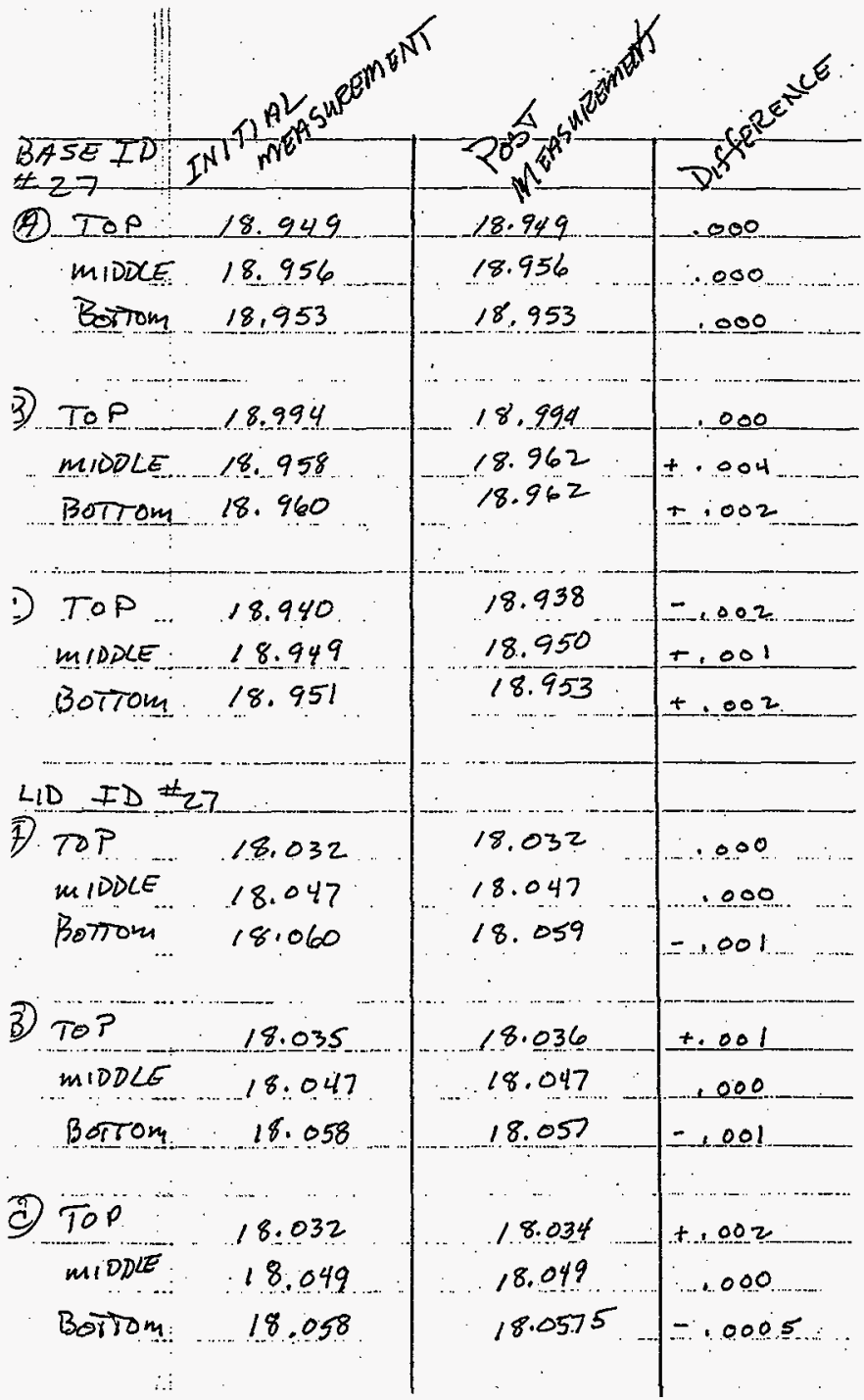




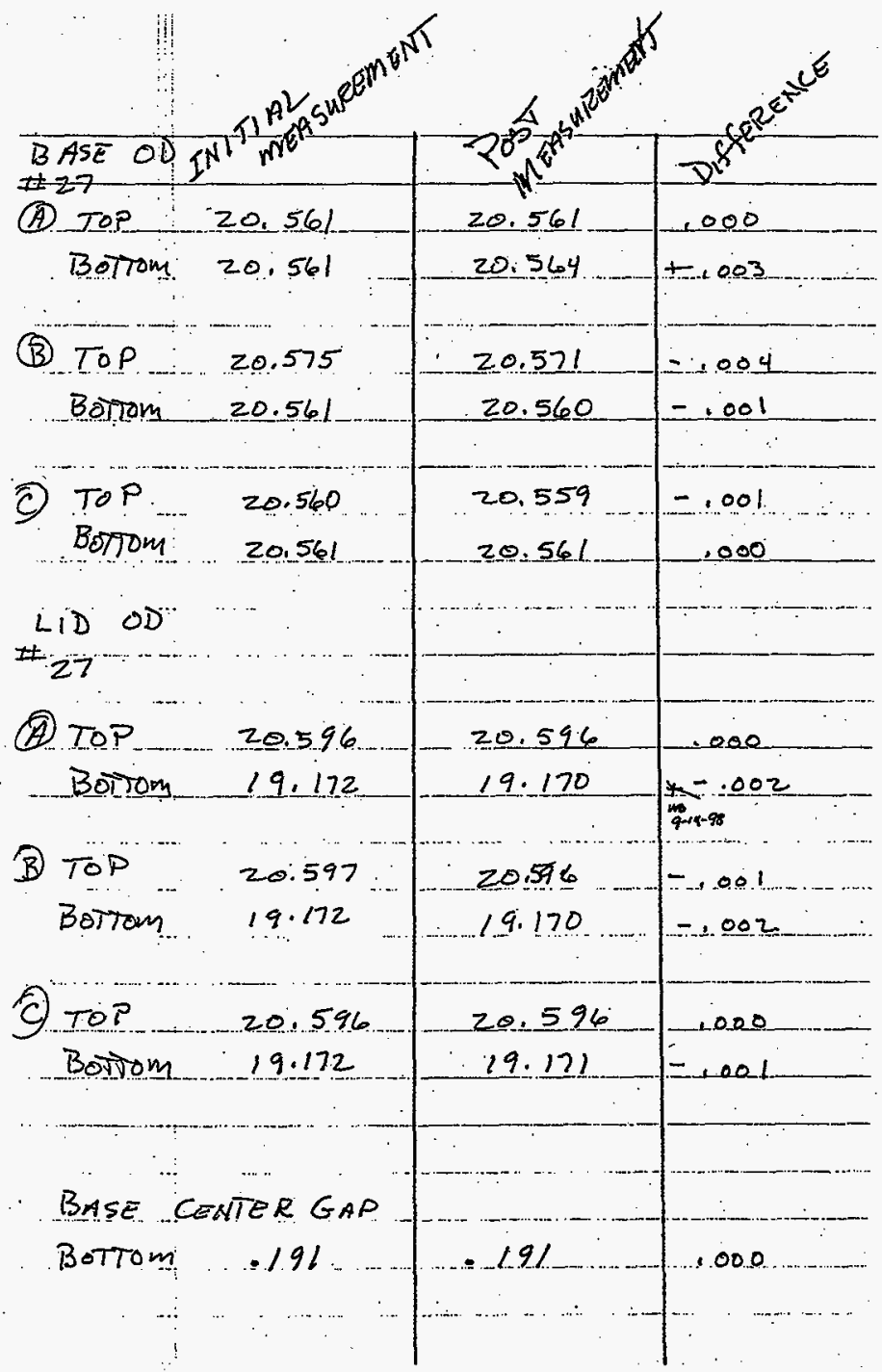


HNF-3516, Rev. 0

\section{APPENDIX C}

\section{TEST REPORT FOR DYE PENETRANT EXAMINATIONS}

C-i 
HNF-3516, Rev. 0

This page intentionally left blank.

C-ii 


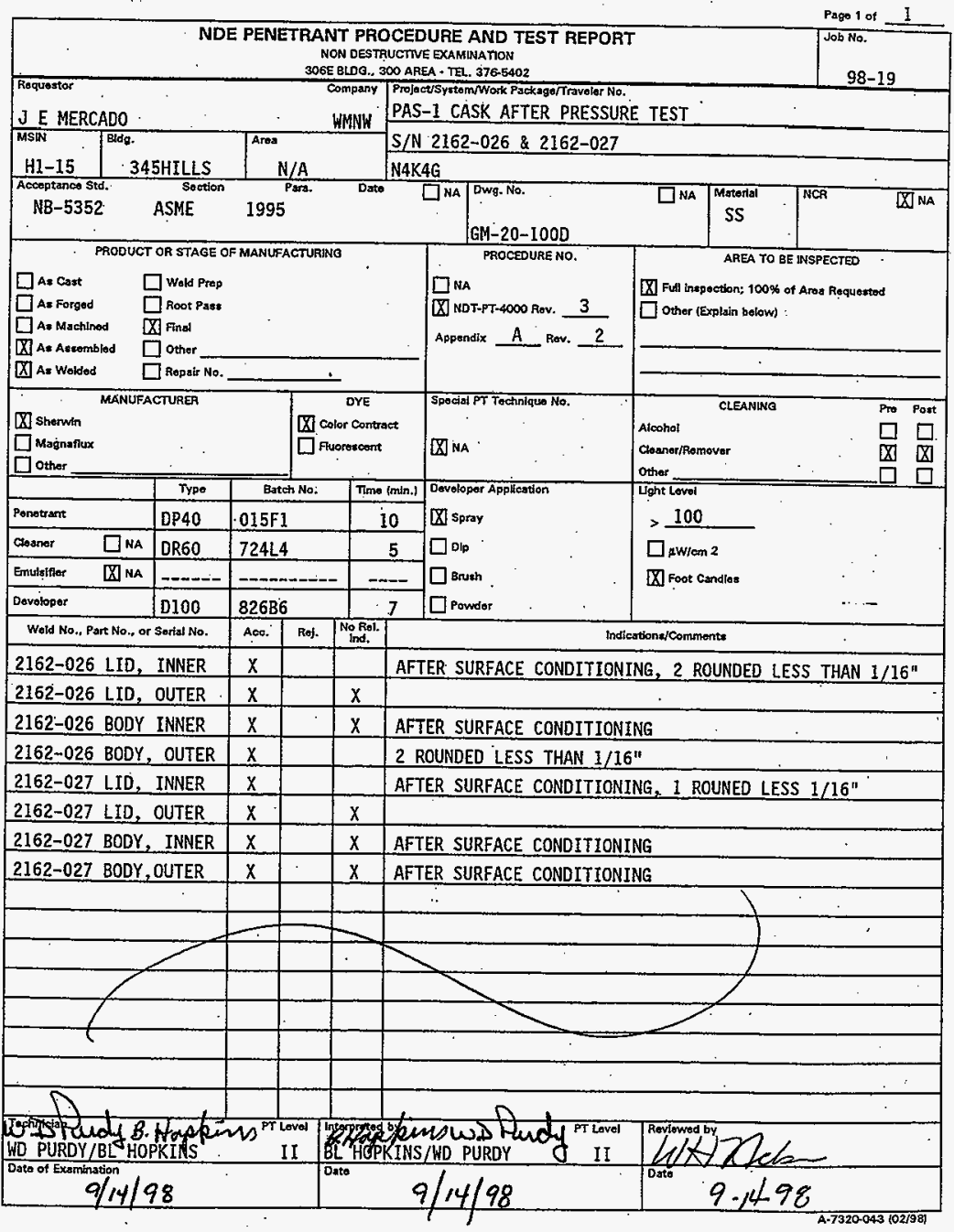




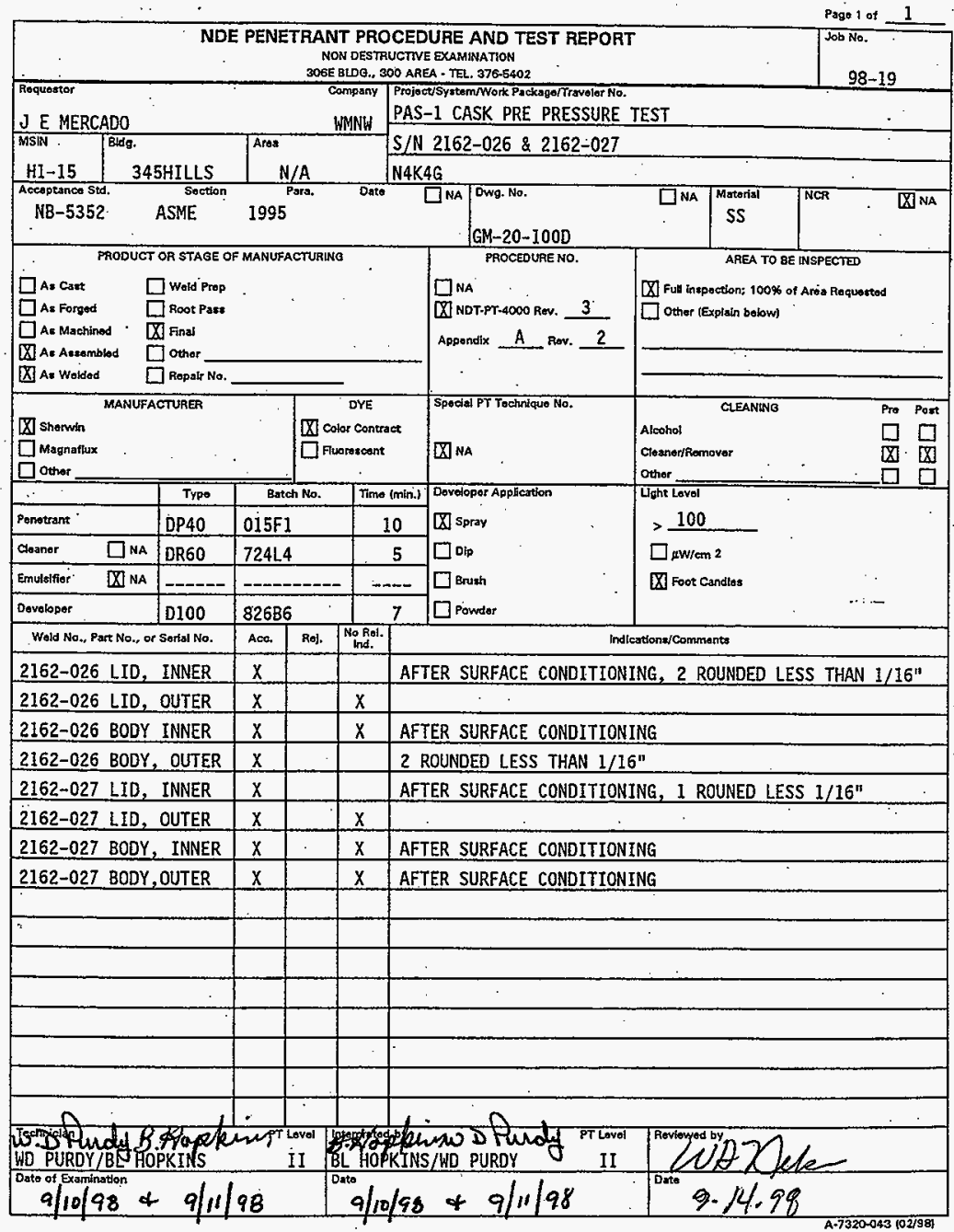


HNF-3516, Rev. 0

APPENDIX D

TEST REPORT FOR HELIUM LEAK TESTING

D-i 
HNF-3516, Rev. 0

This page intentionally left blank.

D-ii 


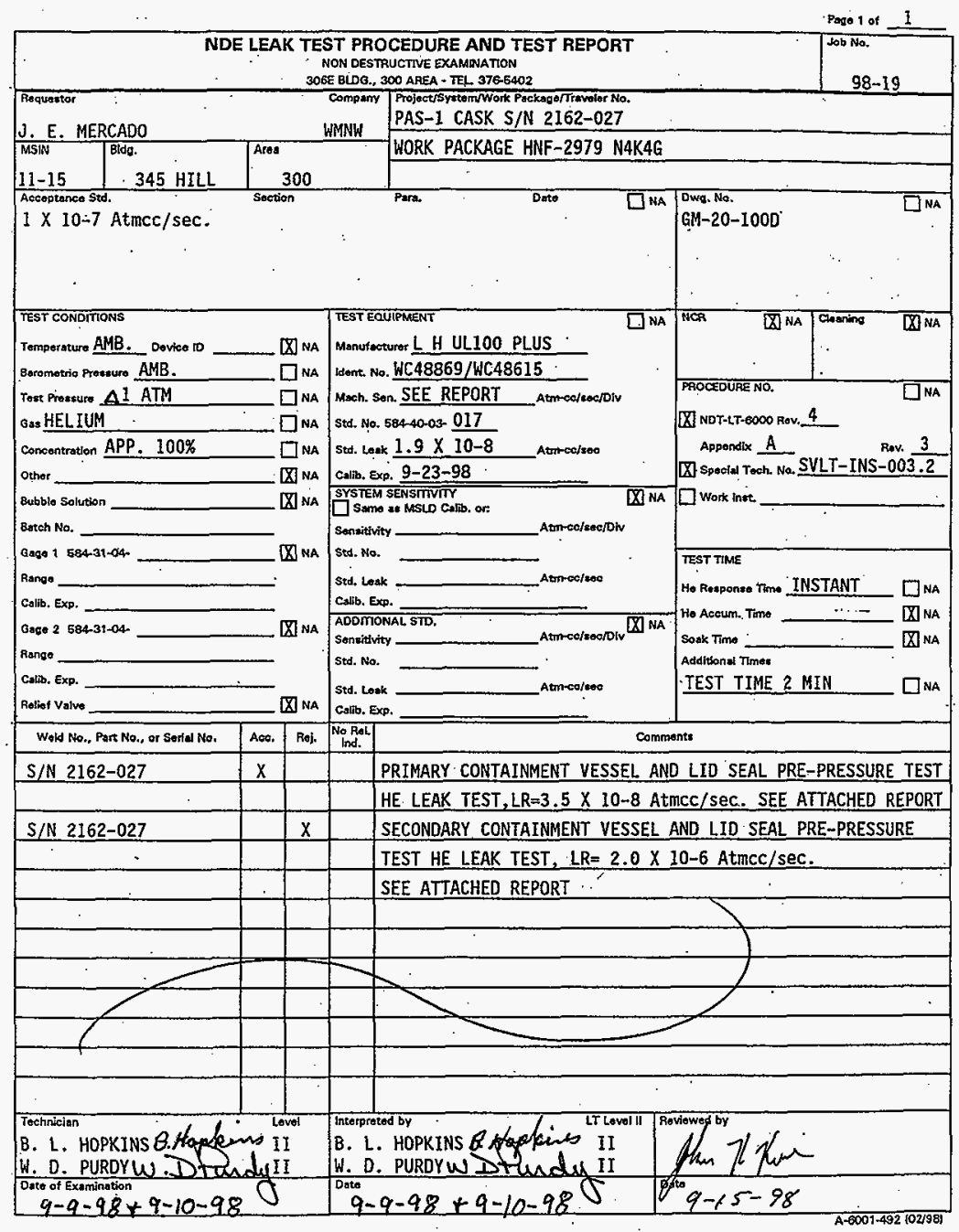


HNF-3516, Rev. 0

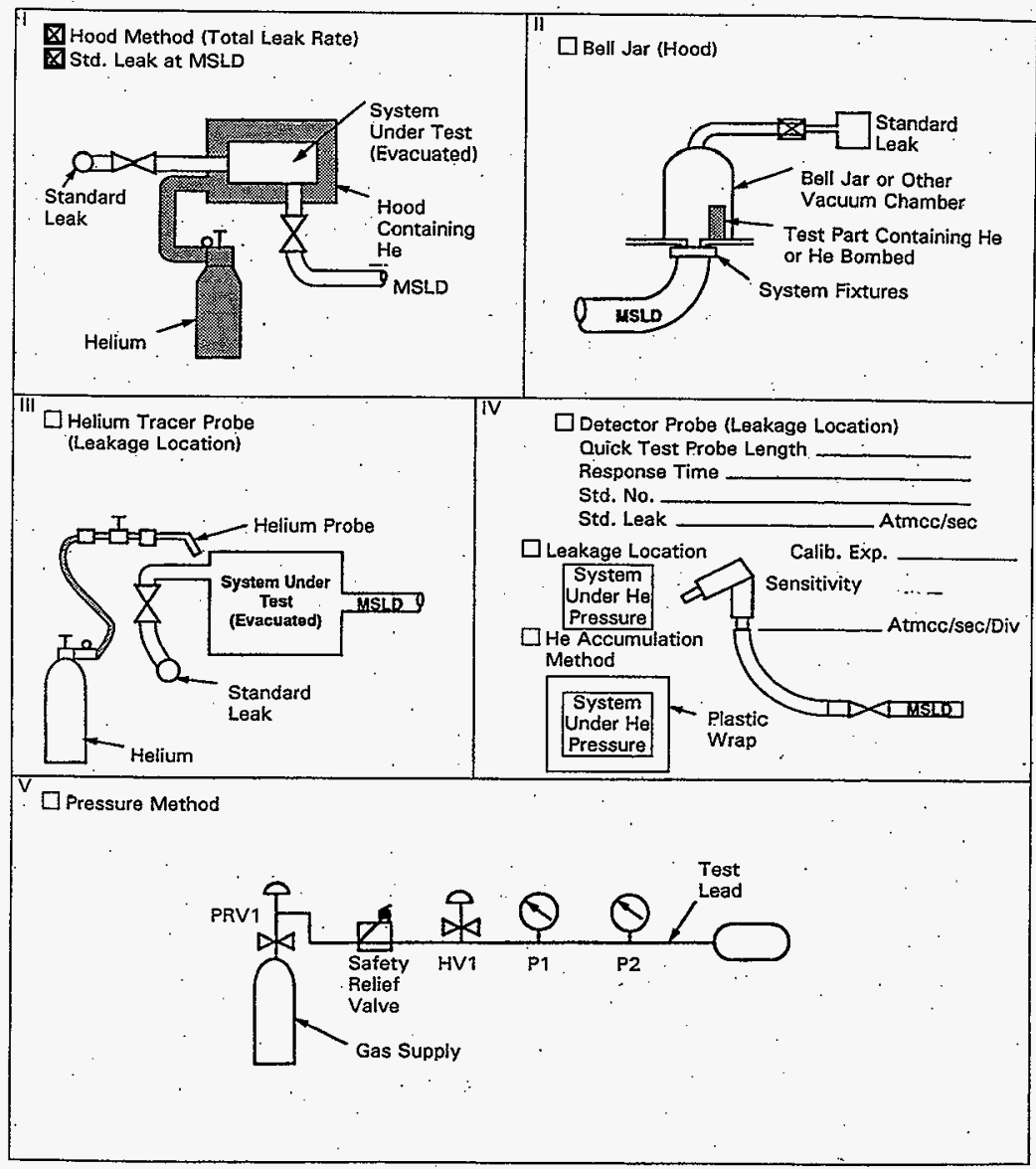

A-6001-492R (02/98) 
DOCUMENT APPROVAL/TRANSMITTAL RECORD

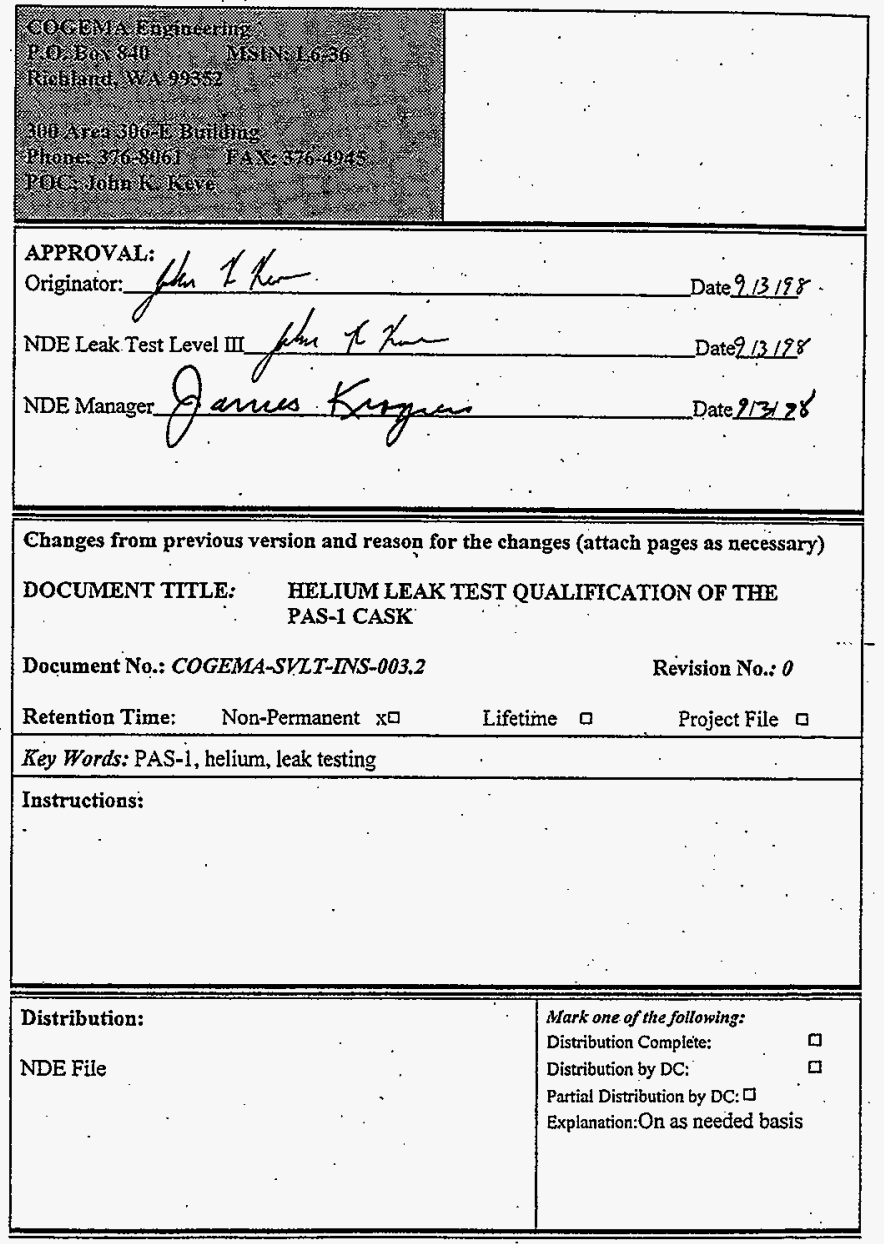


HNF-3516, Rev. 0

$$
\begin{gathered}
\text { PAS-1 Cask Serial Number Pre LeAK TesT } \\
\qquad / \sqrt{2162-027} \\
\text { Date } 919198
\end{gathered}
$$

\subsection{SCOPE}

This specific procedure addresses the helium leak testing of the vessel, outer $\mathrm{O}$-ring seal, and the stat-0-seal in the primary and secondary PAS-1 cask. This technique shall be used in conjunction with NDT-LT-6000 General Leak Test Examination Procedure.

\subsection{INSTRUCTIONS}

Helium Mass Spectrometer Leak Detector (MSLD)

1. Operate the MSLD according to the manufacturer's operating manual.

2. Calibrate the MSLD using a $\times 10^{-8}$ atm-cc/sec calibrated standard.

Helium Standard Identification

Helium Standard

Helium Standard Calibration Expiration
$584-40-05-017$

$1.9 \times 10^{-8}$ atm-cc/sec

$9 / 23 / 98$

3. The MSLD shall have a machine sensitivity of at least $1 \times 10^{-9} \mathrm{~atm}-\mathrm{cc} / \mathrm{sec} / \mathrm{div}$.

Date and Time $919198 \quad 1040$

MISLD Reading $2.4 \times 10^{-1} \times$ Range Factor $500=$ MSLD Div. 1200

Background $I \times 10^{20} \times$ Range Factor $\underline{5}=$ Backgnd Div. 5

MSLD Div. 1200 - Backgnd Div. $5=$ Net Div. $1 / 95$

Helium Std $1.9 \times 10^{-8} \div$ Net Div. $1195=$

MSLD Sensitivity $1.6 \times 10^{-11}$ atm-ce/sec/div 


\section{BELTUM LEAK TEST QUALIFICATION OF THE PAS-1 CASK}

\section{Primary Containment Vessel and Lid Seal}

1. Clean and lightly apply a thin coating of Apiezon vacuum grease on the outer O-ring seal.

2. Install the outer O-ring onto the lid and insert the lid onto the body of the Primary Containment Vessel (PCV).

3. Torque the bolts in a star pattern to $16-18 \mathrm{ft}-1 \mathrm{bs}$.

4. Remove the lid test plug(s) and stat-o-seal. Connect the test equipment as depicted in Figure 1:

5. Evacuate the PCV with the MSLD. When the MSLD reaches testing conditions check for leaks around the test fittings. To test the PCV place helium inside the plastic hood surrounding the body of the cask. Be sure to cut and tape the plastic so the leak test fitting remains outside of the plastic hood. The test duration should be approximately 2 minutes.

6. Determine the vessel and outer O-ring seal leakage rate for the primary containment $\cdots$ vessel.

Date and Time 919198,1417

MSLD Reading 5.6\%0 $8 \times$ Range Factor $500=$ MSLD Div.

Background $1.2 \times 10^{-8} \times$ Range Factor $500=$ Backgnd Div.

MSLD Div. 2800-Backgnd Div. $6000 \doteq$ Net Div.

MSLD Sensitivity $1.6 \times 10^{-11} \times$ Net Div. $2200=$

Primary Vessel and O-ring leakage Rate $3.5 \times 10^{-8}$ aton celsec

\section{MACH SeN}

$$
\begin{aligned}
& R 2.6 \times 10^{-8} \times 500=1300 \\
& B G 4 \times 10^{-10} \times 5=\frac{20}{1280} \quad \frac{1.9 \times 10^{-8}}{1280}=1.5 \times 10^{-1 !} .
\end{aligned}
$$


HNF-3516, Rev. 0

\section{HELIUM LEAK TEST QUALIFICATION OF TEE PAS-1 CASK}

Primary Containment Vessel Stat-O-Seal

1. Connect the test equipment as depicted in Figure 2. Note the atmospheric pressure on the gage.

Gage Calibration Identification

Gage Aange

PSLA

Gage Calioxation Expiration

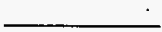

Gage Reading

PSIA 2. Evacuate the PCV whth the vacuy pump to less than 0.5 PSLA Record the gage
reading.

Gage Reading

3. Valve the vacuum pump out of thefystem afd Bactfill the PCV with helium to atmospheric pressure gage reading step if

4. Remove the manifold. Install the stat-ofseal and tighten to the closed position with the test port tool. Reconnect the MSL $D$ to tho cask test port.

5. Evacuate the stat-0-seal area with the MSLD.

6. When the MISLD switches to the test mode a largh helium signal may be present. Ideally, the high helium background should decrease steadix to the background level established during the PCV test. However, experience has shown that the background level will settle out higher but to an acceptable level. The test dutation should be long enough to establish a stable MSLD reading. To be conservative in celculating the leak rate of the vessel the background level established during the PCV tesh will be subtracted from the MSLD reading. Therefore, the stat-o-seal will probably have leak rate associated with it, however, the leak rate should be smaller than the acceptance tandard. 
HELIUMI LEAK TEST QUALIFICATION OF THE PAS-1 CASK

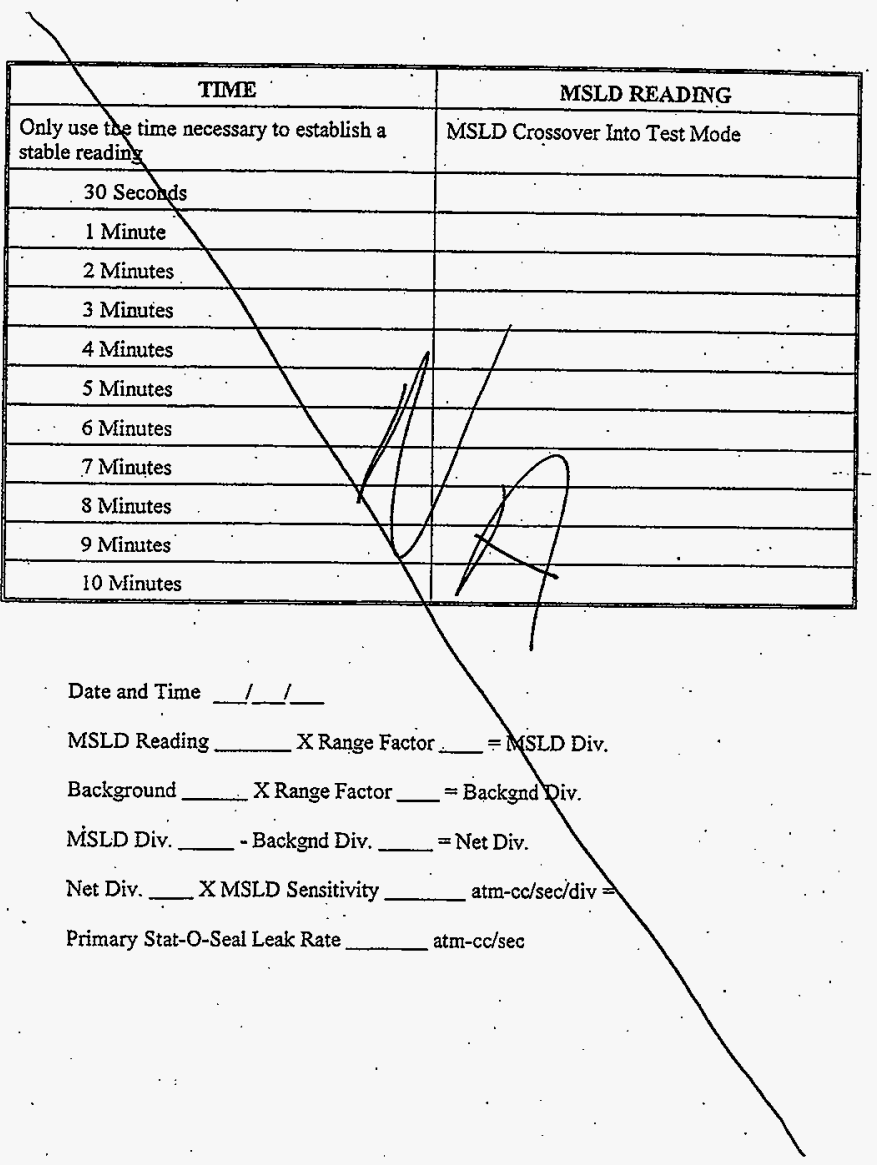




\section{HELIUM LEAK TEST QUALIFICATION OF THE PAS-I CASK}

\section{Secondary Containment Vessel and Lid Seal}

1. Clean and lightly apply a thin coating of Apiezon vacuum grease on the outer $\mathrm{O}$-ring seal.

2. Install the outer $\mathrm{O}$-ring onto the lid and insert the lid onto the body of the Secondary Containment Vessel (SCV).

3. Torque the bolts in a star pattern to $100-150 \mathrm{ft}$-lbs. Repeat the sequence at $300-350 \mathrm{ft}-$ lbs with the final torquing being $450-500 \mathrm{f}-\mathrm{lbs}$.

4. Remove the lid test plug(s) and stat-o-seal. Connect the test equipment as depicted in Figure 1.

5. Evacuate the SCV with the MSLD. When the MSLD reaches testing conditions check for leaks around the test fittings. To test the SCV place helium inside the plastic hood surrounding the body of the vessel. Be sure to cut and tape the plastic so the leak test fitting remains outside of the plastic hood. The test duration should be approximately 2 minutes.

6. Determine the vessel and the $\mathrm{O}$-ring seal leakage rate for the secondary containment vessel.

Date and Time 9.101980700

MSLD Reading $7.8 \times 0^{-6} \times$ Range Factor $50 \mathrm{~K}=$ MSLD Div.

Background $3.4 x_{0} \times{ }^{9}$ Range Factor $50=$ Backgnd Div.

MSLD Div.170K - Backgnd Div. $170=$ Net Div.

MSLD Sensitivity $1.2 \times 10^{-1} \times$ Net Div. $169830=$

Secondary vessel and O-ring leakage Rate $2.0 \times 10^{-6}$ Atm co./sec

MACH SeN. $9 \% 10 \% 98$ 0715.

e $4.0 \times 10^{-8} \times 100=2000$

$867.0 \times 10^{-9} \times 30=\frac{350}{1650} \frac{1.9 \times 10^{-8}}{1650}=1.2 \times 10^{-11}$ 


\section{HELIUM LEAK TEST QUALIFICATION OF TEE PAS-1 CASK}

\section{Secondary Containment Vessel Stat-O-Seal}

1. Conngct the test equipment as depicted in Figure 3: Note the atmospheric pressure on the gage.

Gage Reading

PSLA

2. Evacuate the SCV withe vacuum pump to less than 0.5 PSIA. Record the gage reading.

\section{Gage Reading}

3. Valve the vacumm pump out of the system afd backfin the SCV with helium to the atmospheric pressure gage reading in step 1 . .

4. Remove the manifold. Install and tightey the stat-o-seal to the closed position with the test port tool. Reconnect the MSLD to the ask test port.

5. Evacuate the stat-o-seal area with the MSLD.

6. When the MSLD switches to the test mode a large holium signal may bepresent. Ideally, the high helium background should decrease steadily to the background established during the SCV seal test. However, experience has showy that the background level will settle out higher but to an acceptable level. The test duration should be long enough to establish a stable MSLD reading. To be conservative in calculating the leak rate of the vessel the background level established during the SCV test will pe subtracted from the MSLD reading. Therefore, the stat-o-seal will probably have a leak rate associated with it, however, the leak rate should be smaller than the acceptance standard.

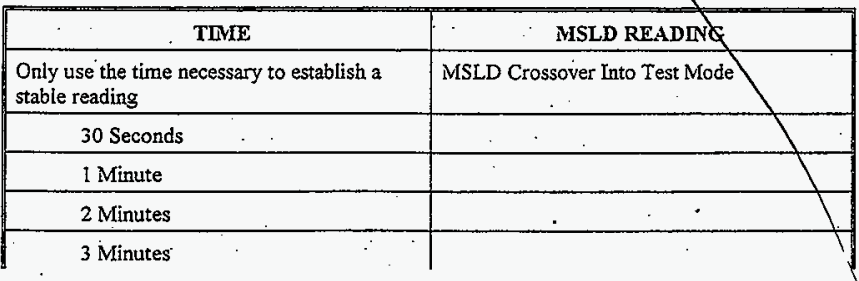


HNF-3516, Rev. 0

COGEMA

COGEMA-SVLT-INS-003.2

Revision 0

ENGINEERING CORP.

September 3, 1998

Page 7 of 11

\section{HELIUM LEAK TEST QUALIFICATION OF THE PAS-1 CASK}

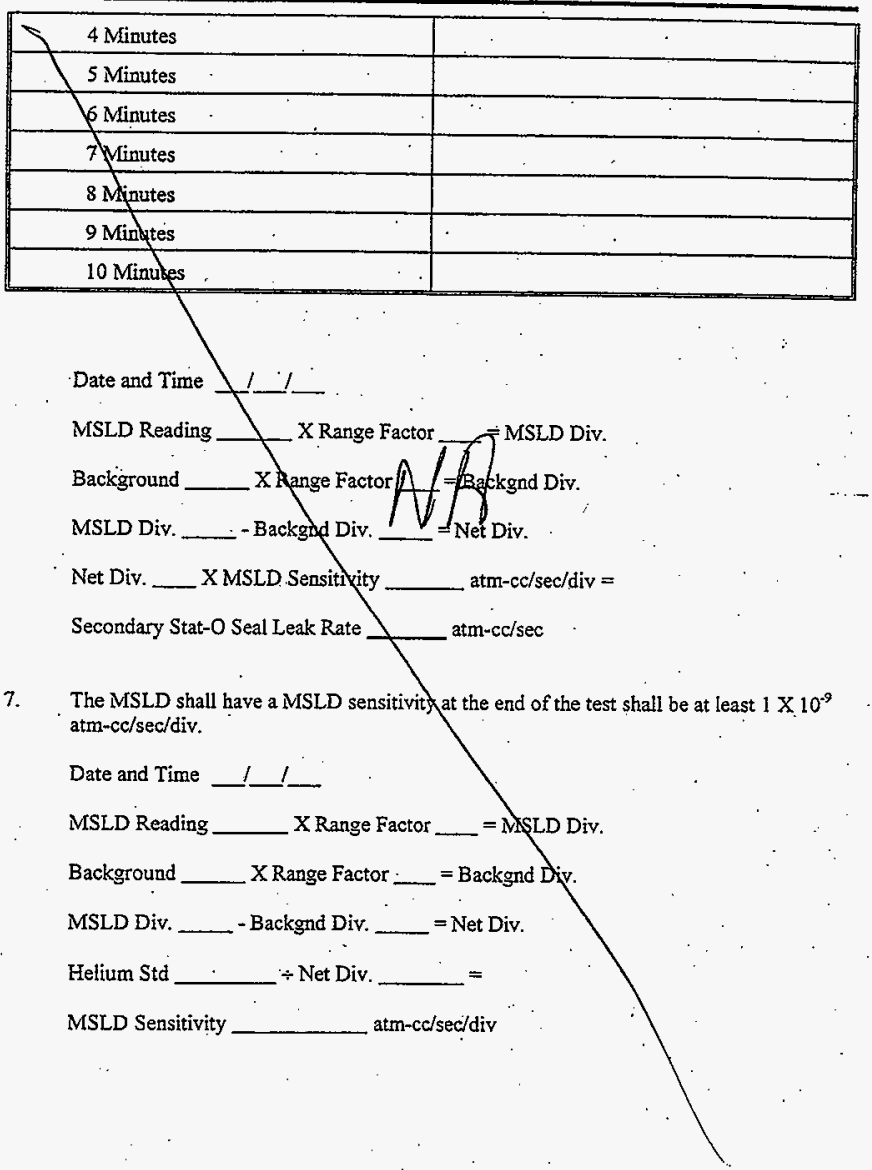


HNF-3516, Rev. 0

\section{HELIUM LEAK TEST QUALIFICATION OF THE PAS-1 CASK}

8. If the MSLD sensitivity has decreased 35 percent (less sensitive) during a calibration period the seal(s) examined since the last valid calibration period shall be retested:

9. Intermediate calibrations, if necessary.

Date and Time 1

MSLD Reading _... X Range Factor ____ $=$ MSLD Div.

Background ___ X Range Factor ___ = Backgnd Div.

MSLD Div. __ _ Backgnd Div. ___ = Net Div.

Helium Std ___ Net Div. ___ $\doteq$

MSLD Sensitivity atm-ce/sec/div

Date and Time _L

MSLD Reading _ _ X Range Factor __ $=$ MSLD Div.

Background _____ X Range Factor___ = Backgnd Div.

MSLD Div. ____ Backgnd Div. ___ = Net Div.

Helium Std ___ $\div$ Net Div. ____ $=$

MSLD Sensitivity ___ atm-co/sec/div

Acceptance Criteria

Each of the seals leakage rate shall be less than $1 \times 10^{-7} \mathrm{~atm}-\mathrm{cc} / \mathrm{sec}$ (air) or $2.6 \times 10^{-7} \mathrm{~atm}-\mathrm{cc} / \mathrm{sec}$ (helium). 
HNF-3516, Rev. 0

Figure 1

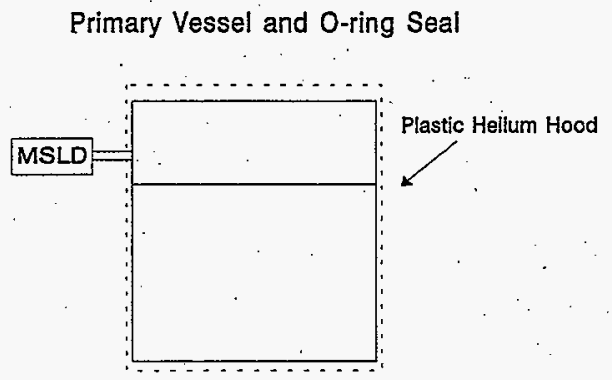

Secondary Vessel and O-ring Seal

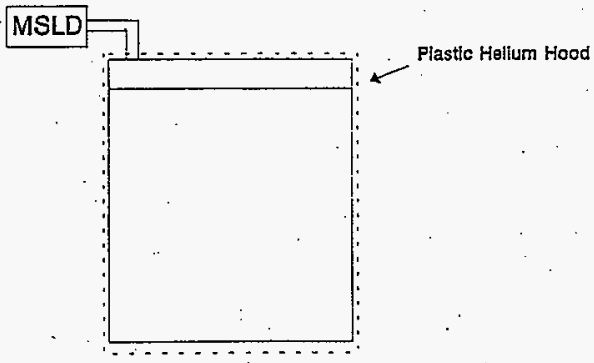


HNF-3516, Rev. 0

HELIUM LEAK TEST OUALIFICATION OF THE PAS-1 CASK

Figure 2

Primary Stat-0-Seal

Helium Backfill

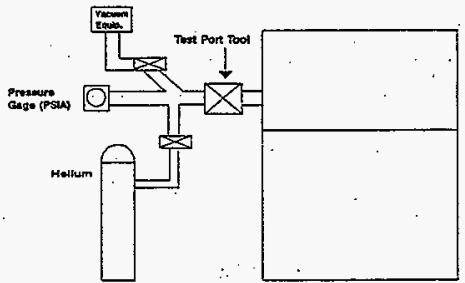

Examination

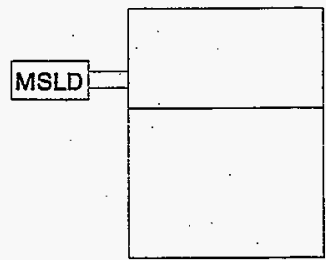


HNF-3516, Rev. 0

Figure 3

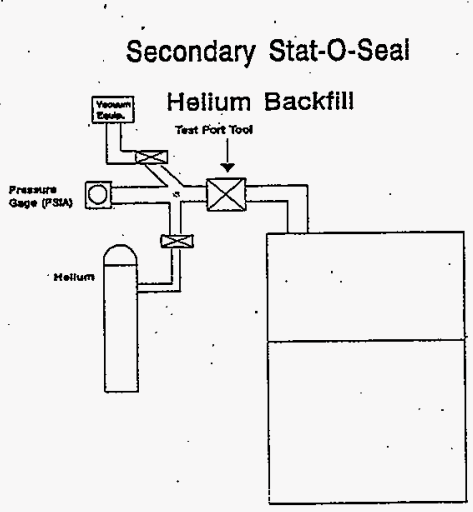

Examination

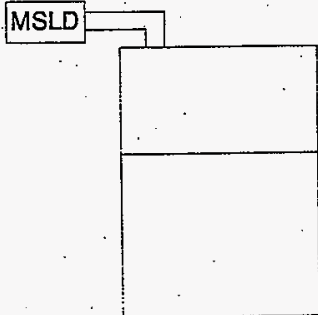




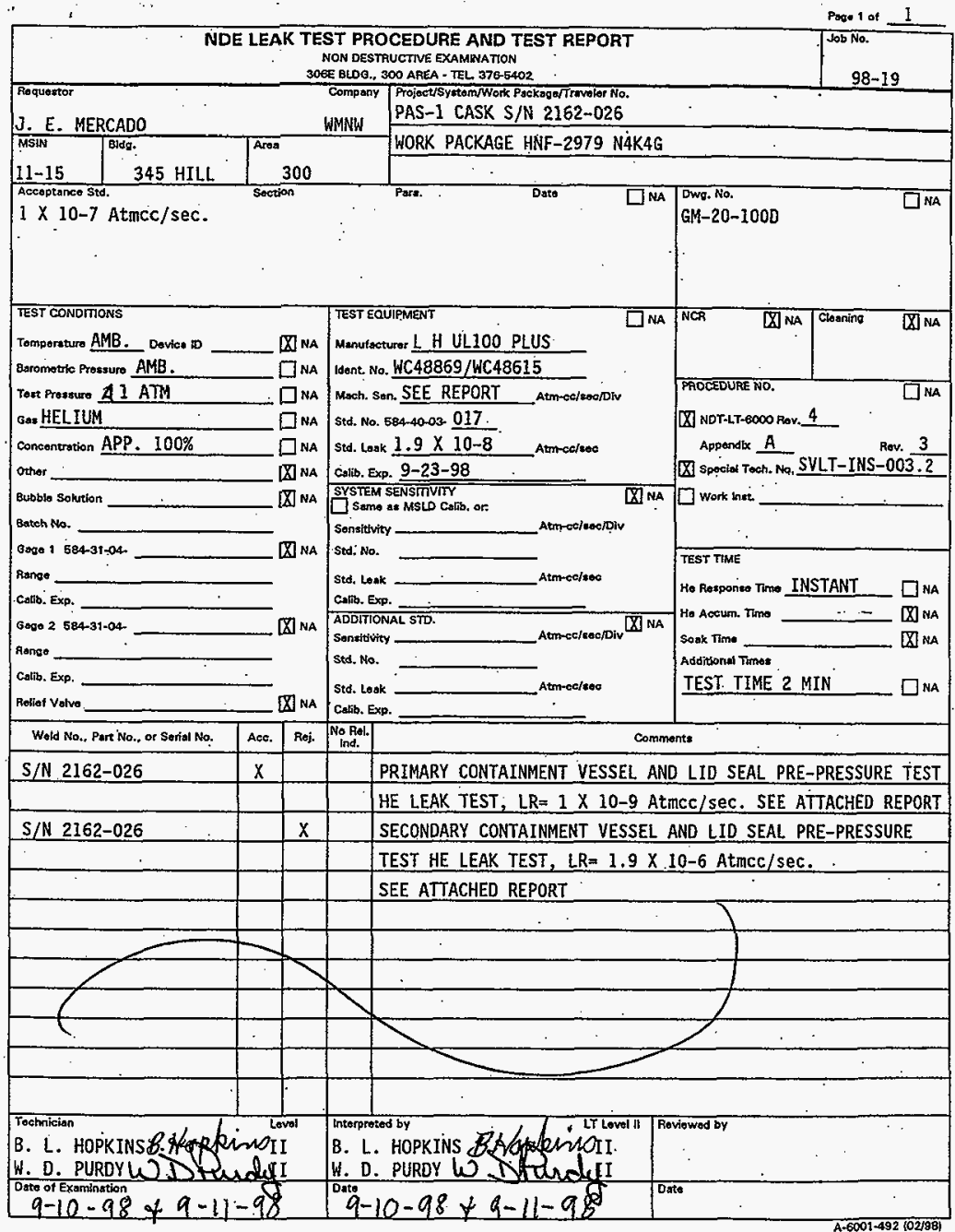


HNF-3516, Rev. 0

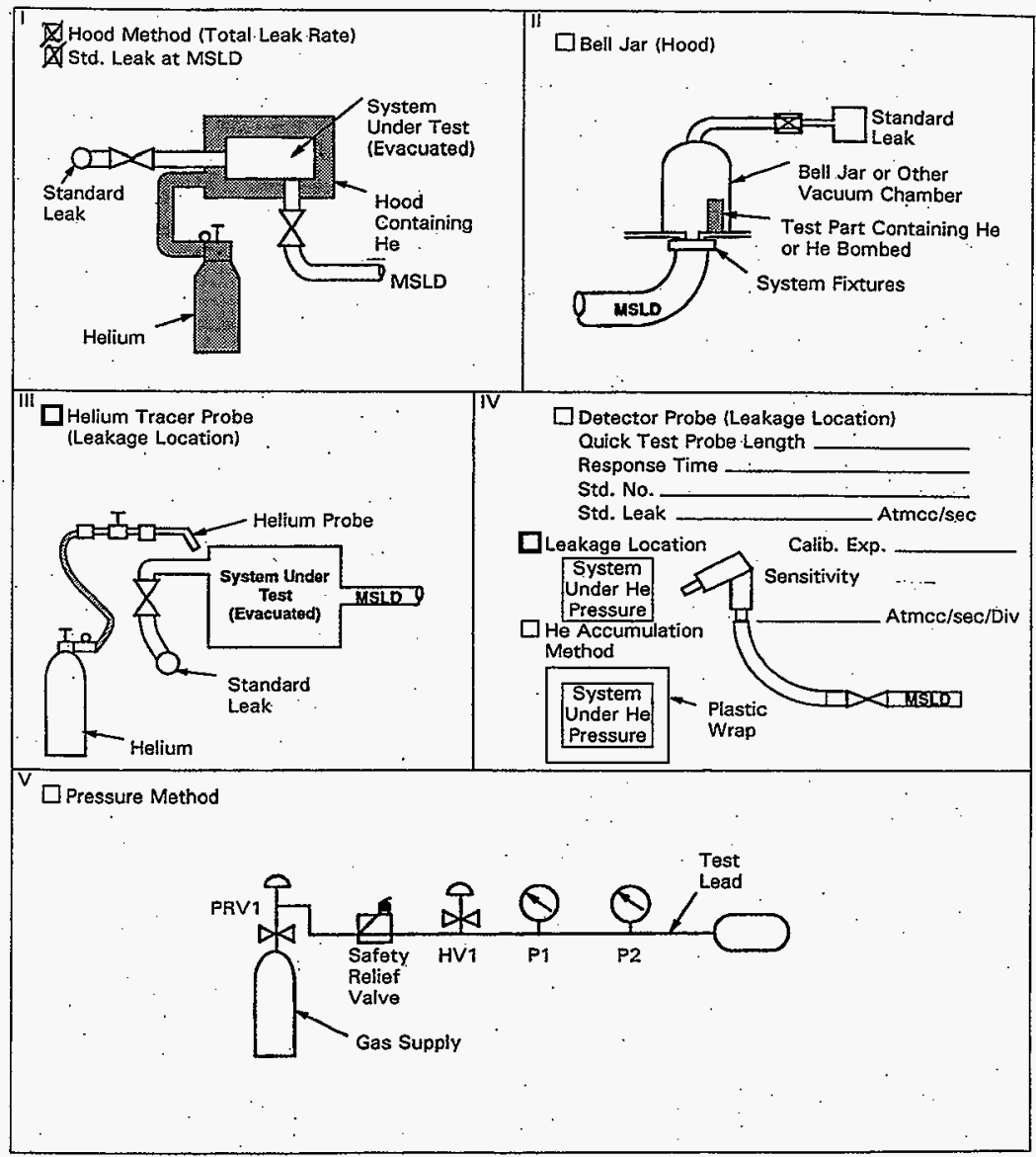




\section{DOCUMENT APPROVAL/TRANSMTTTAL RECORD}

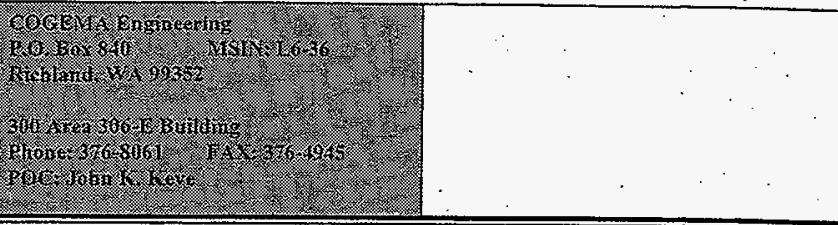

\section{APPROVAL:}

Originator:<smiles>CC(C)C1CCCC1C(C)C</smiles>

NDE Leak Test Levei iIf pan $\not$ Ran Date $913 / 98$ Date2/3/98

NDE Manager ances

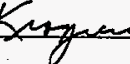
Date $9 / 3 / 2 \%$.

Changes from previous version and reason for the changes (attach pages as necessary)

DOCUMENT TITLE: HELIUM LEAKTEST QUALIFICATION OF THE PAS-1 CASK

Document No.: COGEMA-SVLT-INS-003.2

Revision No.: 0

Retention Time: Non-Permanent $x \square \quad$ Lifetime $\square \quad$ Project File $\square$

Key Words: PAS-1, helium, leak testing

Instructions:

.

Distribution:

NDE File
Mark one of the following:

Distribution Compiete;

ㅁ

Distribution by DC:

Partial Distribution by DC: $\square$

Explanation:On as needed basis 
HNF-3516, Rev. 0

PAS-1 Cask Serial Number Pre Leak TesT S/N 2/62-026

Date $9 / 10 / 98$

\section{$1.0 \quad$ SCOPE}

This specific procedure addresses the helium leak testing of the vessel, outer O-ring seal, and the stat-o-seal in the primary and secondary PAS-1 cask. This technique shall be used in conjunction with NDT-LT-6000 General Leak Test Examination Procedure.

\subsection{INSTRUCTIONS}

Helium Mass Spectrometer Leak Detector (MSLD)

1. Operate the MSLD according to the manufacturer's operating manual.

2. Calibrate the MSLD using a $\times 10^{-8}$ atm-ce/sec calibrated standard.

Helium Standard Identification

Helium Standard

Helium Standard Calibration Expiration

\section{$584-40-03-017$}

$1.9 \times 10^{-8} \mathrm{~atm}-\mathrm{cc} / \mathrm{sec}$

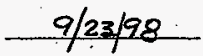

3. The MSLD shall have a machine sensitivity of at least $1 \times 10^{-0} \mathrm{~atm}-\mathrm{cc} / \mathrm{sec} / \mathrm{div}$.

Date and Time 9110198 . 0645

MSLD Reading $2.8 \times 10^{-8} \times$ Range Factor $500=$ MSLD Div.

Background $1 \times 10^{\circ 10} \times$ Range Factor $\underline{5}=$ Backgnd Div.

MSLD Div. 1400. - Backgnd Div. $5=$ Net Div.

Helium Std $1.9 \times 10^{.8} \div$ Net Div. $1395=$

MSLD Sensitivity $1.4 \times 10^{-1 /}$ atm-cc/sec/div

WC 48615 


\section{HELIUM LEAK TEST QUALIFICATTON OF THE PAS-1 CASK}

Primary Containment Vessel and Lid Seal

1. Clean and lightly apply a thin coating of Apiezon vacuum grease on the outer $\mathrm{O}$-ring seal.

2. Install the outer O-ring onto the lid and insert the lid onto the body of the Primary Containment Vessel (PCV).

3. Torque the bolts in a star pattern to $16-18 \mathrm{ft}-\mathrm{lbs}$.

4. Remove the lid test plug(s) and stat-o-seal. Connect the test equipment as depicted in Figure 1.

5. Evacuate the PCV with the MSLD. When the MSLD reaches testing conditions check for leaks around the test fittings. To test the PCV place helium inside the plastic hood surrounding the body of the cask. Be sure to cut and tape the plastic so the leak test fitting remains outside of the plastic hood. The test duration should be approximately. 2 minutes.

6. Determine the vessel and outer O-ring seal leakage rate for the primary containment vessel.

Date and Time 9/10/98 12:50 PM

MSLD Reading $1.6 \times$ Range Factor -8 S00 MSL D Div.

Background $6.4 \times$ Range Factor $-8^{500}=$ Backgnd Div.

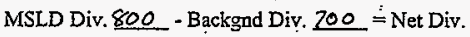

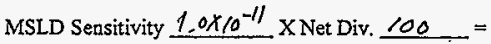

Primary Vessel and O-ring leakage Rate $1 \times 10^{-9}$ \& th:oc/sec

wC 48869

std. 584-40.03-0i7 Exp 9-23-98 9:00 AM

R $3.8 \times 10^{-8} \times 500=.1900$

$867 \times 10^{-10} \times \quad 5=\frac{35}{1865} \frac{1.9 \times 10^{-8}}{1865}=1.0 \times 10^{-11} \mathrm{atmce} / \mathrm{sec} . / \mathrm{div}$. 
HNF-3516, Rev. 0

\section{HELIUM LEAK TEST QUALFICATION OF THE PAS-1 CASK}

Primary Containment Vessel Stat-0-Seal N/A for Pre-Lak Test

1. Connect the test equipment as depicted in Figure 2. Note the atmospherif pressure on the gage.
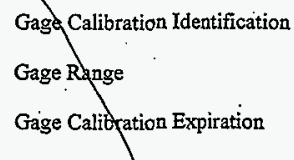

Gage Reading

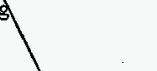

2. Evacuate the PC र with the vacuum puyp to less than 0.5 PSIA. Record the gage reading.

Gage Reading

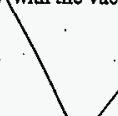

PSIA

3. Valve the vacuum pump oft of the system and backfill the PCV with helium to atmospheric pressure gzge reading in step 1 .

4. Remove the maniford. Install the stat-o-seal and tighten to the closed position with the test port tool. Reconnect the MSCD to the cask test port.

5. Evacuate this stat-o-seal area with the MSLD.

6. When the MSLD switches to the test inode a large helium signal may be present. Ideally, the high helium background should dectease steadily to the background level established during the PCV test. However, experience has shown that the background level will settle out higher but to an acceptable leve The test duration should be long enough to establish a stable MSLD reading. To be conservative in calculating the leak rate of the vessel the background level established duning the PCV test will be subtracted from the MSLD reading. Therefore, the stat-o-seal will probably have a leak rate associated with it, however, the leak rate should be smaller than the acceptance standard. 
HELTUM LEAK TEST QUALIFICATION OF THE PAS-1 CASK'

\begin{tabular}{|l|l|}
\hline \multicolumn{1}{|c|}{ TIME } & MSLD READING \\
\hline $\begin{array}{l}\text { Oniy use the time necessary to establish a } \\
\text { stable reading }\end{array}$ & MSLD Crossover Into Test Modg \\
\hline 30 Seconds & \\
\hline 1 Minute & \\
\hline 2 Minutes & \\
\hline 3 Minutes & \\
\hline 4 Minutes & \\
\hline 5 Minutes & \\
\hline 6 Minutes & \\
\hline 7 Minutes & \\
\hline 8 Minutes & \\
\hline 9 Minutes & \\
\hline 10 Minutes
\end{tabular}

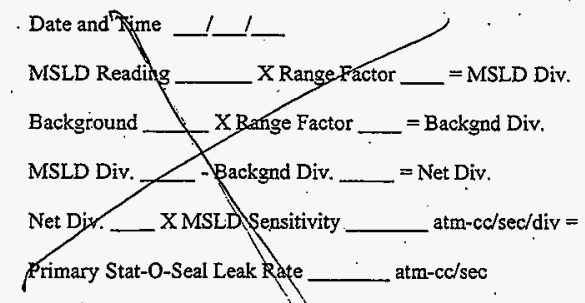




\section{HELIUM LEAK TEST QUALIFICATION OF THE PAS-1 CASK}

\section{Secondary Containment Vessel and Lid Seal}

1. Clean and lightiy apply a thin coating of Apiezon vacuum grease on the outer O-ring seal.

2. Install the outer O-ring onto the lid and insert the lid onto the body of the Secondary Containment Vessel (SCV).

3. Torque the bolts in a star pattern to $100-150 \mathrm{ft}-\mathrm{lbs}$. Repeat the sequence at $300-350 \mathrm{ft}$ lbs with the final torquing being $450-500 \mathrm{ft}-1 \mathrm{bs}$.

4. Remove the lid test plug(s) and stat-o-seal. Connect the test equipment as depicted in Figure 1 .

5. Evacuate the SCV with the MSLD: Whien the MSLD reaches testing conditions check for leaks around the test fittings. To test the SCV place helium iriside the plastic hood surrounding the body of the vessel. Be sure to cut and tape the plastic so the leak test fitting remains outside of the plastic hood. The test duration should be approximately 2 minutes.

6. Determine the vessel and the $\mathrm{O}$-ring seal leakage rate for the secondary containment vessel.

Date and Time 9/11/98 0753

MSLD Reading $3,4 \times 10^{\circ}$ Range Factor $50 \mathrm{~K}=$ MSLD Div,

Background $3.2 \times 10^{-9} \times$ Range Factor $50=$ Backgnd Div.

MSLD Div. 170K - Backgnd Div. $160=$ Net Div.

$\frac{1.1 \times 10^{-11}}{14}$ as 911198

MSLD Sensitivity $\times$ Net Div. $169840=$

Secondary vessel and $O$-ring leakage Rate 


\section{HELIUM LEAK TEST QUALIFICATION OF THE PAS-1 CASK}

\section{Secondary Containment Yessel Stat-0-Seal}

1. Sonnect the test equipment as depicted in Figure 3: Note the atmospheric pressure on the gage.<smiles></smiles>
PSIA

2. Evacuate the SCY with the vacuum pump to less than 0.5 PSIA. Record the gage reading.

Gage Reading PSIA

3. Valve the vacuum pump outiof the system and backfill the SCV with helium to the atmospheric pressure gage reading in 1 .

4. Remove the manifold. Install and ighten the slat-o-seal to the closed position with the test port tool. Reconnect the MSLD to the cask test port.

5. Evacuate the stat-o-seal area with the MSLD.

6. When the MSLD switches to the test mode a Varge helium signal may be.present. Ideaily, the high helium background should decrease steadily to the background established during the SCV seal test. However, experience has shown that the background level will settle out higher but to an acceptable level. The test duration should be long enough to esrablish a stable MSLD reading. To be conservativg in calculating the lear rate of the vessel the background level established during the.SCY test will be subtracted from the MSLD reading. Therefore, the stat-o-seal will probably kave a leak rate associated with it, however, the leak rate should be smaller than the acceptance standard.

\begin{tabular}{|l|l|}
\hline \multicolumn{1}{|c|}{ TIME } & MSLD READING \\
\hline $\begin{array}{l}\text { Only use the time necessary to establish a } \\
\text { stable reading. }\end{array}$ & MSLD Crossover Into Test Mode \\
\hline 30 Seconds & \\
\hline 1 Minute & \\
\hline 2 Minutes & \\
\hline 3 Minutes & \\
\hline
\end{tabular}


HNF-3516, Rev. 0

HELIUM LEAK TEST QUALIFICATION OF THE PAS-1 CASK

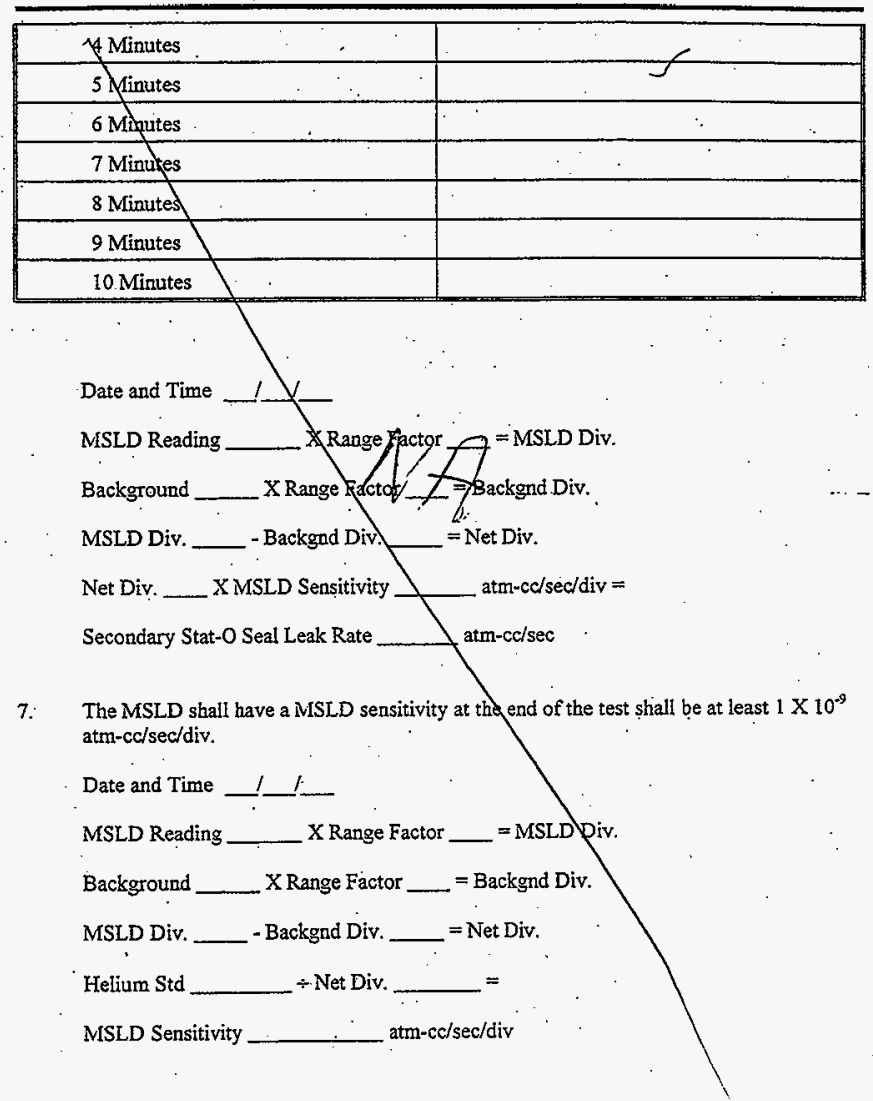




\section{BELIUM LEAK TEST QUALIFICATION OF THE PAS-1 CASK}

8. If the MSLD sensitivity has decreased 35 percent (less sensitive) during a calibration period the seal(s) exanined since the last valid calibration period shall be retested.

9. Intermediate calibrations, if necessary.

Date and Time 2110188 is $\angle D$ wCY8869@DO7

MSLD Reading $3.8 \_\times$Range Factor $5100=$ MSLD Div.

Background $5 \times$ Range Factor $5=$ Backgnid Div. madine std $1.9 \times 10^{-8}+\tan 60 / \mathrm{sa}$

MSLD Div. 1900 - Backgnd Div. $25=$ Net Div. $584-401-03.017$

Felium Std $1.9 \times 10^{-8} \div$ Net Div. $1875=$ MSLD Sensitivity $1.01 \times 10^{-11}$ atm-cc/sec/div

$$
\begin{aligned}
& \text { close out calibration } \\
& \text { for Primary conturment bosul } \\
& \text { and Lidsere pest }
\end{aligned}
$$

\section{Date and Time $9111198.0800 \mathrm{AM}$}

MSLD Reading $3.6 \times 10^{-\frac{\gamma}{X}}$ Range Factor $500=$ MSLD Div.

Background $1 \times 10^{-1}$ X Range Factor $S=$ Backgnd Div.

MSLD Div. 1800 - Backgnd Div. _5 = Net Div.

Helium Std $1.9 \times 10^{-8} \div$ Net Div. 1795 $=$

MSLD Sensitivity $1.1 \times 10^{-1 !}$ atm-ce/sec/div

\section{Acceptance Criteria}

Each of the seais leakage rate shall be less than $1 \times 10^{-7} \mathrm{afm}-\mathrm{cc} / \mathrm{sec}$ (air) or $2.6 \times 10^{-7} \mathrm{~atm}-\mathrm{cc} / \mathrm{sec}$ (helium). 
HNF-3516, Rev. 0

\section{Figure 1}

Primary Vessel and O-ring Seal

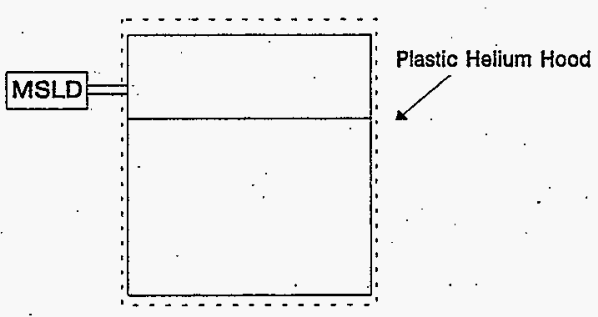

Secondary Vessel and O-ring Seal

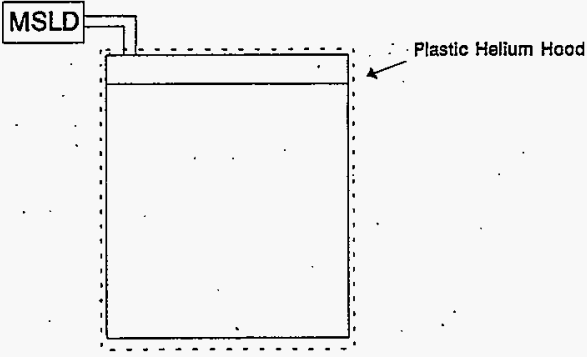


HNF-3516, Rev. 0

Figure 2

Primary Stat-0-Seal

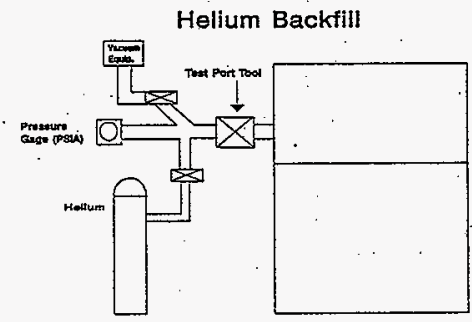

Examination

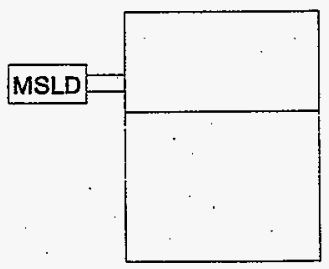


HNF-3516, Rev. 0

HELIUM LEAK TEST QUALIFICATION OF THE PAS-1 CASK

Figure 3

Secondary Stat-O-Seal

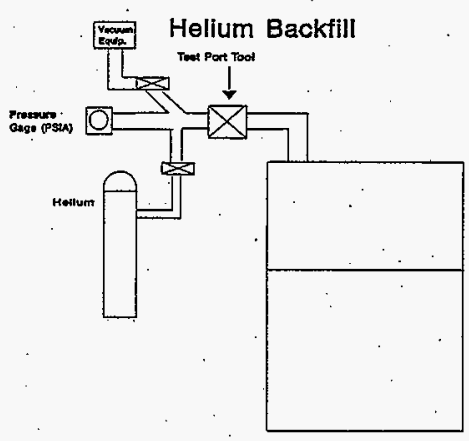

Examination

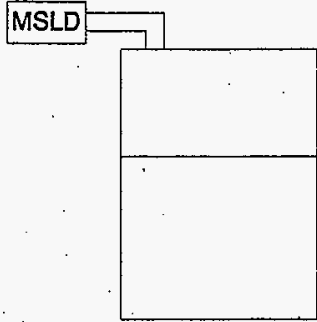




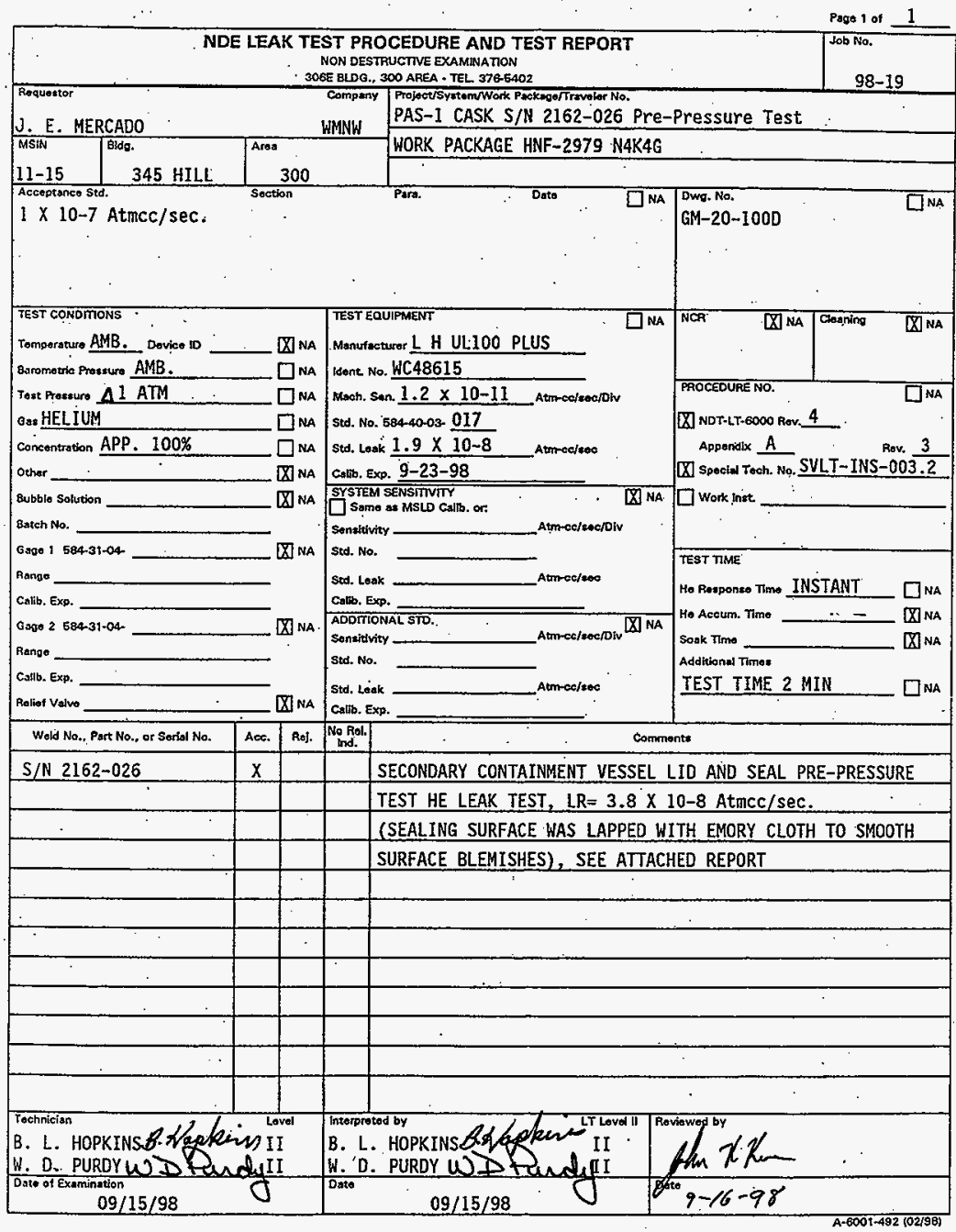


HNF-3516, Rev. 0

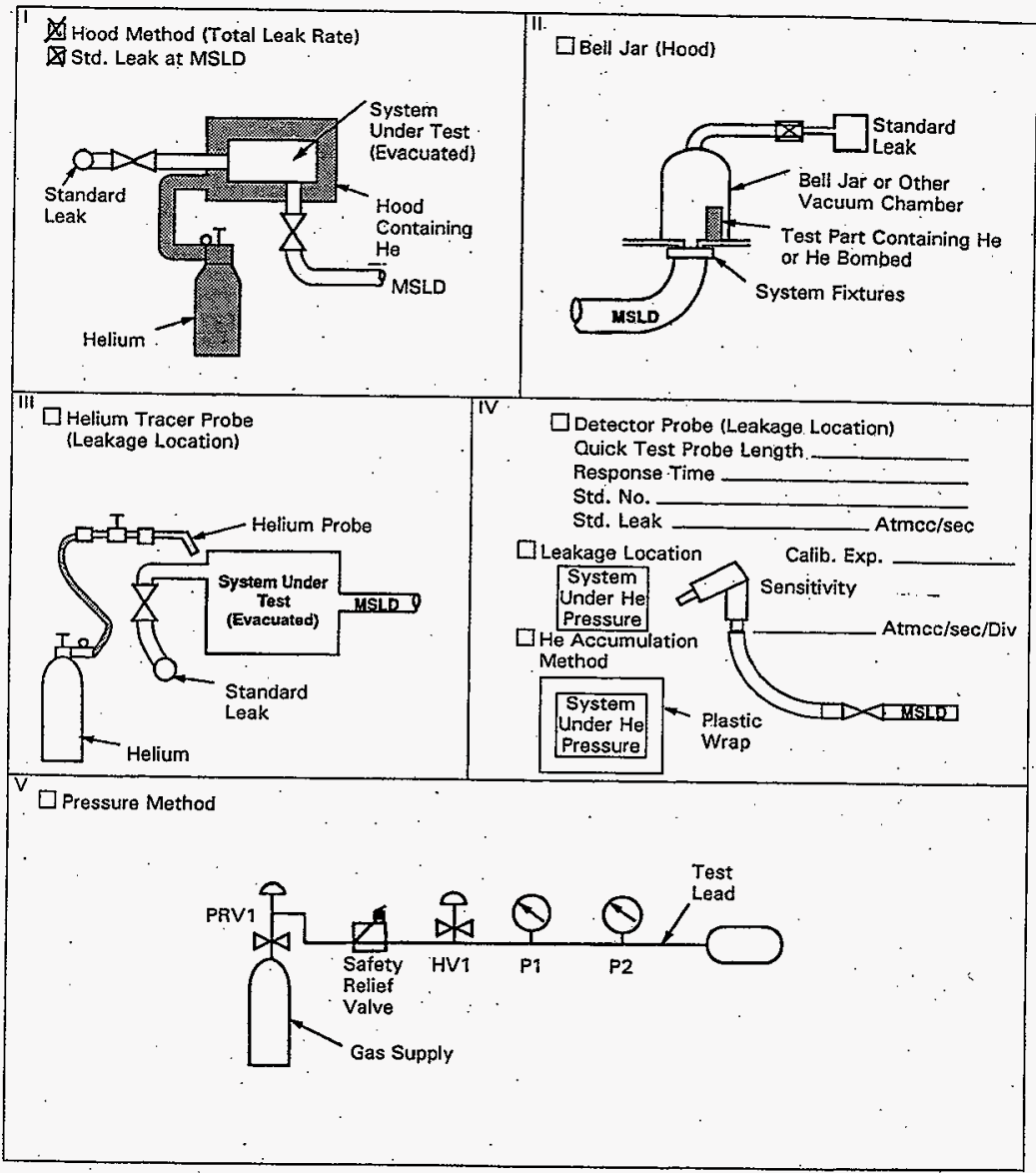

A.6001-492R (02/98) 


\section{DOCUMENT APPROVAL/TRANSMITTAL RECORD}

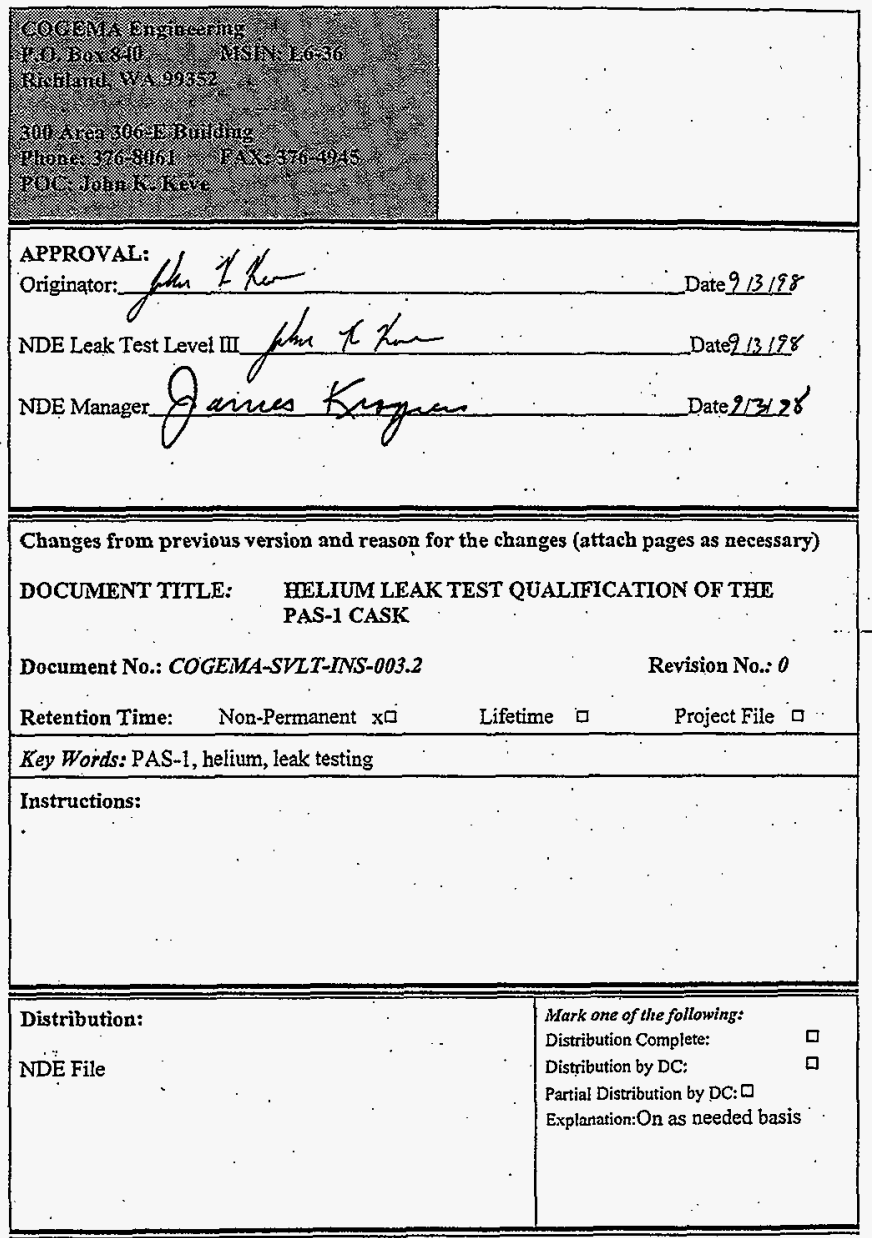




\section{PAS-1 Cask Serial Number $2162-0.26$ Pre Pressure Test Sealing Sursace Lapped \\ Date 9115198}

\subsection{SCOPE}

This specific procedure addresses the helium leak testing of the vessel, outer O-ring seal, and the stat-o-seal in the primary and secondary PAS-1 cask. This technique shall be used in conjunction with NDT-LT-6000 General Leak Test Examination Procedure.

\subsection{INSTRUCTIONS}

\section{Helium Mass Spectrometer Leak Detector (MSLD)}

1. Operate the MSLD according to the manufacturer's operating manual.

2. Calibrate the MSLD using a $\times 10^{-3} \mathrm{~atm}-\mathrm{cc} / \mathrm{sec}$ calibrated standard. WC 48615

Helium Standard Identification

$$
584-40-03-017
$$

Helium Standard $1.9 \times 10^{-8}$ atm-cc/sec

Helium Standard Calibration Expiration

$$
9-23-98
$$

3. The MSLD shall have a machine sensitivity of at least $1 \times 10^{-9} \mathrm{~atm}-\mathrm{cc} / \mathrm{sec} / \mathrm{div}$.

Date and Time $9115198 \quad 275 \mathrm{PM}$

MSLD Reading 3.2 X Range Factor $500=$ MSLD Div.

Background 2 X Rarige Factor $5=$ Backgnd Div.

MSLD Div. 1600 -Backgnd Div. $10=$ Net Div.

Helium Std $1.9 \times 10^{-8} \div$ Net Div. $1590=$

MSLD Sensitivity $1.2 \times 10^{-11}$ atm-cc/sec/div 


\section{HELIUM LEAK TEST QUALIFICATION OF THE PAS-1 CASK}

\section{Primary Containment Vessel and Lid Seal}

1. Clean and lightly apply a thin coating of Apliezon vacuum grease on the outer O-ring seal.

2. Instali the outer O-ring onto the lid and insert the lid onto the body of the Primary Containment Vessel (PCV).

3. $\cdots$ Torque the boxs in a star pattern to $16-18 \mathrm{ft}-\mathrm{lbs}$.

4. Remove the lid test plug(s) and stat-o-seal. Connect the test equipment as depicted in Figure 1.

5. Evacuate the PCV with the MSLD. When the MSLD reaches testing conditions check for leaks around the test fitings. To test the PCV place helium inside the plastic hood surrounding the body of the casic. Be sure to cut and tape the plastic so the leak test fitting remains outside of the platic hood. The festduration should be approximately 2 minutes.

6. Determine the vessel and outer $\mathrm{O}$-ring seal leakage rate for the primary containment vessel.

Date and Time

MSLD Reading $\mathrm{X}$ Range Factor $=$ MSLD Div.

Background $\mathrm{X}$ Range Factor $=$ Backgnd Div.

MSLD Div. - Backgnd Div. $=$ Net Div.

MSLD Sensitivity $\mathrm{X}$ Net Div.

Primary Vessel and O-ring leakage Rate 
HNF-3516, Rev. 0

\section{HELIUM LEAK TEST QUALIFICATION OF THE PAS-1 CASK}

Primary Containment Vessel Stat-O-Seal

1. Connect the test equipment as depicted in Figure 2. Note the atmospheric pressure on the

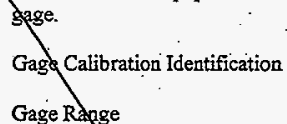

2. Evacuate the PCV with the vacuum pumpto less than 0.5 PSIA. Record the gage

$$
\text { reading. }
$$

- Gage Reading

3. Valve the vacuum pump out of the system and backfill the PCV with helium to atmospheric pressure gage reading instep 1.

4. Remove the manifold. Install the stat-o-seal and tighten to the closed position with the test port tool. Reconnect the MSLD to the dask test port.

5. Evacuate the stat-o-seal area with the MSLD.

6. When the MSLD switches to the test mode a large helium signal may be present. Ideally, the high helium background should decrease steadily to the background level established during the PCV test. However, experience has shown that the background level will settle out bigher but to an acceptable level. The test duration should be long enough to establish a stable MSLD reading. To be conservative in calcylating the leak rate of the vessel the background level established during the PCV test whl be subtracted from the MSLD reading. Therefore, the stat-o-seal will probably have a leak rate associated with it, however, the leak rate should be smaller than the acceptance standard. 
HNF-3516, Rev. 0

HELTUM LEAK TEST QUALIFICATION OF THE PAS-1 CASK

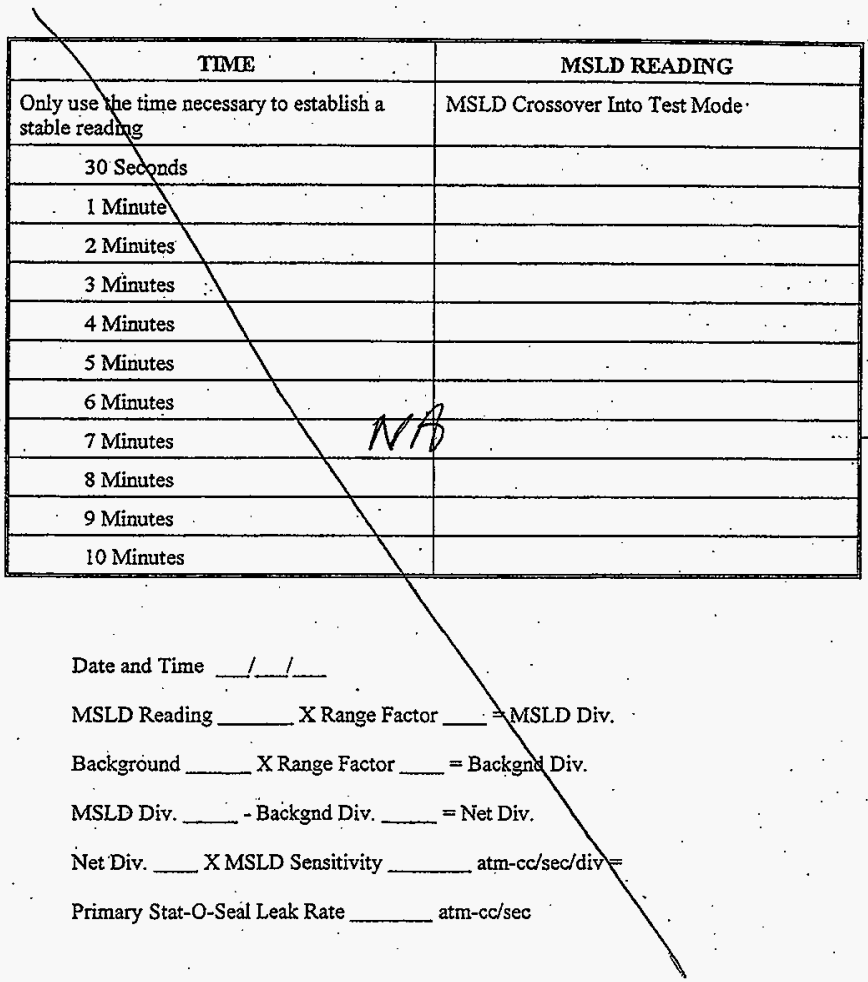


HNF-3516, Rev. 0

\section{HELTUM LEAK TEST QUALIFICATION OF THE PAS-1 CASK}

\section{Secondary Containment Vessel and Lid Seal}

1. Clean and lightly apply a thin coating of Apiezon yacuum grease on the outer O-ring seal.

2. Install the outer O-ring onto the lid and insert the lid onto the body of the Secondary Containment Vessel (SCV).

3. Torque the bolts in a star pattern to $100-150 \mathrm{ft}-1 \mathrm{bs}$. Repeat the sequence at $300-350 \mathrm{ft}$ . lbs with the final torquing being $450-500 \mathrm{ft}-1 \mathrm{bs}$.

4. Remove the lid test plug(s) and stat-o-seal. Connect the test equipment as depicted in Figure 1.

5. Evacuate the SCV with the MSLD. When the MSLD reaches testing conditions check for leaks around the test fittings. To test the SCV piace helium inside the plastic hood surrounding the body of the vessel. Be sure to cut and tape the plastic so the leak test fitting remains outside of the plastic hood. The test duration should be approximately 2 minutes.

6. Determine the vessel and the $\mathrm{O}$-ring seal leakage rate for the secondary containment vessel.

Date and Time $9115198 \quad 2: 30$ PM

MSLD Reading 7.2 X Range Factor $500=$ MSLD Div.

Background $\$ .6 \times$ Range Factor $50=$ Backgnd Div.

MSLD Div. 3600 - Backgnd Div. 430 = Net Div.

MSLD Sensitivity $1.2 \times 10^{-11} \times$ Net Div.3170=

Secondary vessel and O-ring leakage Rate $3.8 \times 10^{-8} \mathrm{ktm} \mathrm{cc} / \mathrm{sec}$ 
HNF-3516, Rev. 0

\section{HELIUM LEAK TEST QUALIFICATION OF THE PAS-1 CASK}

\section{Secondary Containment Vessel Stat-0-Seal}

I. Connect the test equipment as depicted in Figure 3: Note the atmospheric pressure on the gage.

2. Evacurate the SCV with the vacuum pump to less than 0.5 PSIA. Record the gage

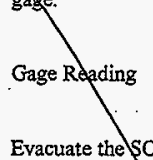

PSLA Gage Reading PSIA

3. Valve the vacuum punp out of the system and backfill the SCV with helium to the atmospheric pressure gage reading in step 1.

4. Remove the manifold. Install and tighteft that-o-seal to the closed position with the test port tool. Reconnect the WSLD to the cask test port.

5. Evacuate the stat-o-seal area with the MSLD.

6. When the MSID switches to the test mode a large belium signal may be-present. Ideally, the high helium background should dedrease steadily to the background established during the SCV seal test. However, experience has shown that the background level will settle out higher but to an acceptable level. The test duration should be long enough to establish a stable MSLD reading. To be conservative in calculating the leak rate of the vessel the background level established duringthe SCV test will be subtracted from the MSLD reading. Therefore, the stat-0-seal will pyobably have a leak rate associated with it, however, the leak rate should be smaller than the acceptance standard.

\begin{tabular}{|l|l|}
\hline \multicolumn{1}{|c|}{ TIME } & \\
\hline $\begin{array}{l}\text { Only use the time necessary to establish a } \\
\text { stable reading }\end{array}$ & MSLD Crossover Into Test Mode \\
\hline 30 Seconds & \\
\hline 1 Minute & \\
\hline 2 Minutes & \\
\hline 3 Minutes & \\
\hline
\end{tabular}


HELIUM LEAK TEST QUALIFICATION OF THE PAS-1 CASK

\begin{tabular}{|l|l|}
\hline 4 Minutes & \\
\hline 5 Minutes & \\
\hline 6 Minutes & $\cdots$ \\
\hline 7 Minutes & \\
\hline 8 Minutes & \\
\hline 9 Mintutes & \\
\hline 10 Minutes. & \\
\hline
\end{tabular}

-Date and Time

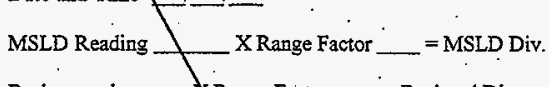

Background Range Factor $=$ Backgnd Div.

MSLD Div - Backgad Div. Af Net Div.

Net Div. X MSLD Sertitivity

Secondary Stat-O Seal Leak Rate atm-cc/sed div $=$

7. The MSLD shall have a MSLD sensitivity at the end of the test shall be at least I X $10^{-9}$ atm-cc/sec/div.

Date and Time

MSLD Reading

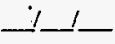
X Range Factor atm-cc/sec

Background $\mathrm{X}$ Range Factor $=$ Badkgnd Div.

MSLD Div. - Backgrid Div. $\Rightarrow$ Net Div.

Helium Std $\div$ Net Div MSLD Sensitivity atm-ce/sec/div $=$

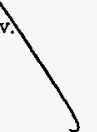




\section{HELTUM LEAK TEST QUALIFICATION OF THE PAS-1 CASK}

8. If the MSLD sensitivity has decreased 35 percent (less sensitive) during a calibration period the seal(s) examined since the last valid calibration period shall be retested.

9. Intermediate calibrations, if necessary.

Date and Time

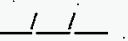

MSLD Reading $\mathrm{X}$ Range Factor $=$ MSLD Div:

Background $\mathrm{X}$ Range Factor = Backgud Div.

MSLD Div - Backgnd Div. $=$ Net Div.

Helium Std $\div$ Net Div.

MSLD Sensitivity atm-ce/sec/div

Date and Time

MSLD Reading $X$ Range Factor $=$ MSLD Div.

Background $\mathrm{X}$ Range Factor = Backgnd Div.

MSLD Div. - Backgnd Div. $=$ Net Div.

Helium Std $\div$ Net Div. $=$

MSLD Sensitivity atm-cc/sec/div

\section{Acceptance Criteria}

Each of the seals leakage rate shall be less than $1 \times 10^{-7} \mathrm{~atm}-\mathrm{cc} / \mathrm{sec}$ (air) or $2.6 \times 10^{-7} \mathrm{~atm}-\mathrm{cc} / \mathrm{sec}$ (helium). 
HNF-3516, Rev. 0

Figure 1

Primary Vessel and O-ring Seal

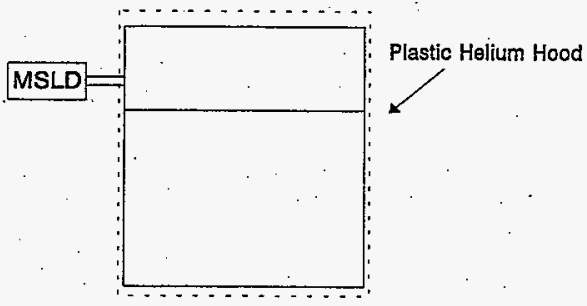

Secondary Vessel and O-ring Seal

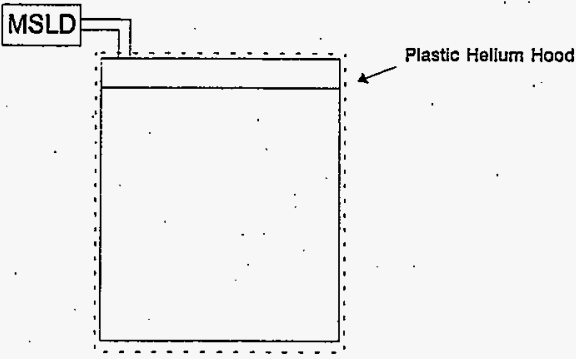


HNF-3516, Rev. 0

Figure 2

- Primary Stat-O-Seal

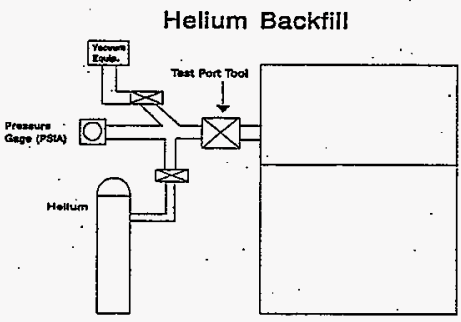

Examination

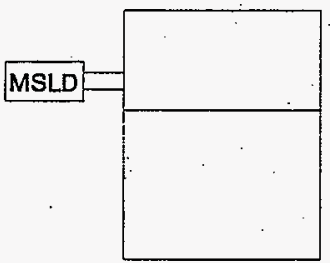


HNF-3516, Rev. 0

Figure 3
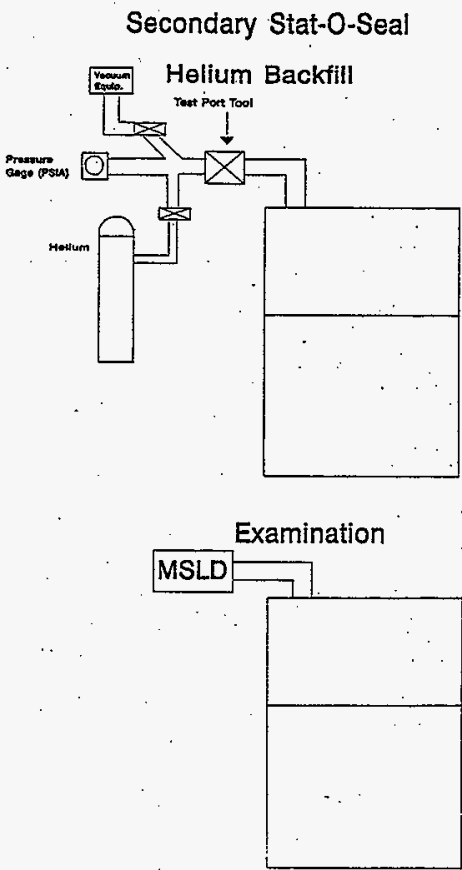


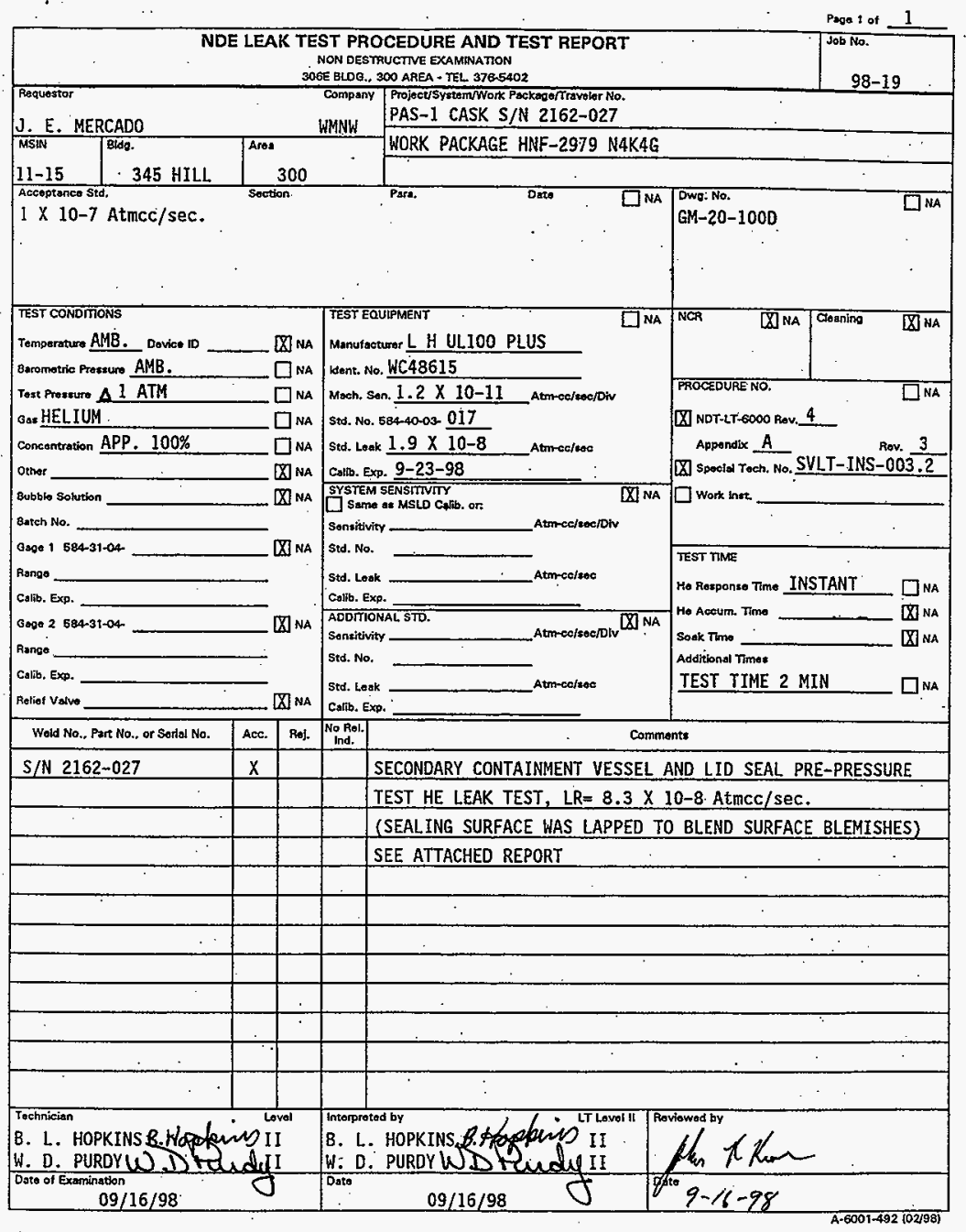


HNF-3516, Rev. 0

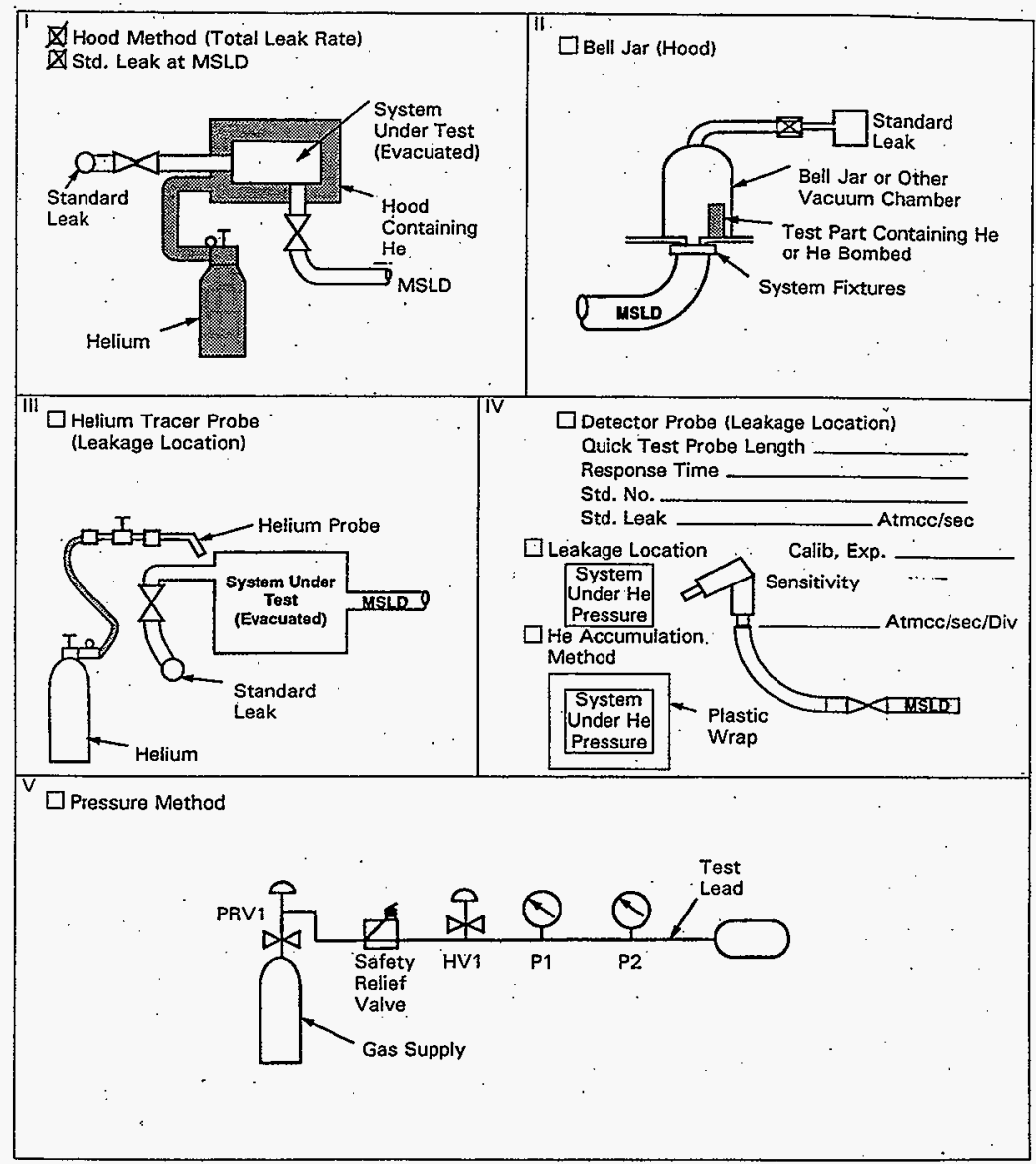

A. $6001-492$ (02/98) 
HNF-3516, Rev. 0

DOCUMENT APPROVAL/TRANSMITTAL RECORD

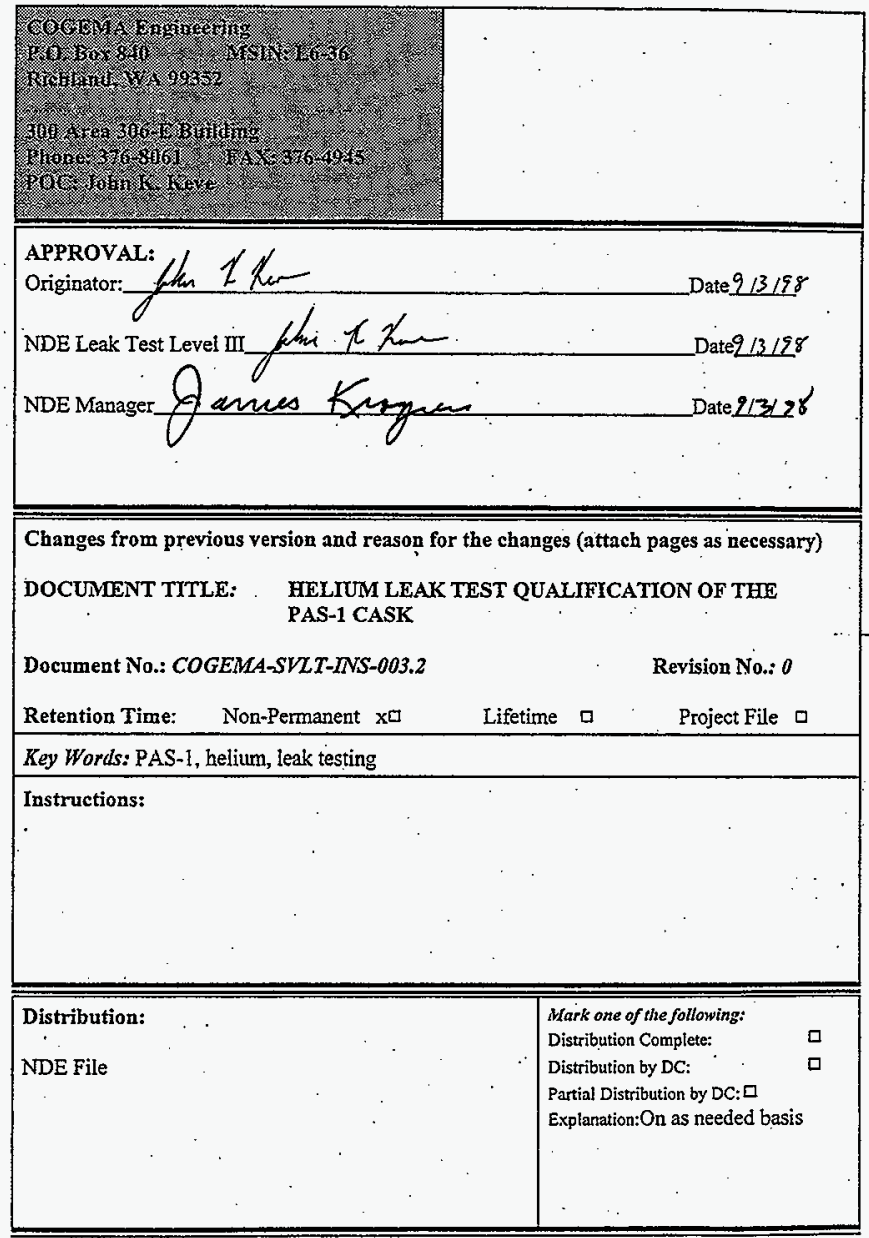




\section{HELIUM LEAK TEST QUALIFICATION OF THE PAS-1 CASK}

\section{PAS-1 Cask Serial Number 2162-027 Are Pressure Test Sealing Surface Lapped}

\section{Date 9116198}

\section{$1.0 \quad$ SCOPE}

This specific procedure addresses the helium leak testing of the vessel, outer $\mathrm{O}$-ring seal, and the stat-o-seal in the primary and secondary PAS- 1 cask. This technique shall be used in conjunction with NDT-LT-6000. General Leak Test Examination Procedure.

\subsection{INSTRUCTIONS}

Helium Mass Spectrometer Leak Detector (MSLD)

1. Operate the MSLD according to the manufacturer's operating manual.

2. Calibrate the MSLD using a $\times 10^{-8} \mathrm{~atm}-\mathrm{cc} / \mathrm{sec}$ calibrated standard.

Helium Standard Identification

$584-40-03-017$

Helium Standard $1.9 \times 10^{-8}$ atm-cc/sec

Helium Standard Calibration Expiration

$9-23-98$

3. The MSLD shall have a machine sensitivity of at least $1 \times 10^{-9} \mathrm{~atm}=\mathrm{cc} / \mathrm{sec} / \mathrm{div}$.

Date and Time $9.16 / 98$ 7:45 $\mathrm{AM}$

MSED Reading 3.2. X Range Factor $500=$ MSLD Div.

Background 1 . X Range Factor $5=$ Backgrid Div.

MSLD Div. 1600 - Backgnd Div. $\underline{5}_{-}=$Net Div.

Helium Std $1.9 \times 10^{-8} \div$ Net Div. $1595=$

MSLD Sensitivity $1.2 \times 10^{-11}$ atm-cc/sec/div 
HNF-3516, Rev. 0

\section{BELIUM LEAK TEST QUALIFICATION OF THE PAS-1 CASK}

\section{Ptimary Containment Vessel and Lid Seal}

-1. Clean and lightly apply a thin coating of Apiezon vacuum. grease on the outer O-ring seal.

2. Install the outer O-ring onto the lid and insert the lid onto the body of the Primary Containment Vessel (PCV).

3. Torque the bolts in a star pattern to $16-18 \mathrm{ft}-1 \mathrm{bs}$.

4. Remove the lid test plug(s) and stat-o-seal. Connect the test equipment as depicted in Figure 1.

5. Evacuate the PCr with the MSLD. When the MSLD reaches testing conditions check for leaks around the fest fittings. To test the $\mathrm{PCV}$ place helium inside the plastic hood surrounding the body of the cask. Be sure to cut and tape the plastic so the leak test fitting remains outside of the plastic hood. The test duration should be approximately 2 minutes.

6. Determine the vessel and outefo-rnofyal akage rate for the primary containment vessel.

Date and Time

MSLD Reading

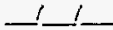

Background $X$ Range Factot $=$ MSLD Div.

MSLD Div. $X$ Range Factor = Backgnid Div.

MSLD Sensitivity - Backgnd Div $\doteq$ Net Div.

Primary Vessel and O-ring leakage Rate $X$ Net Div.

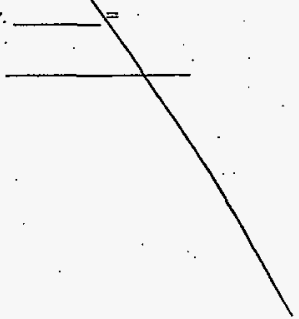


HNF-3516, Rev. 0

\section{HELIUM LEAK TEST QUALIFICATION OF THE PAS-1 CASK}

\section{Pripgary Containment Vessel Stat-O-Seal}

1. Gonnect the test equipment as depicted in Figure 2. Note the atmospheric pressure on the gage.

Gage Qalibration Identification

Gage Range

PSIA

Gage Calibratipn Expiration

Gage Reading

PSIA

2. Evacuate the PCV with the vacuum pump to less than 0.5 PSIA. Record the gage reading.

Gage Reading

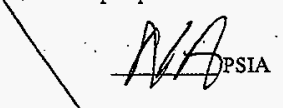

3. Valve the vacuum pump out of the system and backfill the PCV with helium to atmospheric pressure gage reading in trep 1 .

4. Remove the manifold. Install the stat-o-sed and tighten to the closed position with the test port tool. Reconnect the MSLD to the cdsk test port.

5. Evacuate the stat-o-seal area with the MSLD.

6. When the MSLD switches to the test mode a large helum signal may be present. Ideally, the high helium background should decrease steadily to the background level established during the PCV test. However, experience has shown that the background level will settle out higher but to an acceptable level. The test duration should be long enough to establish a stable MSLD reading. To be conservative in calculating the leak rate of the . vessel the background level established during the PCV test wh be subtracted from the MSLD reading. Therefore, the stat-0-seal will probably have a idak rate associated with it, however, the leak rate should be smaller than the acceptance stahdard.

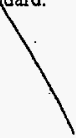


HELIUM LEAK TEST QUALIFICATION OF THE PAS-1 CASK

\begin{tabular}{|l|l|}
\hline \multicolumn{1}{|c|}{ TIME } & \multicolumn{1}{|c|}{ MSLD READING } \\
\hline $\begin{array}{l}\text { Only use the time necessary to establish a } \\
\text { stable reading }\end{array}$ & MSLD Crossover Into Test Mode \\
\hline 30 Seconds & \\
\hline 1 Minute \\
\hline 2 Minutes \\
\hline 3 Minutes \\
\hline 4 Minutes \\
\hline 5 Minutes \\
\hline 6 Minutes .
\end{tabular}


Secondary Containment Vessel and Lid Seal

1. Clean and lightly apply a thin coating of Apiezon vacuum grease on the outer O-ring seal.

2. Install the outer O-ring onto the lid and insert the lid onto the body of the Secondary Containment Vessel (SCV).

3. Torque the bolts in a star pattern to $100-150 \mathrm{ft}-1 \mathrm{bs}$. Repeat the sequence at $300-350 \mathrm{ft}-$ lbs with the final torquing being $450-500 \mathrm{ft}-1 \mathrm{bs}$.

4. Remove the lid test plug(s) and stat-o-seal. Connect the test equipment as depicted in Figure 1.

5. Evacuate the SCV with the MSLD: When the MSLD reaches testing conditions check for leaks around the test fittings. To test the SCV place helium inside the plastic hood surrounding the body of the vessel. Be sure to cut and tape the plastic so the leak test fitting remains outside of the plastic hood. The test duration should be approximately . 2 minutes.

6. Determine the vessel and the $\mathrm{O}$-ring seal leakage rate for the secondary containment: vessel.

Date and Time $91 / 6198$ 0800

MSI.D Reading $64 \times 10^{-7} \times$ Range Factor $5000=$ MSLD Div.

Background $/ .2 \times 10^{\circ} \times$ Range Factor $50=$ Backgnd Div.

MSLD Div. 7000 - Backgnd Div. 60 = Net Div.

MSLD Sensitivity $1.2 \times 10^{-11} \times$ Net Div. $6940=8.3 \times 10^{-8}$

Secondary vessel and 0 -ring leakage Rate $8.3 \times 10^{-8} \mathrm{Atm} .<</ \mathrm{sec}$ 


\section{BELIUM LEAK TEST QUALIFICATION OF THE PÁS-1 CASK}

Secondary Containment Yessel Stat-O-Seal

1. Connect the test equipment as depicted in Figure 3: Note the atmospheric pressure on the gaga

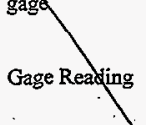
PSLA

2. Evacuate the SQV with the vacuum pump to less than 0.5 PSLA. Record the gage reading.

\section{Gage Reading}

PSIA

3. Valve the yacuum pump oyt of the system and backfill the SCV with helium to the atmospheric pressure gage reading in step 1

4. Remove the manifold. Install aud tighten/th stayo-seal to the closed position with the test port tool. Reconnect the MSLQ to the chas test port.

5. Evacuate the stat-o-seal area with the MSLD.

6. When the MSLD switches to the test modda large helium signal may be.present. Ideally, the high helium background should decrease steadily to the background established during the SCV seal test. However, experience has shown that the background level will settle out higher but to an acceptable level. The test duration should be long enough to establish a stable MSLD reading. To be conservatye in calculating the leak rate of the vessel the background level established during the $\$ \& V$ test will be subtracted from the MSLD reading. Therefore, the stat-o-seal will probably have a leak rate associated with it, however, the leak rate should be smaller than the accentance standard.

\begin{tabular}{|l|c|}
\hline \multicolumn{1}{|c|}{ TIME } & MSLD READING \\
\hline $\begin{array}{l}\text { Only use the time necessary to establish a } \\
\text { stable reading }\end{array}$ & MSLD Crossover Into Test Mode \\
\hline 30 Seconds & \\
\hline 1 Minute & \\
\hline 2 Minutes & \\
\hline 3 Minutes & \\
\hline
\end{tabular}


HELTUM LEAK TEST QUALIFICATION OF THE.PAS-1 CASK

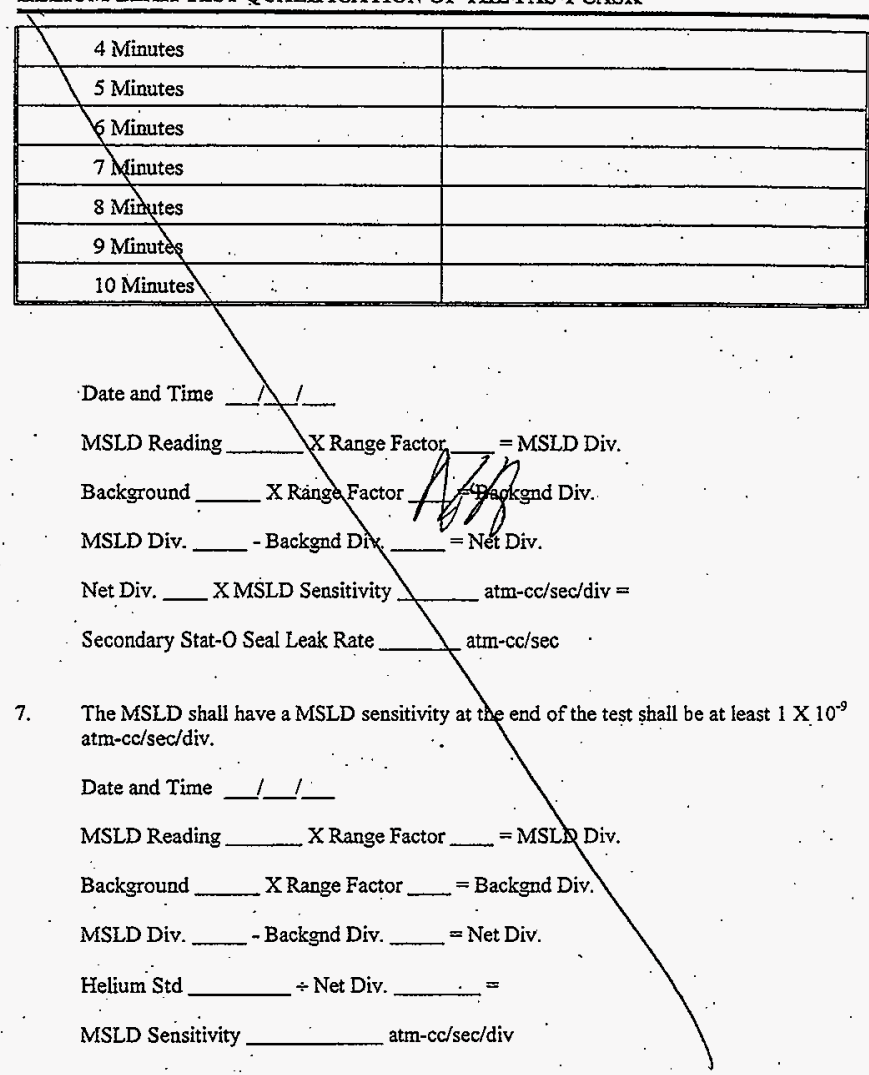


HNF-3516, Rev. 0

HELTUM LEAK TEST QUALIFICATMON OF THE PAS-1 CASK

3. . If the MSLD sensitivity has decreased 35 percent (less sensitive) during a calibration period the seal(s) examined since the last valid calibration period shall be retested.

9. Intermediate calibrations, if necessary.

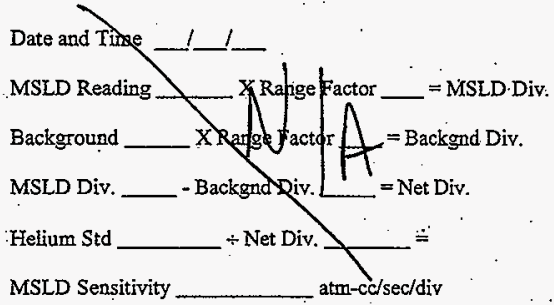

Date and Time $9 / 16 / 98 \quad 08 / 0$

MSLD Reading $3.4 \times 10^{-8}$ X Range Factor $500=$ MSLD Div.

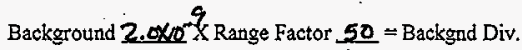

MSLD Div. 1700 - Backgnd Div. $\frac{67_{D P}^{\Delta 0}}{\sigma_{D P}}=$ Net Div.

Helium Std $1.9 \times 10^{-8} \div$ Net Div. $1600=$

MSLD Sensitivity $1.2 \times 10^{-11}$ atm-cc/sed div

\section{Acceptance Criteria}

Each of the seals leakage rate shall be less than $1 \times 10^{-7} \mathrm{~atm}-\mathrm{cc} / \mathrm{sec}$ (air) or $2.6 \times 10^{-7} \mathrm{~atm}-\mathrm{cc} / \mathrm{sec}$ (helium). 
HNF-3516, Rev. 0

Figure 1

Primary Vessel and O-ring. Seal.

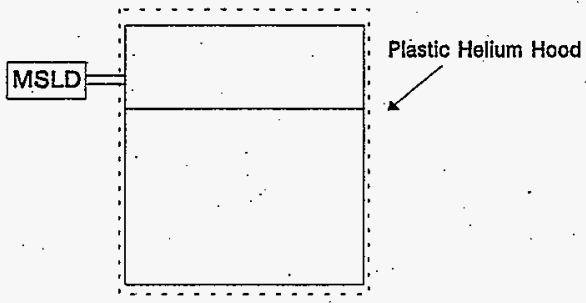

Secondary Vessel and O-ring Seal

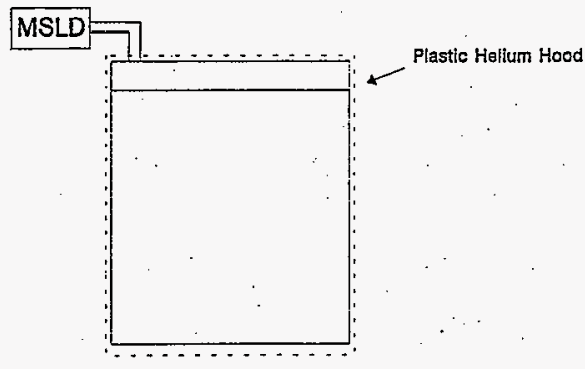


HNF-3516, Rev. 0

Figure 2

\section{Primary Stat-O-Seal}
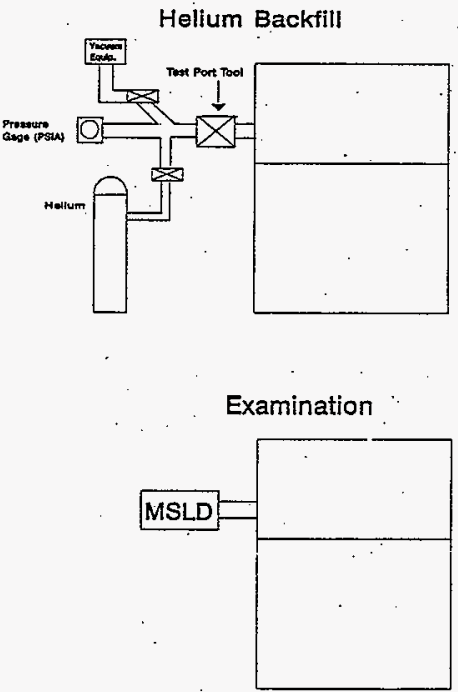
HNF-3516, Rev. 0

Figure 3
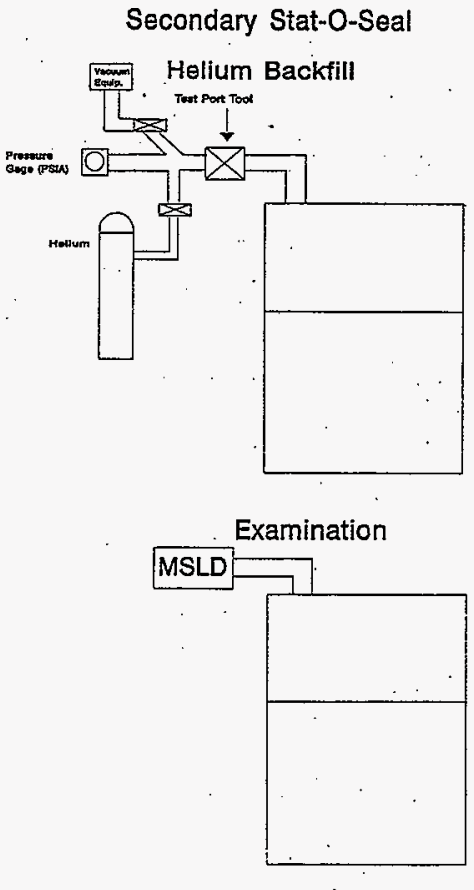


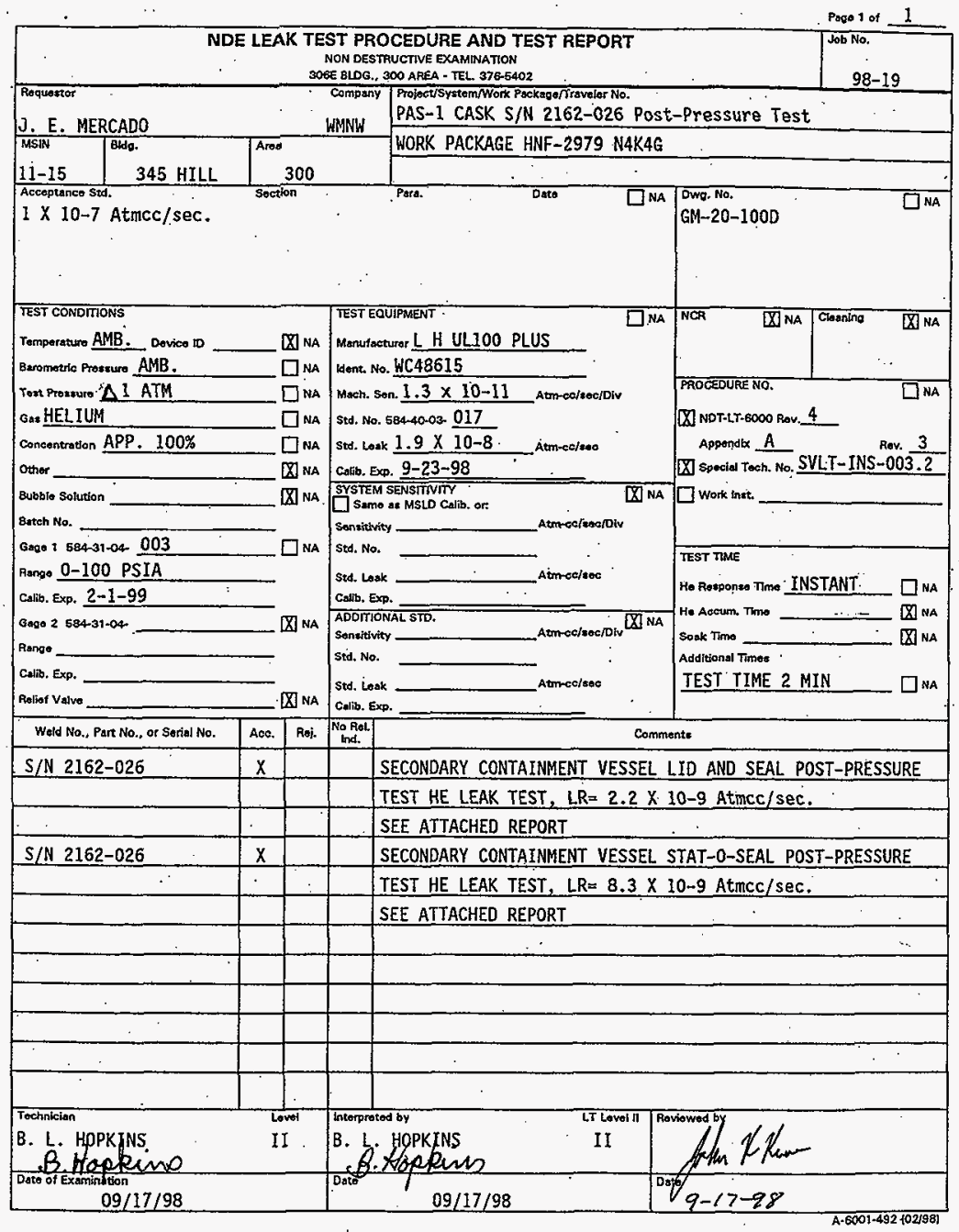


HNF-3516, Rev. 0

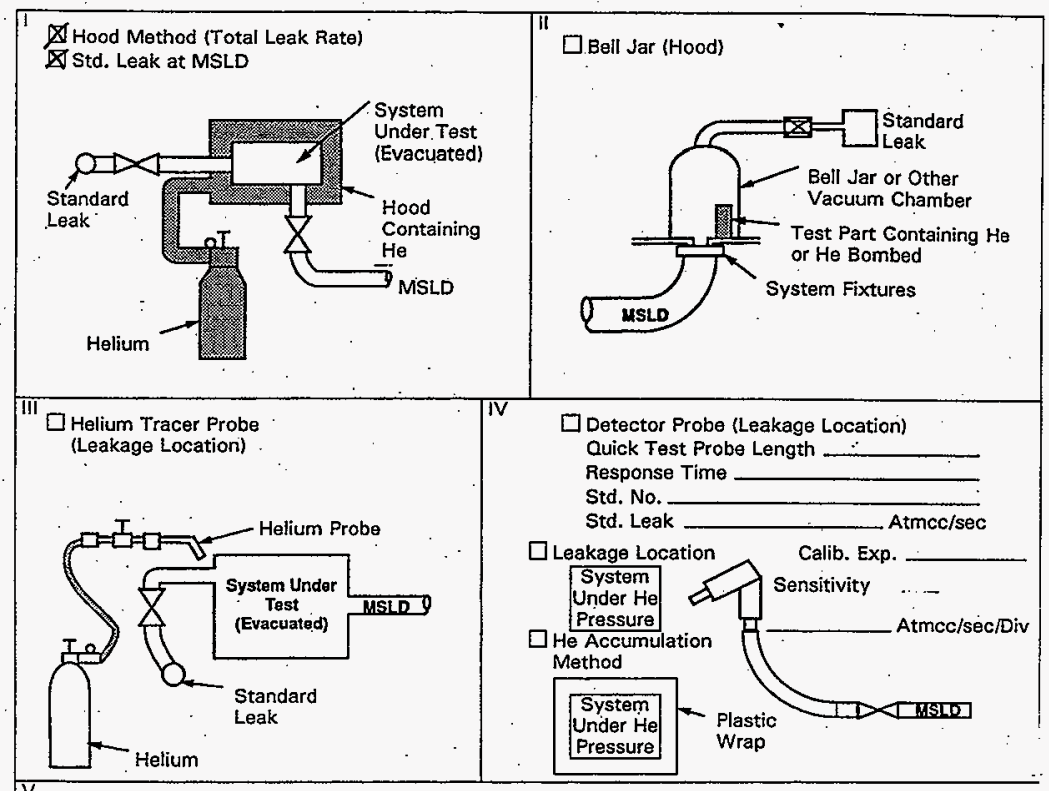

${ }^{V} \square$ Pressure Method

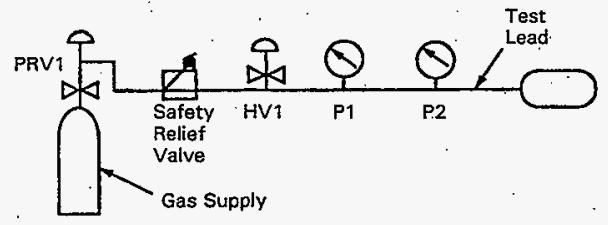

A-6001-492ก (02/983) 


\section{DOCUMENT APPROVAL/TRANSMITTAL RECORD}
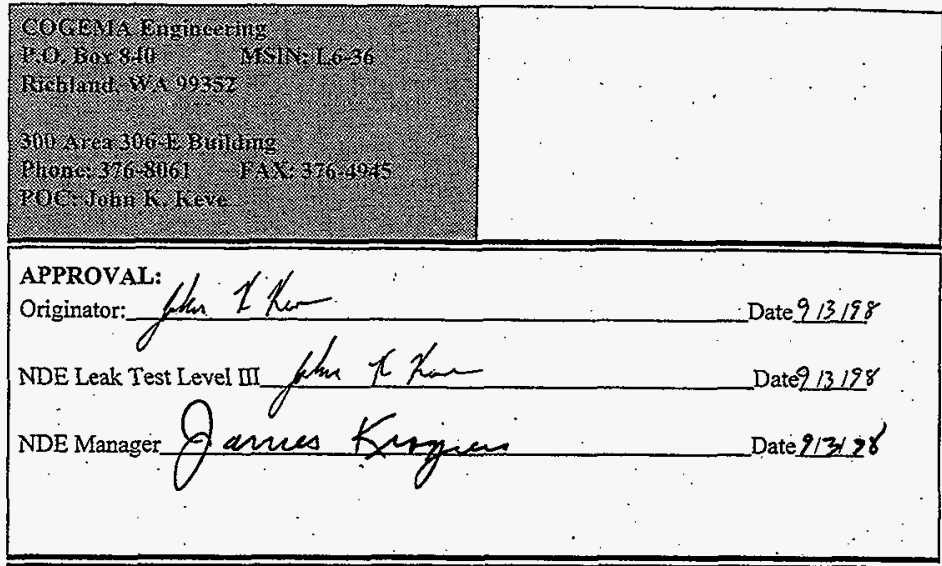

Changes from previous version and reason for the changes (attach pages as necessary) DOCUMENT TITLE: HELIUM LEAK TEST QUALIFICATION OF THE PAS-1 CASK

Document No.: COGEMA-SVLT-INS-003.2

Revision No.: 0

Retention Time: Non-Permanent $x \square$. Lifetime $\square \quad$ Project File $\square$

Key Words: PAS-1, helium, leak testing

Instructions:

.

Distribution:

Mark one of the following:

Distribution Complete:

NDE File

Distribution by DC:

Explariation:On as needed basis 


\section{PAS-1 Cask Serial Number $2162-026$ Post Pressure Test}

Date $9 / 17 / 98$

\section{$1.0 \quad$ SCOPE}

This specific procedure addresses the helium leak testing of the vessel, outer O-ring seal, and the stat-0-seal in the primary and secondary PAS-1 cask. This technique shall be used.in conjunction with NDT-LT-6000 General Leak Test Examination Procedure.

\subsection{INSTRUCTIONS}

\section{Helium Mass Spectrometer Leak Detector (MSLD)}

1. Operate the MSLD according to the manufacturer's operating manual.

2. Calibrate the MSLD using a $X 10^{-8}$ atm-ce/sec calibrated standard. WC 48615

Helium Standard Identification

Helium Standard

Helium Standard Calibration Expiration
$584-40 \cdot 03-017$ $1.9 \times 10^{-8} \mathrm{~atm}-\mathrm{cc} / \mathrm{sec}$

$$
9-23-98
$$

3. The MSLD shall have a machine sensitivity of at least $1 \times 10^{-9} \mathrm{~atm}-\mathrm{cc} / \mathrm{sec} /$ div.

Date and Time $9 / 17 / 98$

MSLD Reading $3.0 \times$ Range Factor $500=$ MSLD Div.

Background I $\quad$ X Range Factor $5=$ Backgnd Div.

MSLD Div. 1500 - Backgnd Div. .5 = Net Div.

Helium Std $1.9 \times 10^{-8} \div$ Net Div. $1495=$

MSLD Sensitivity $1.3 \times 10^{-11}$ atm-cc/sec/div 
HNF-3516, Rev. 0

\section{HELIUMI LEAK TEST QUALIFICATION OF THE PAS-1 CASK}

\section{Primary Contairment Vessel and Lid Seal}

1. Glean and lightly apply a thin coating of Apiezon vacuum grease on the outer O-ring seal.

2. Install the outer $\mathrm{O}$-ring onto the lid and insert the lid onto the body of the Primary Containment Vessel (PCV).

3. Torque the bolts in a star pattern to $16-18 \mathrm{ft}-\mathrm{lbs}$.

4. Remove the ldest plug(s) and stat-o-seal: Connect the test equipment as depicted in Figure 1.

5. Evacuate the PCV the MSLD. When the MSLD reaches testing conditions check for leaks around the test fittings. To test the PCV place helium inside the plastic hood surrounding the body of the cask. Be sure to cut and tape the plastic so the leak test fitting remains outside of the plastic hood. The test duration should be approximately 2 minutes.

6. Determine the vessel and outero-ring seal leakage rate for the primary containment vessel.

Date and Time

MSLD Reading

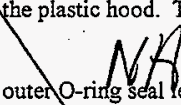

Background $\mathrm{X}$ Range Factor $\mathrm{X}$ Range Facto $=$ MSLD Div.

MSLD Div - Backgnd Div. $\doteq$ Net Qiv.

MSLD Sensitivity X Net Div.

Primary Vessel and O-ring leakage Rate 


\section{HELIUM LEAK TEST QUALIFICATION OF THE PAS-1 CASK}

\section{Primary Containment Vessel Stat-O-Seal}

1. Connect the test equipment as depicted in Figure 2. Note the atmospheric pressure on the gage.

Gage Calibration Identification

Gage Range

Gage Calibration Expiration

Gage Reading

\section{$584-31-04-003$}

$0-100$ PSIA

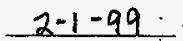

14.5 PSIA.

2. Evdcuate the PCV with the vacuum pump to less than 0.5 PSIA. Record the gage reading.<smiles>[13CH3][14CH3]</smiles>
PSIA

3. Valve the vacuum ptup out of the system and backfill the PCV with helium to atmospheric pressure gage reading in step 1 .

4. Remove the manifold. Instay the stat-o-seal and tighten to the closed position with the test port tool. Reconnect the MSLD to the cAl fest port.

5. Evacuate the stat-o-seal area with the MSLD.

6. When the MSLD switches to the test mode Large helium signal may be present. Ideally, the high helium background should decrease stodily to the background level established during the PCV test. However, experience has shdyn that the background level will settle out higher but to an acceptable level. The test dyration should be long enough to establish a stable MSLD reading. To be conservative incalculating the leak rate of the. vessel the background level established during the PCV test will be subtracted from the MSLD reading. Therefore, the stat-o-seal will probably have leak rate associated with it, however, the leak rate should be smaller than the acceptance standard. 


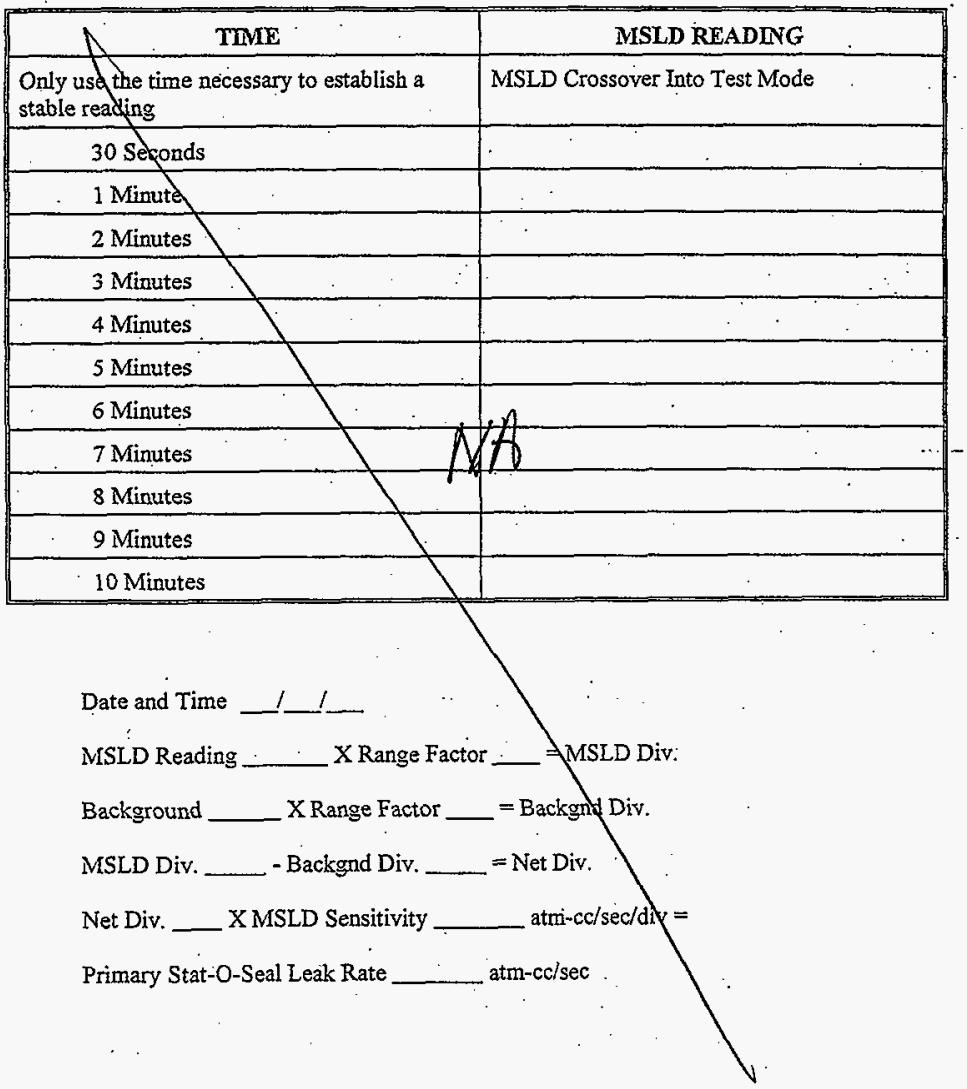




\section{HELIUM LEAK TEST QUALIFICATION OF THE PAS-1 CASK}

\section{Secondary Containment Vessel and Lid Seal}

1. Clean and lightly apply a thin coating of Apiezon vacuum grease on the outer $\mathrm{O}$-ring seal.

2. Install the outer O-ring onto the lid and insert the lid onto the body of the Secondary Containment Vessel (SCV).

3. Torque the bolts in a star pattern to $100-150 \mathrm{ft}-1 \mathrm{bs}$. Repeat the sequence at $300-350 \mathrm{ft}$ lbs with the final torquing being $450-500 \mathrm{ft}-\mathrm{lbs}$. .

4. Remove the lid test plug(s) and stat-o-seal. Connect the test equipment as depicted in Figure 1 .

5. Evacuate the SCV with the MSLD. When the MSLD reaches testing conditions check for leaks around the test fittings. To test the SCV place helium inside the plastic hood surrounding the body of the vessel. Be sure to cut and tape the plastic so the leak test fitting remains outside of the plastic hood. The test duration should be approximately 2 minutes.

6. Determine the vessel and the O-ring seal leakage rate for the secondary containment vessel.

Date and Time 9117198 8:55 AM

MSLD Reading 6.6 X Range Factor $50=$ MSLD Div.

Background \$.2 X Range Factor $50=$ Backgnid Div.

MSLD Div. 330 - Backgnd Div. $160=$ Net Div.

MSLD Sensitivity $1.3 \times 10^{-11} \times$ Net Div. $170=$

Secondary vessel and O-ring leakage Rate $2.2 \times 10^{-9} \mathrm{Atumcc} / \mathrm{sec}$. 


\section{HELIUM LEAK TEST QUALIFICATION OF THE PAS-1 CASK}

\section{Secondary Containment Vessel Stat-O-Seal}

1. Connect the test equipment as depicted in Figure 3: Note the atmospheric pressure on the gage.

Gage Reading

14.5 PSIA

2. Evacuate the SCV with the vacuum pump to less than 0.5 PSIA. Record the gage reading.

Gage Reading

$.04 \quad$ PSLA

3. Valve the vacumm pump out of the system and backfill the SCV with helium to the atmospheric pressure gage reading in step $\mathrm{L}$.

4. Remove the manifold. Install and tighten the stat-0-seal to the closed position with the test port tool. Reconnect the MSLD to the cask test port.

5. Evacuate the stat-o-seal area with the MSLD.

6. When the MSLD switches to the test mode a large helium signal may be.present. Ideally, the high helium background should decrease steadily to the background established during the SCV seal test. However, experience has shown that the background level will settle out higher but to an acceptable level. The test duration should be long enough to establish a stable MSLD reading. To be conservative in calculating the leak rate of the vessel the background level established during the SCV test will be subtracted from the MSLD reading. Therefore, the stat-o-seal will probably have a leak rate associated with it, however, the leak rate should be smaller than the acceptance standard.

\begin{tabular}{|l|c|}
\hline \multicolumn{1}{|c|}{ TIME } & MSLD READING \\
\hline $\begin{array}{l}\text { Only use the time necessary to establish a } \\
\text { stable reading }\end{array}$ & MSLD Crossover Into Test Mode \\
\hline 30 Seconds & $1.8 \times 10^{-8}$ \\
\hline 1 Minute & $1.6 \times 10^{-8}$ \\
\hline 2 Minutes & $1.6 \times 10^{-8}$ \\
\hline 3 Minutes & \\
\hline
\end{tabular}


HELIUM LEAK TEST QUALIFICATION OF THE PAS-1 CASK

\begin{tabular}{|l|l|}
\hline 4 Minutes & \\
\hline 5 Minutes & \\
\hline 6 Minutes & \\
\hline 7 Minutes & \\
\hline 8 Minutes & \\
\hline 9 Minutes & \\
\hline 10 Minutes & \\
\hline
\end{tabular}

Date and Time 9/17/98:10:40 AM

MSLD Reading $1.6 \times$ Range Factor $500=$ MSLD Div.

Background $3.2 \times$ Range Factor $50=$ Backgnd Div.

MSLD Div. 800 - Backgnd Div. $160=$ Net Div.

Net Div. 640 X MSLD Sensitiyity $1.3 \times 10^{-11}$ atm-ce/sec/div =

Secondary Stat-O Seal Leak Rate $8.3 \times 10^{-9}$ atm-cc/sec

7. The MSLD shall have a MSLD sensitivity at the end of the test șall be at least $1 \times 10^{-9}$ atm-cc/sec/div.

Date and Time 9/17/98, 10:50 AM

MSLD Reading 3.2 X Range Factor $500=$ MSLD Div.

Background 2 X Range Factor 5 = Backgnd Div.

MSLD Div. 1600 - Backgnd Div. $10=$ Net Div.

Helium Std $1.9 \times 10^{-8} \div$ Net Div. $1.590=$

MSLD Sensitivity $1.2 \times 10^{-1 !}$ atm-cc/sec/div 


\section{HELIUM LEAK TEST QUALIFICATION OF THE PAS-1 CASK}

8. If the MSLD sensitivity has decreased 35 percent (less sensitive) during a calibration period the seal(s) examined since the last valid calibration period shall be retested.

9. Intermediate calibrations, if necessary.

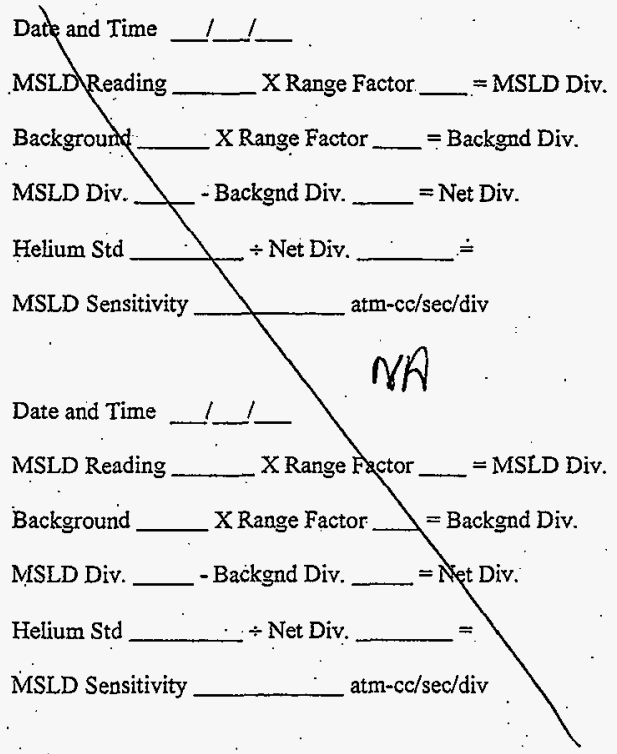

\section{Acceptance Criteria}

Each of the seals leakage rate shall be less than $1 \times 10^{-7} \mathrm{~atm}-\mathrm{cc} / \mathrm{sec}$ (air) or $2.6 \times 10^{-7} \mathrm{~atm}-\mathrm{cc} / \mathrm{sec}$ (helium). 
HNF-3516, Rev. 0

\section{Figure 1}

\section{Primary Vessel and O-ring Seal}

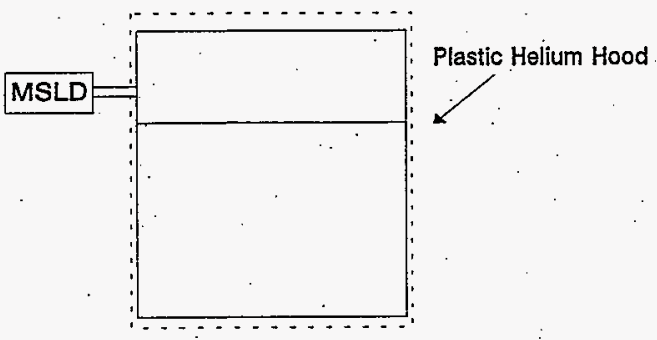

Secondary Vessel and O-ring Seal

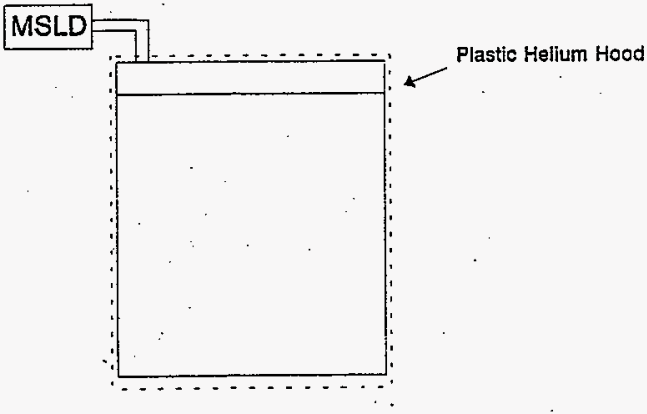


HNF-3516, Rev. 0

Figure 2

\section{Primary Stat-O-Seal}

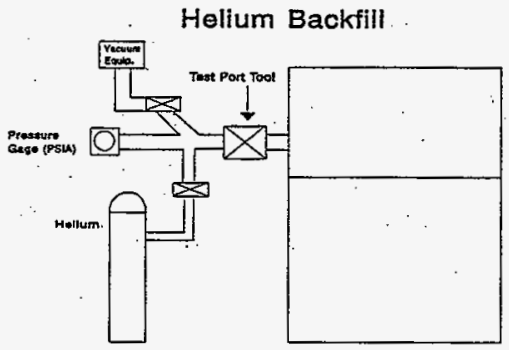

Examination

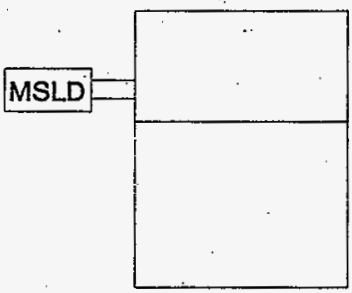


Figure 3
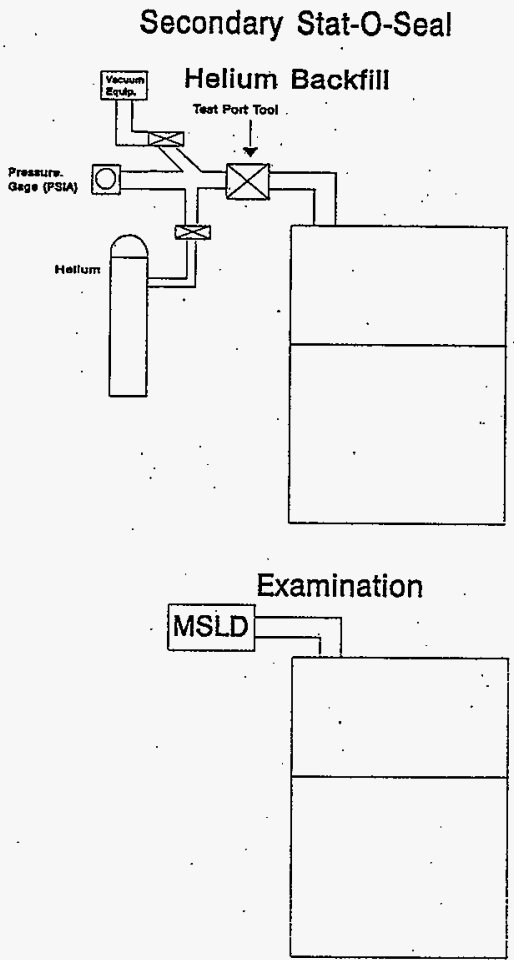
HNF-3516, Rev. 0

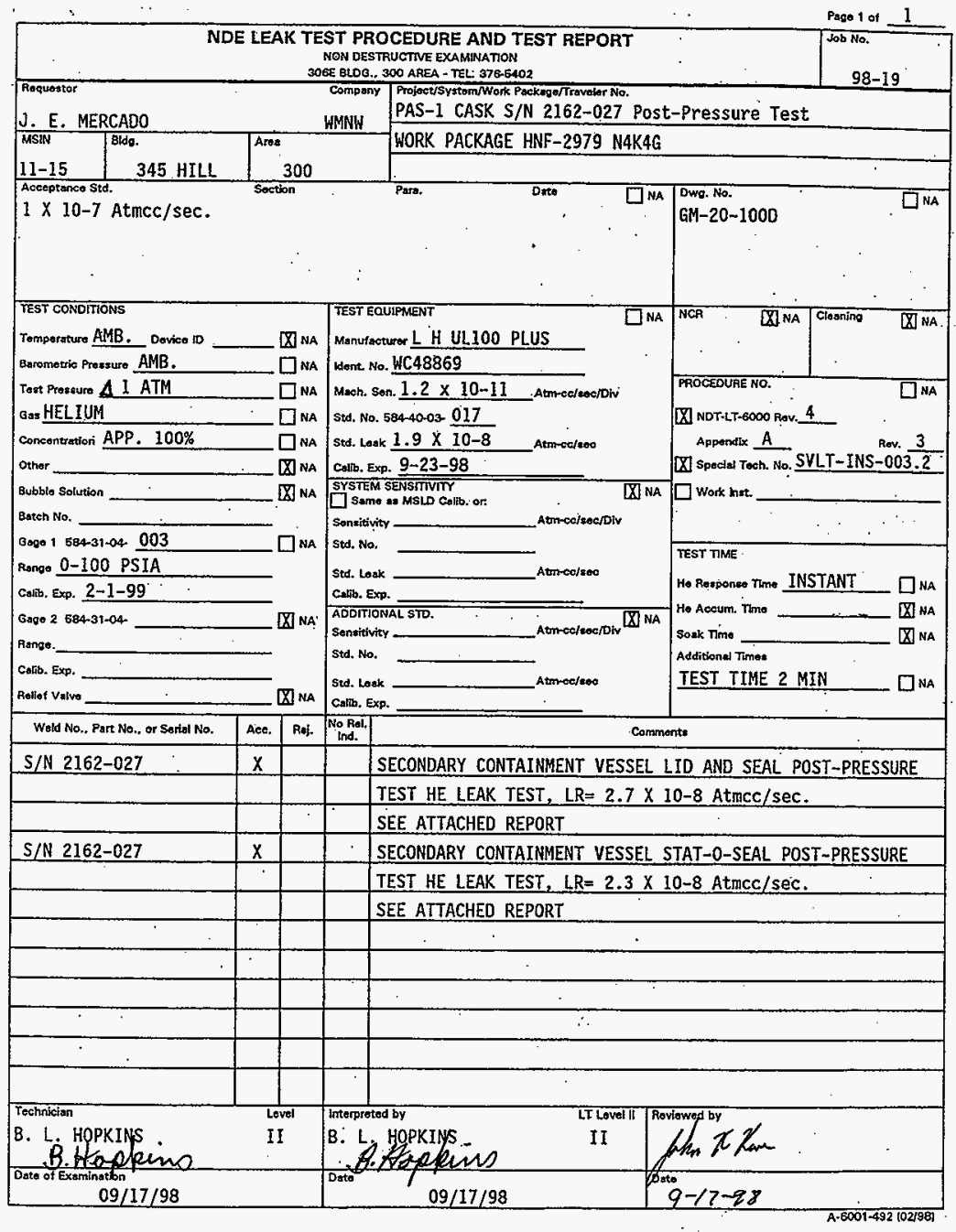


HNF-3516, Rev. 0

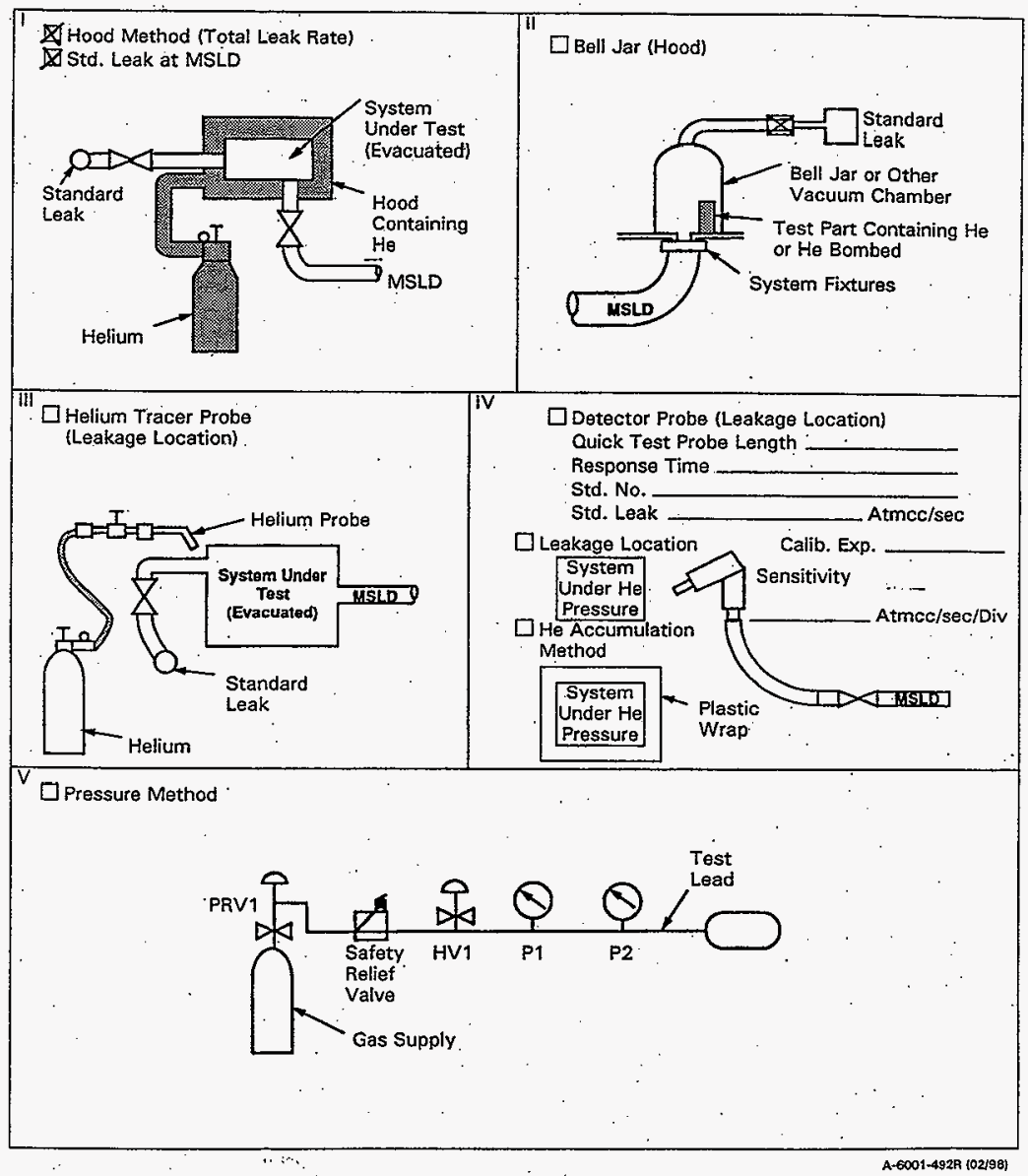




\section{DOCUMENT APPROVAL/TRANSMITTAL RECORD}

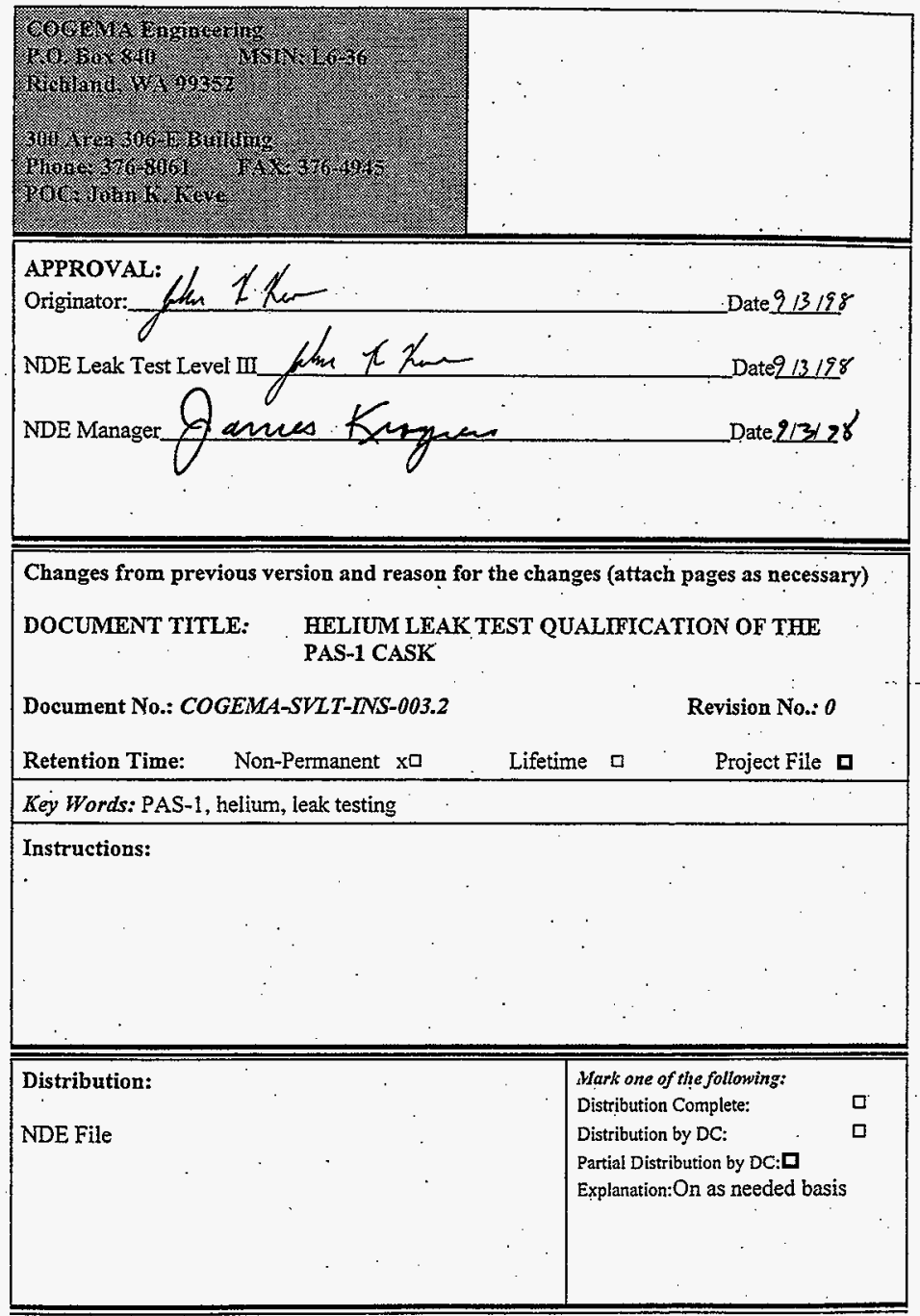


HNF-3516, Rev. 0

PAS-1 Cask Serial Number 2162-027 Post Pressure Test

Date $9 / 17 / 98$

\subsection{SCOPE}

This specific procedure addresses the helium leak testing of the vessel, outer $\mathrm{O}$-ring seal, and the stat-o-seal in the primary and secondary PAS-1 cask. This technique shall be used in conjunction with NDT-LT-6000 General Leak Test Examination Procedure.

\subsection{INSTRUCTIONS}

Helium Mass Spectrometer Leak Detector (MSLD)

i. Operate the MSLD according to the manufacturer's operating manual.

2. Calibrate the MSLD using a $\times 10^{-8}$ atm-cc/sec calibrated standard. WC 48869

Helium Standard Identification $584-40-03-017$

Felium Standard $1.4 \times 10^{-8} \mathrm{~atm}-\mathrm{cc} / \mathrm{sec}$

Helium Standard Calibration Expiration $9-23-98$

3. The MSLD shall have a machine sensitivity of at least $1 \times 10^{-9} \mathrm{~atm}-\mathrm{cc} / \mathrm{sec} / \mathrm{div}$.

Date and Time $9 / 17 / 98.8: 15 \mathrm{AM}$

MSLD Reading $3.2 \times$ Range Factor $\underline{500}=$ MSLD Div.

Background 2 X Range Factor $5=$ Backgnd Div.

MSLD Div. 1600 - Backgnd Div. $10=$ Net Div.

Helium Std $1.9 \times 10^{-8} \div$ Net Div $1590=$

MSLD Sensitivity $1.2 \times 10^{-11}$ atm-cc/sec/div 


\section{HELIUM LEAK TEST QUALIFICATION OF THE PAS-1 CASK}

Primary Containment Vessel and Lid Seal

1. Clean and lightly apply a thin coating of Apiezon vacuum grease on the outer O-ring seal.

2. Install the outer $O$-ring onto the lid and insert the lid onto the body of the Primary Containtent Vessel (PCV).

3. Torque the golts in a star pattern to $16-18 \mathrm{ft}-\mathrm{lbs}$.

4. Remove the lidtest plug(s) and stat-o-seai. Connect the test equipment as depicted in Figure 1.

5. Evacuate the PCV with the MSLD. When the MSLD reaches testing conditions check for leaks around the t tst fittings. To test the PCV place helium inside the plastic hood surrounding the body of the cask. Be sure to cut and tape the plastic so the leak test fitting remains outside of the plastic hood. The test duration should be approximately 2 minutes.

6. Determine the vessel and outer $Q$-ring seal leakage rate for the primary containment vessel.

Date and Time

MSLD Reading

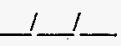

$$
N A
$$

Background $\mathrm{X}$ Range Factor ___ = MSLD Div.

MISLD Div. - Backgnd Div $\mathrm{X}$ Range Factor Backgnd Div.

MSLD Sensitivity XNet Div $=$ Nef Div.

\section{Primary Vessel and O-ring leakage Rate}

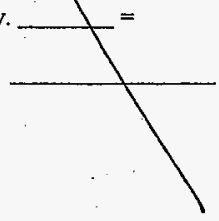


HNF-3516, Rev, 0

\section{HELIUM LEAK TEST QUALIFICATION OF THE PAS-1 CASK}

\section{Primary Containment Vessel Stat-O-Seal}

1. Connect the test equipment as depicted in Figure 2. Note the atmospheric pressure on the gage.

Gage Calibration Identification

Gage Range

Gage Calibration Expiration

Gage Reading

$$
\text { 584-31-04-003. }
$$

$$
0-100 \text { PSIA }
$$
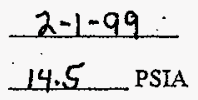

2. Evacuate the PCV with the vacuum pump to less than 0.5 PSIA. Record the gage reading.

Gage Reading

PSIA

3. Valve the vacuum pump out of the system and backfill the PCV with helium to atmospheric presstre gage reading in step 1.

4. Remove the manifold. Install the stat-o-seal and tighten to the closed position with the test port tool. Reconnect the MSLD to the cask test port.

5. Evacuate the stat-o-seal area with the MSLD.

6. When the MSLD switches to the test mode a large helium signal may be present. Ideally, the high helium background should decrease steadil to the background level established during the PCV test. However, experience has shown that the background level will settle out higher but to an acceptable level. The test duratipn should be long enough to establish a stable MSLD reading. To be conservative in calculating the leak rate of the vessel the background level established during the PCV test wixbe subtracted from the MSLD reading. Therefore, the stat-o-seal will probably have a leak rate associated with it, however, the leak rate should be smaller than the acceptance standard. 
HELIUM LEAK TEST QUALIFICATION OF THE PAS-1 CASK

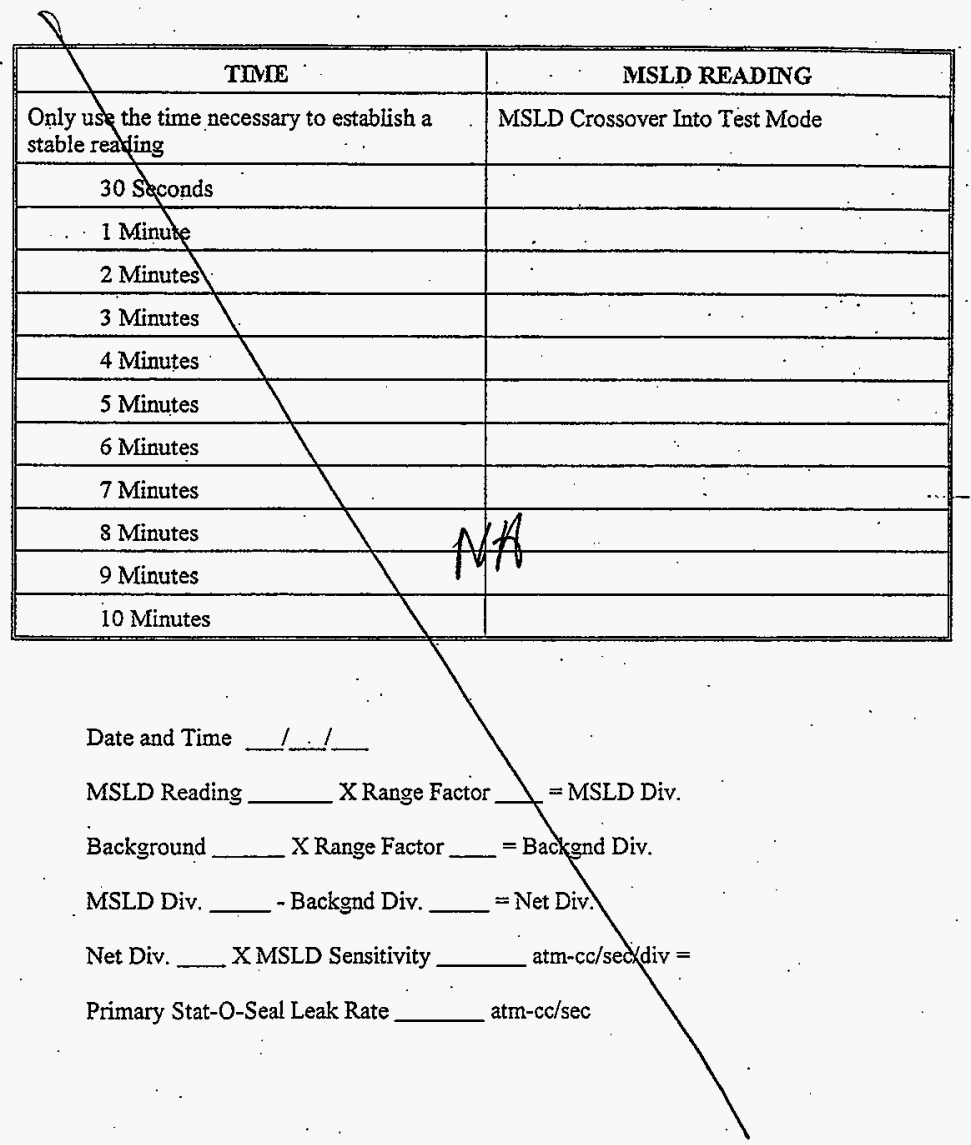




\section{BELIUM LEAK TEST QUALIFICATION OF THE PAS-I CASK}

\section{Secondary Containment Vessel and Lid Seal}

1. Clean and lightly apply a thin coating of Apiezon vacuum grease on the outer O-ring seal.

2. Install the outer-O-ring onto the lid and insert the lid onto the body of the Secondary Containment Vessel (SCV).

3. Torque the bolts in a star pattern to $100-150 \mathrm{ft}-\mathrm{bbs}$. Repeat the sequence at $300-350 \mathrm{ft}$ lbs with the final torquing being $450-500 \mathrm{ft}$-lbs.

4. Remove the lid test plug(s) and stat-o-seal. Connect the test equipment as depicted in Figure 1.

5. Evacuate the SCV with the MSLD. When the MSLD reaches testing conditions check for leaks around the test fittings. To test the SCV place helium inside the plastic hood surrounding the body of the vessel. Be sure to cut and tape the plastic so the leak test fitting remains outside of the plastic hood. The test duration should be approximately . 2 minutes.

6. Determine the vessel and the O-ring seal leakage rate for the secondary containment vessel.

Date and Time $9 / 17 / 98 \quad 8: 45$

MSLD Reading 4.8 $\times$ Range Factor $500=$ MSLD Div.

Background 2.8 X Range Factor $50=$ Backgnd Div.

MSLD Div. 2400 - Backgnd Div. $140=$ Net Div.

MSLD Sensitivity $1.2 \times 10^{-11} \times$ Net Div. $2260=$

Secondary vessel and O-ring leakage Rate $2.7 \times 10^{-8} \mathrm{Atm} \mathrm{me} / \mathrm{sec}$. 


\section{HELIUUM LEAK TEST QUALIFICATION OF THE PAS-1 CASK}

Secondary Containment Vessel Stat-O-Seal

1. Connect the test equipment as depicted in Figure 3: Note the atmospheric pressure on the gage.

Gage Reading

$14.5 \quad$ PSIA

2. Evacuate the SCV with the vacuum pump to less than 0.5 PSIA. Record the gage reading.

\section{Gage Reading}

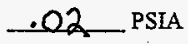

3. Valve the vacuum pump out of the system and backfill the SCV with helium to the atmospheric pressure gage reading in step 1 .

4. Remove the manifold. Install and tighten the stat-o-seal to the closed position with the test port tool. Reconnect the MSLD to the cask test port.

5. Evacuate the stat-o-seal area with the MSLD.

6. When the MSLD switches to the test mode a large helium signal may be present. Ideally; the high helium background should decrease steadily to the background established during the SCV seal test. However, experience has shown that the background level will settle out higher but to an acceptable level. The test duration should be long enough to establish a stable MSLD reading. To be conservative in calculating the leak rate of the vessel the background level established during the SCV test will be subtracted from the MSLD reading. Therefore, the stat-o-seal will probably have a leak rate associated with it, however, the leak rate should be smaller than the acceptance standard.

\begin{tabular}{|l|l|}
\hline \multicolumn{1}{|c|}{ TIME } & \multicolumn{1}{|c|}{ MSLD READING } \\
\hline $\begin{array}{l}\text { Only use the time necessary to establish a } \\
\text { stable reading }\end{array}$ & MSLD Crossover Into Test Mode \\
\hline 30 Seconds & $6 \times 10^{-8}$ \\
\hline 1 Minute & $5.6 \times 10^{-8}$ \\
\hline 2 Minutes & $4.4 \times 10^{-8}$ \\
\hline 3 Minutes & \\
\hline
\end{tabular}


HELIUM LEAK TEST QUALIFICATION OF THE PAS-1 CASK

\begin{tabular}{|l|l|}
\hline 4 Minutes & \\
\hline 5 Minutes & \\
\hline 6 Minutes & \\
\hline 7 Minutes & \\
\hline 8 Minutes & \\
\hline 9 Minutes & \\
\hline 10 Minutes & \\
\hline
\end{tabular}

Date and Time $9 / 17 / 98$ 9:55 AM

MSLD Reading 4.4. X Range Factor $500=$ MSLD Div.

Background 6.2 X Range Factor $\underline{50}=$ Backgnd Div.

MSLD Div. 2200 - Backgnd Div. $310=$ Net Div.

Net Div 1890 XMSLD Sensitivity $1.2 \times 10^{-11}$ atm-cc/sec/div =

Secondary Stat-O Seal Leak Rate $2.3 \times 10^{-8} \mathrm{~atm}-\mathrm{cc} / \mathrm{sec}$

7. The MSLD shall have a MSLD sensitivity at the end of the test shall be at least $1 \times 10^{-9}$. atm-cc/sec/div.

Date and Time $9 / 17 / 98 \quad 10: 10 \mathrm{AM}$

MSLD Reading $3.4 \times$ Range Factor $500=$ MSLD Div.

Background $4 \times$ Range Factor $5=$ Backgnd Div.

MSLD Div. 1700 - Backgnd Div. $20=$ Net Div.

Helium Std $1.9 \times 10^{-8} \div$ Net Div. $1680=$

MSLD Sensitivity $1.1 \times 10^{-11}$ atm-cc/sec/div 
HNF-3516, Rev. 0

\section{HELIUM LEAK TEST QUALIFICATION OF THE PAS-1 CASK}

8. If the MSLD sensitivity has decreased 35 percent (less sensitive) during a calibration period the seal(s) examined since the last valid calibration period shall be retested.

9. Intermediate calibrations, if necessary.

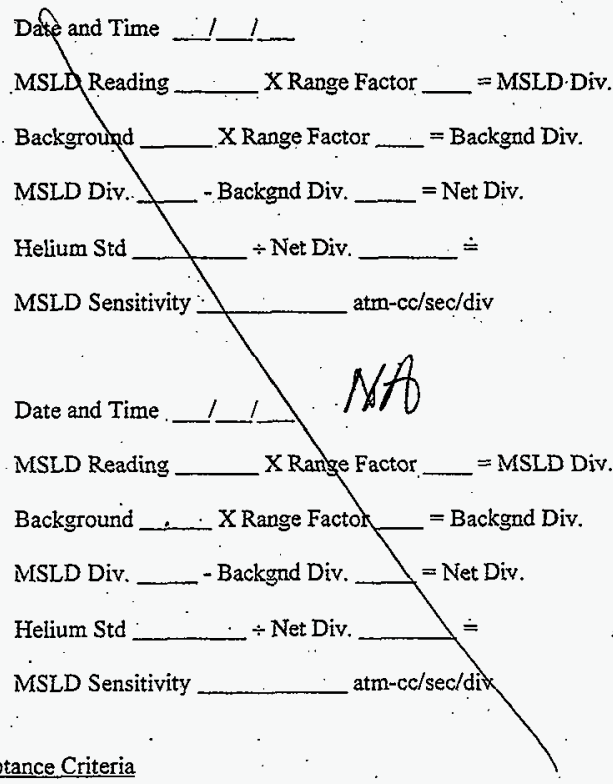

Each of the seals leakage rate shall be less than $1 \times 10^{-7} \mathrm{~atm}-\mathrm{cc} / \mathrm{sec}$ (air) or $2.6 \times 10^{-7} \mathrm{~atm}-\mathrm{cc} / \mathrm{sec}$ (helium). 
HNF-3516, Rev. 0

HELTUM LEAK TEST QUALIFICATION OF THE PAS-1 CASK

Figure 1

Primary Vessel and O-ring Seal

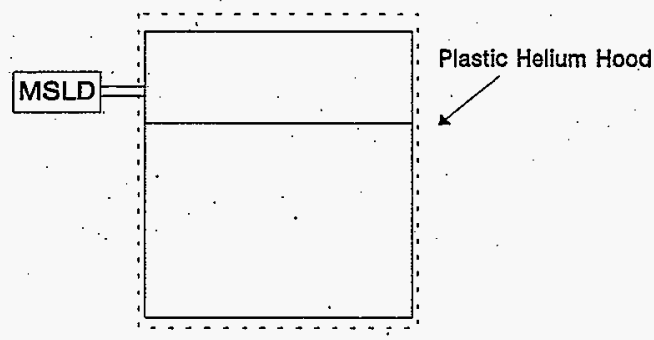

Secondary Vessel and O-ring Seal

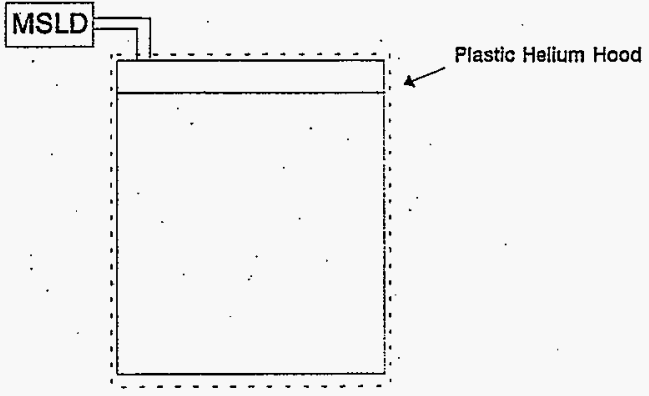


HNF-3516, Rev. 0

Figure 2

Primary Stat-O-Seal

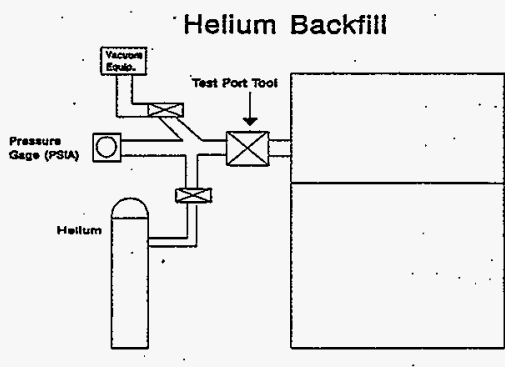

Examination

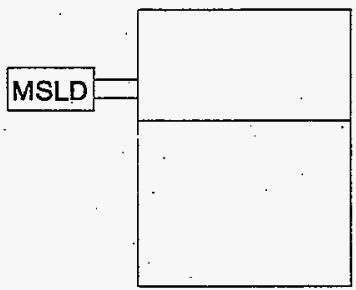


HNF-3516, Rev. 0

Figure 3

Secondary Stat-O-Seal

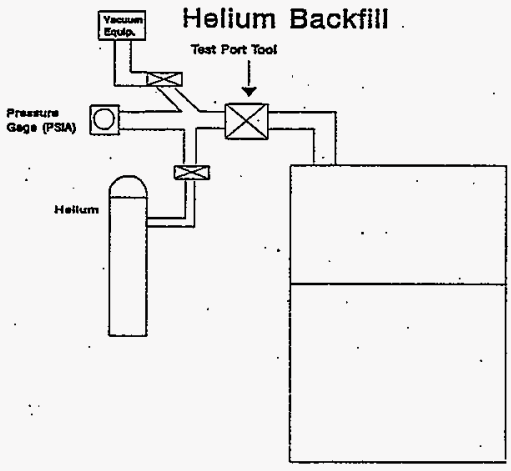

Examination

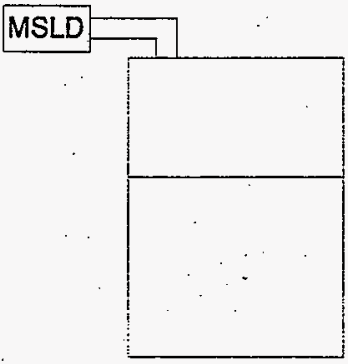




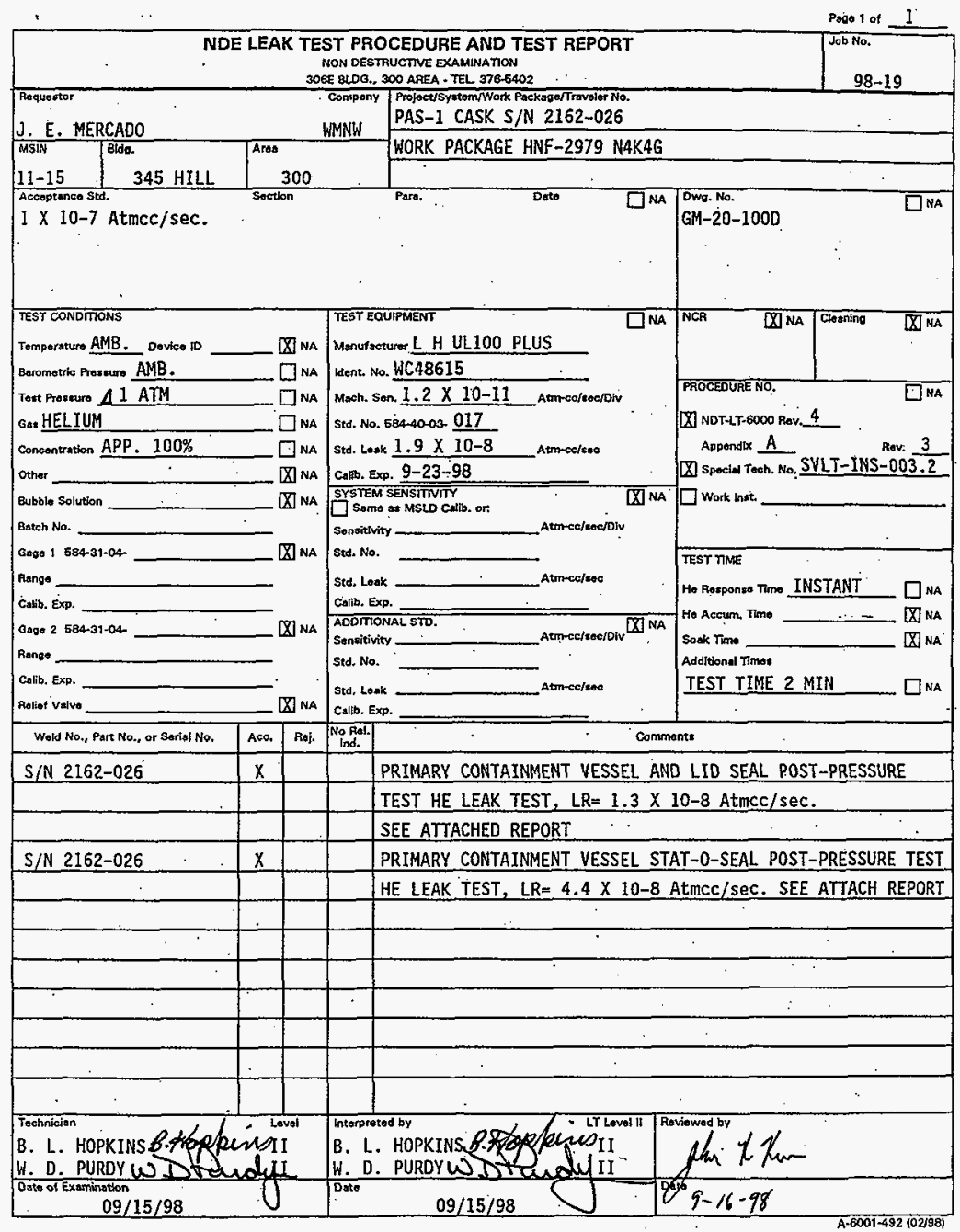


HNF-3516, Rev. 0

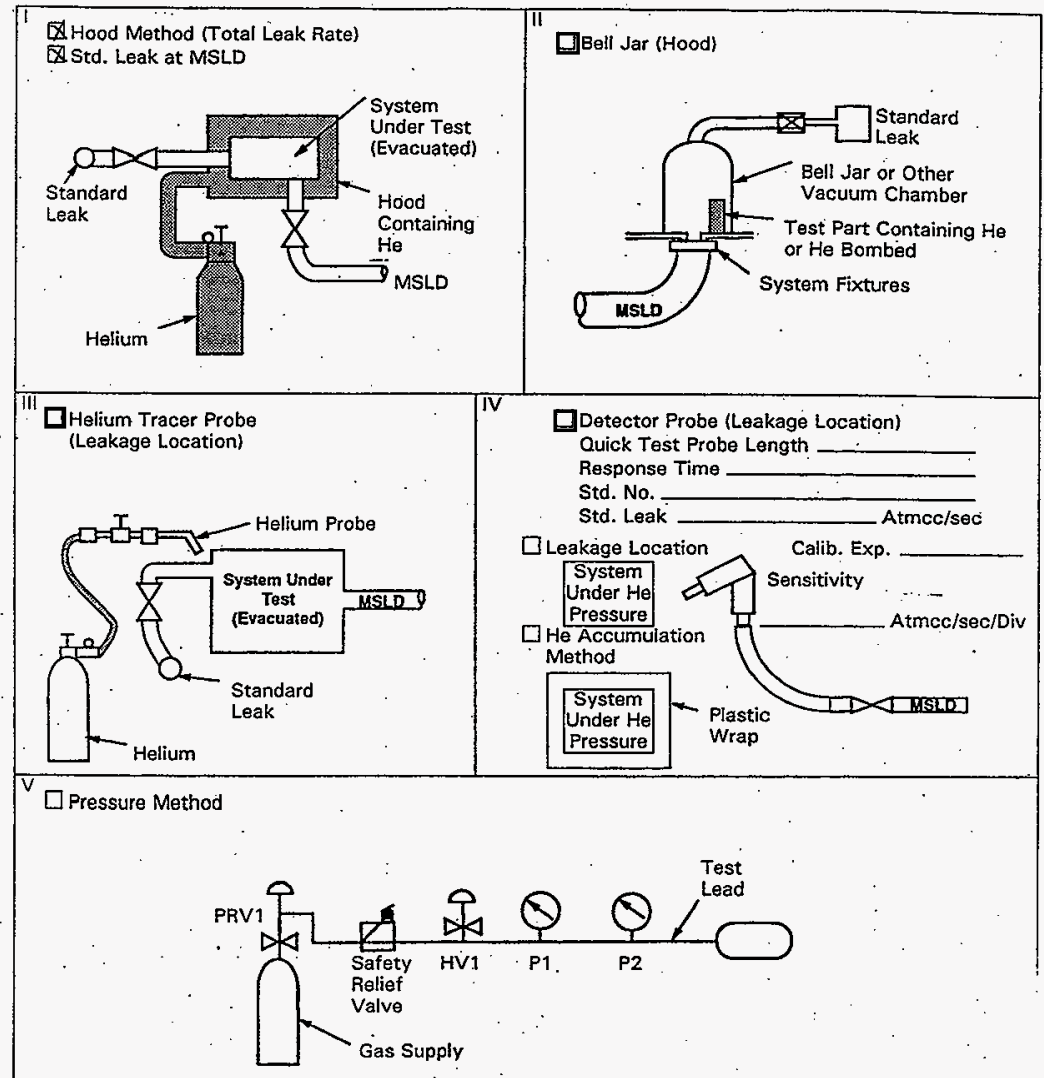

A- $\$ 001-492 R$ (02/98) 


\section{DOCUMENT APPROVAL/TRANSMITTAL RECORD}

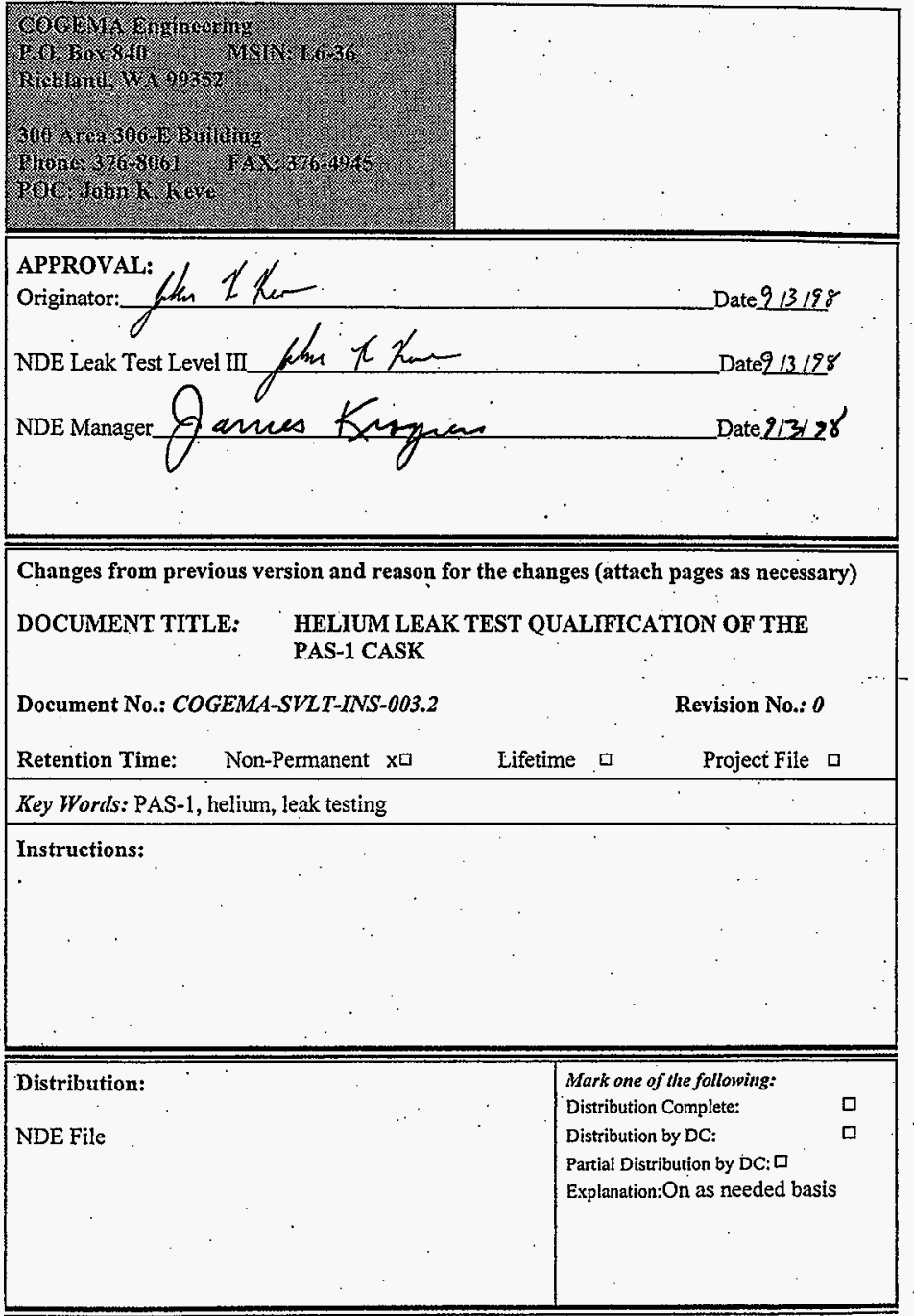


HELIUM LEAK TEST QUALIFICATION OF THE PAS-1 CASK

PAS-1 Cask Serial Number 2162-026 Post Pressiure Test

Date $9 / 15 / 98$

\subsection{SCOPE}

This specific procedure addresses the helium leak testing of the vessel, outer $\mathrm{O}$-ring seal, and the stat-o-seal in the primary and secondary PAS-1 cask. This technique shall be used in conjunction with NDT-LT-6000 General Leak Tesi Examination Procedure.

\subsection{INSTRUCTIONS}

Helium Mass Spectrometer Leak Detector (MSLD)

1. Operate the MSLD according to the manufacturer's operating manual.

2. Calibrate the MSLD using a $\times 10^{-8}$ atm-cc/sec calibrated standard. $\omega C 48615$

Helium Standard Identification $584-40-03-617$

Helium Standard $1.9 \times 10^{-8} \mathrm{~atm}-\mathrm{cc} / \mathrm{sec}$

Helium Standard Calibration Expiration

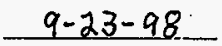

3. The MSLD shall have a machine sensitivity of at least $1 \times 10^{-9} \mathrm{~atm}-\mathrm{cc} / \mathrm{sec} / \mathrm{div}$.

Date and Time $9 / 15 / 98$ 7:30 AM

MSLD Reading $3.2 \times$ Range Factor $500=$ MSLD Div.

Background 1 . X Range Factor $5=$ Backgnd Div.

MSLD Div. 1600 - Backgnd Div. 5 . Net Div.

Helium Std $1.9 \times 10^{-8} \div$ Net Div. $1595=$

MSLD Sensitivity $1.2 \times 10^{-1 !}$ atm-cc/sec/div 


\section{HELIUM LEAK TEST QUALIFICATION OF THE PAS-1 CASK}

Primary Containment Vessel and Lid Seal

1. Clean and lightly apply a thin coating of Apiezon vacuum grease on the outer O-ring seal.

2. Install the outer O-ring onto the lid and insert the lid onto the body of the Primary Containment Vessel (PCV).

3. Torque the bolts in a star pattern to $16-18 \mathrm{ft}-1 \mathrm{bs}$.

4. Remove the lid test plug(s) and stat-0-seal. Connect the test equipment as depicted in Figure 1.

5. Evacuate the PCV with the MSLD. When the MSLD reaches testing conditions check for leaks around the test fittings. To test the PCV place helium inside the plastic hood surrounding the body of the cask. Be sure to cut and tape the plastic so the leak test fitting remains outside of the plastic hood. The test duration should be approximately 2 minutes.

6. Determine the vessel and outer $\mathrm{O}$-ring seal leakage rate for the primary containment vessel.

- Date and Time $9 / 15 / 98 \quad 8: 05 \mathrm{AM}$

MSLD Reading 2.4. X Range Factor $500=$ MSLD Div.

Background $1.6 \quad \times$ Range Factor $\underline{50}=$ Backgnd Div.

MSLD Div. 1200 - Backgnd Div, $80=$ Net Div.

MSLD Sensitivity $1.2 \times 10^{-11} \times$ Net Div. $1120=$

Primary Vessel and O-ring leakage Rate $1.3 \times 10^{-8} \mathrm{Atm} \mathrm{cc} / \mathrm{sec}$. 
HNF-3516, Rev. 0

\section{HELIUM LEAK TEST QUALIFICATION OF THE PAS-1 CASK}

\section{Primary Containment Vessel Stat-0-Seal}

1. Connect the test equipment as depicted in Figure 2. Note the atmospheric pressure on the gage.

Gage Calibration Identification $584-31-04-003$

Gage Range $0-100$ PSIA

Gage Calibration Expiration $2-1-99$

Gage Reading 14.6 PSIA

2. Evacuate the PCV with the vacuum pump to less than 0.5 PSIA. Record the gage reading.

Gage Reading .02 PSIA

3. Valve the vacuum pump out of the system and backfill the PCV with helium to atmospheric pressure gage reading in step 1 .

4. Remove the manifold. Install the stat-o-seal and tighten to the closed position with the test port tool. Reconnect the MSLD to the cask test port.

5. Evacuate the stat-o-seal area with the MSLD.

6. When the MSLD switches to the test mode a large helium signal may be present. Ideally, the high helium background should decrease steadily to the background level established during the PCV test. However, experience has shown that the background level will settle out higher but to an acceptable level. The test duration should be long enough to establish a stable MSLD reading. To be conservative in calculating the leak rate of the vessel the background level established during the PCV test will be subtracted from the MSLD reading. Therefore, the stat-o-seal will probably have a leak rate associated with it, however, the leak rate should be smaller than the acceptance standard. 
HNF-3516, Rev. 0

\section{HELIUM LEAK TEST QUALIFICATION OF THE PAS-1 CASK}

\begin{tabular}{|l|l|}
\hline \multicolumn{1}{|c|}{ TIME } & \multicolumn{1}{|c|}{ MSLD READING } \\
\hline $\begin{array}{l}\text { Only use the time necessary to establish a } \\
\text { stable reading }\end{array}$ & MSLD Crossover Into Test Mode \\
\hline 30 Seconds & $1.2 \times 10^{-7}$ \\
\hline 1 Minute & $2.0 \times 10^{-8}$ \\
\hline 2 Minutes & $7.6 \times 10^{-8}$ \\
\hline 3 Minutes & \\
\hline 4 Minutes & \\
\hline 5 Minutes & \\
\hline 6 Minutes. & \\
\hline 7 Minutes & \\
\hline 8 Minutes & \\
\hline 9 Minutes & \\
\hline 10 Minutes & \\
\hline
\end{tabular}

Date and Time $9115198 \quad 9: 20 \mathrm{AM}$

MSLD Reading $7.6 \times$ Range Factor $500=$ MSLD Div.

Background $2 \times$ Range Factor $\underline{50}=$ Backgnd Div.

MSLD Div. 3800 - Backgnd Div. $100=$ Net Div.

Net Div. 3700 X MSLD Sensitivity $1.2 \times 10^{-11}$ atm-cc/sec/div =

Primary Stat-O-Seal Leak Rate $4.4 \times 10^{-8}$ atm-cc/sec 


\section{HELIUM LEAK TEST QUALIFICATION OF THE PAS-1 CASK}

\section{Secondary Containment Vessel and Lid Seal}

1. Clean and lightly apply a thin coating of Apiezon vacuum grease on the outer O-ring seal.

2. Install the outer O-ring onto the lid and insert the lid onto the body of the Secondary Containpient Vessel (SCV).

3. Torque the bolts in a star pattern to $100-150 \mathrm{ft}-\mathrm{lbs}$. Repeat the sequence at $300-350 \mathrm{ft}-$ lbs with the final torquing being $450-500 \mathrm{ft}-\mathrm{lbs}$.

4. Remove the lid test plug( $(\mathbf{s})$ and stat-o-seal. Connect the test equipment as depicted in Figure 1.

5. Evacuate the SCV with MSLD. When the MSLD reaches testing conditions check for leaks around the test fttings. To test the SCV place helium inside the plastic hood surrounding the body of the vessel. Be sure to cut and tape the plastic so the leak test fitting remains outside of the plastic hood. The test duration should be approximately . 2 minutes.

6. Determine the vessel and the O-ring seal l lakage rate for the secondary containment vessel.

Date and Time

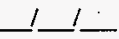

MSLD Reading __ X Range Factor $\_=$MSLD Div.

Background $\mathrm{X}$ Range Factor $=$ Badkgnd Div.

MSLD Div - Backgnd Div. $=$ Net $\operatorname{Din}$

MSLD Sensitivity XNet Div.

Secondary vessel and O-ring leakage Rate 


\section{HELIUM LEAK TEST QUALIFICATION OF THE PAS-1 CASK}

\section{Secondary Containment Vessel Stat-O-Seal}

1. Gonnect the test equipment as depicted in Figure 3. Note the atmospheric pressure on the gage.

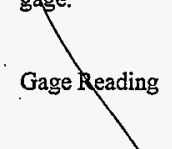

PSIA

2. Evacuate the SCV with the vacuum pump to less than 0.5 PSIA. Record the gage reading.

Gage Reađing

PSIA

3. Valve the vacuum pump out of the system and backfill the SCV with helium to the atmospheric pressure gage reading in step 1.

4. Remove the manifold. Install and tighted thefsat-o-seal to the closed position with the test port tool. Reconnect the XISLD to the fask test port.

5. Evacuate the stat-o-seal area with the MSLD.

6. When the MSLD switches to the test mode a large helium signal may be present. Ideally, the high helium background should deckease steadily to the background established during the SCV seal test. However, expexience has shown that the background level will settle out higher but to an acceptable level. The test duration should be long enough to establish a stable MSLD reading. To be conservative in calculating the leak rate of the vessel the background level established during the SCV test will be subtracted from the MSLD reading. Therefore, the stat-o-seal will probably have a leak rate associated with it, however, the leak rate should be smaller than thacceptance standard.

\begin{tabular}{|l|l|}
\hline \multicolumn{1}{|c|}{ TINIE : } & MISLD READING \\
\hline $\begin{array}{l}\text { Only use the time necessary to establish a } \\
\text { stable reading }\end{array}$ & MSLD Crossover Into Test Mode \\
\hline 30 Seconds & \\
\hline 1 Minute & \\
\hline 2 Minutes & \\
\hline 3 Minutes & \\
\hline
\end{tabular}


HNF-3516, Rev. 0

\section{HELIUM LEAK TEST QUALTFICATION OF THE PAS-1 CASK}

\begin{tabular}{|l|l|}
\hline 4 Minutes & \\
\hline 5 Minutes & \\
\hline 6 Minutes & \\
\hline 7 Minutes & \\
\hline 8 Minutes & \\
\hline 9 Mintutes & \\
\hline 10 Minutes & \\
\hline
\end{tabular}

7. The MSLD shall have a MSLD sensitivity at the end of the test shall be at least $1 \times 10^{-9}$ atm-cc/sec/div.

Date and Time

MSLD Reading $\mathrm{X}$ Range Factor $=$ MSLD Div.

Background Xange Factor $=$ Backgnd Div.

MSLD Div. Backgnd Div.

Net Div. X MSLD Sensitivity

Secondary Stat-O Seal Leak Rate

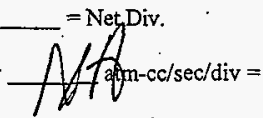
atm-cc/sec

Background $\mathrm{X}$ Range Factor $=$ MSLD Div

MSLD Div. $\mathrm{X}$ Range Factor $=$ Backgnd Div.

Helium Std -Backgnd Div. $=$ Net Div.

MSLD Sensitivity $\div$ Net Div. $\mathrm{atm}-\mathrm{cc} / \mathrm{sec} / \mathrm{div}$ 


\section{HELIUM LEAK TEST QUALIFICATION OF THE PAS-1 CASK}

8. If the MSLD sensitivity has decreased 35 percent (less sensitive) during a calibration period the seal(s) examined since the last valid calibration period shall be retested:

9. Intermediate calibrations, if necessary.

Date and Time 91/5/98 9:30 AM Closeoüt

MSLD Reading $3.4 \times$ Range Factor $500=$ MSLD Div.

Background 2 X.Range Factor 5 = Backgnd Div.

MSLD Div: 1700 - Backgnd Div. $10=$ Net Div.

Helium Std $+.9 \times 10^{-8} \div$ Net Div. $1690 \doteq$

MSLD Sensitivity $1 . / \times 10^{-1 !}$ atm-cc/sec/div

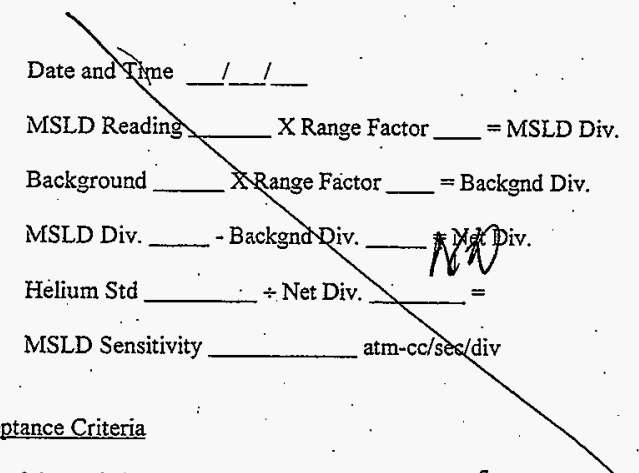

Each of the seals leakage rate shall be less than $1 \times 10^{-7} \mathrm{~atm}-\mathrm{cc} / \mathrm{sec}$ (air) or $2.6 \times 10^{-7} \mathrm{~atm}-\mathrm{cc} / \mathrm{sec}$ (helium) 
HELIUM LEAK TEST QUALIFICATION OF THE PAS-1 CASK

\section{Figure 1}

\section{Primary Vessel and O-ring Seal}

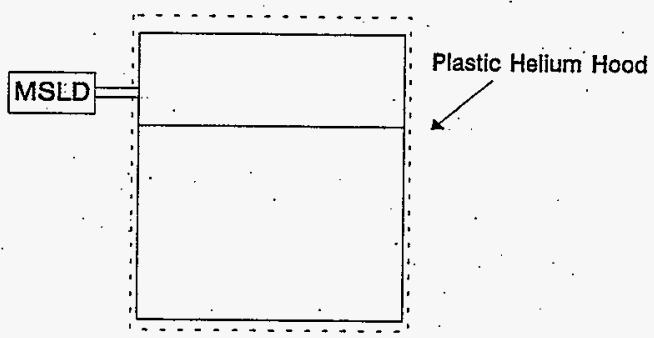

Secondary Vessel and O-ring Seal

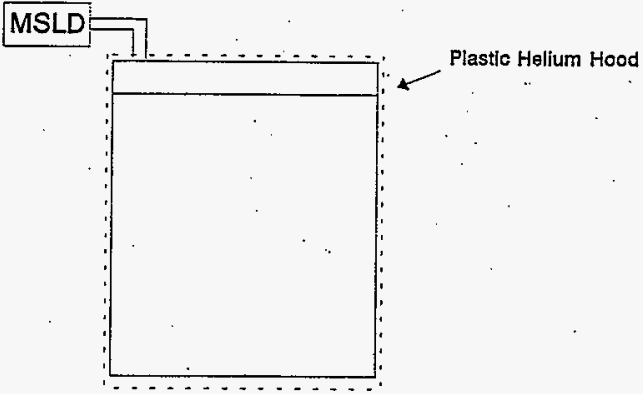


HNF-3516, Rev. 0

Figure 2

Primary Stat-O-Seal

Helium Backfill

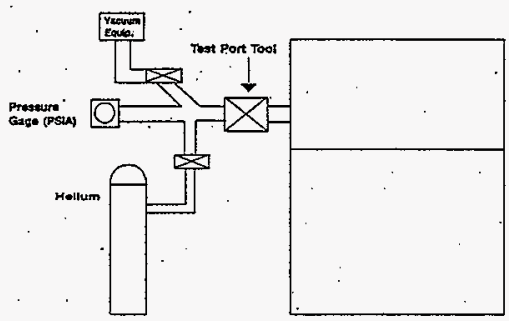

Examination

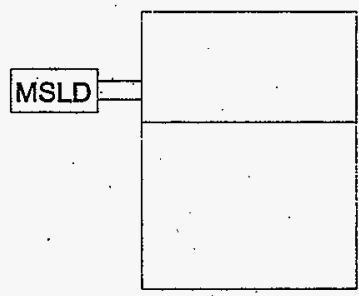


HNF-3516, Rev. 0

Figure 3

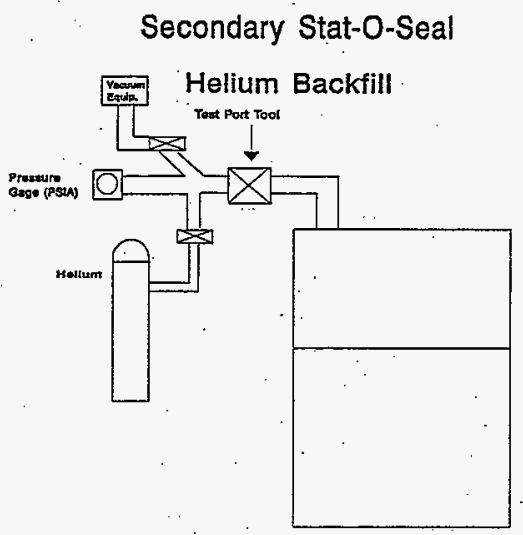

Examination

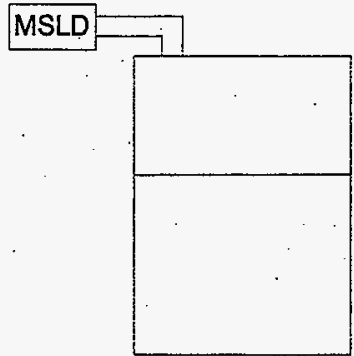




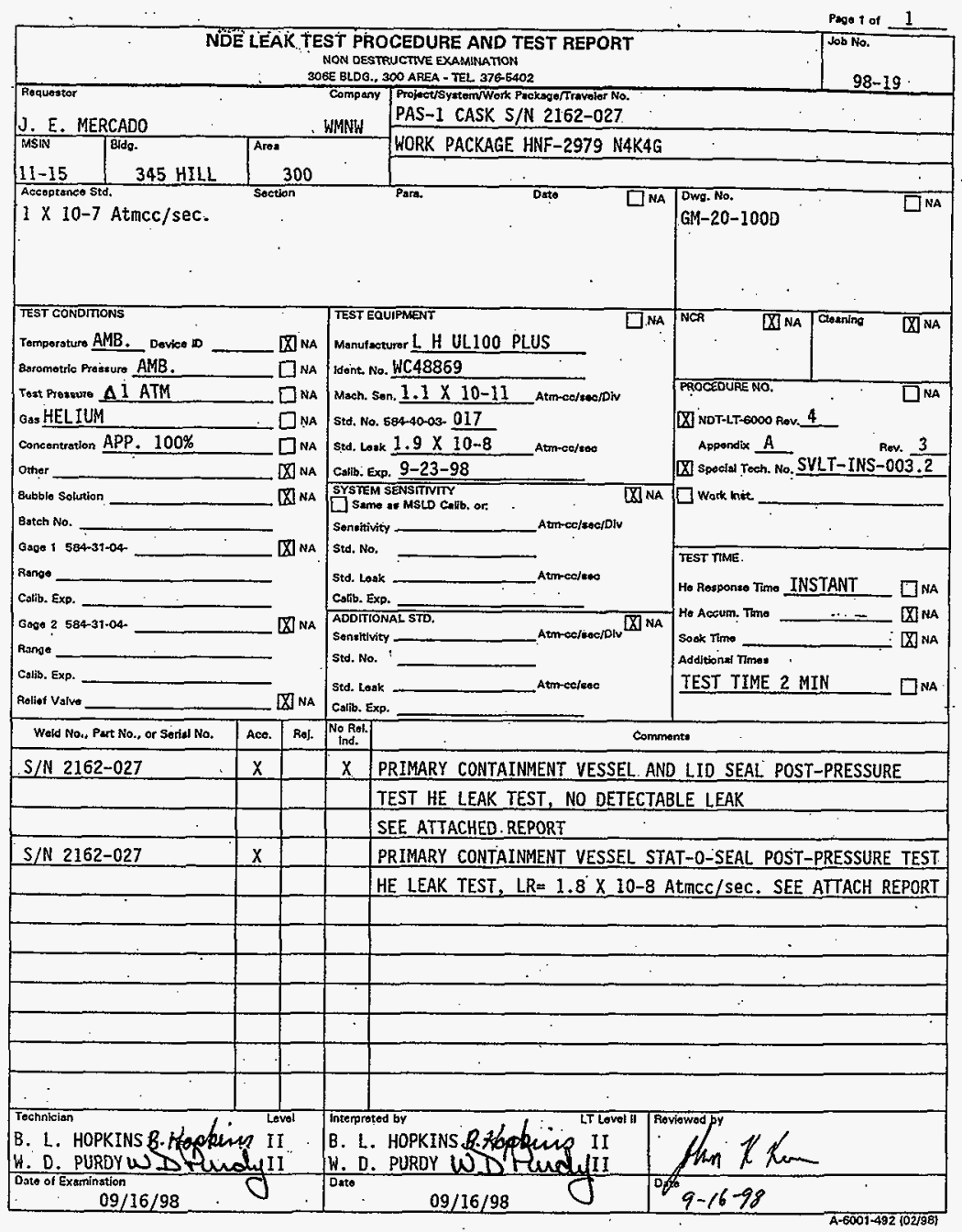




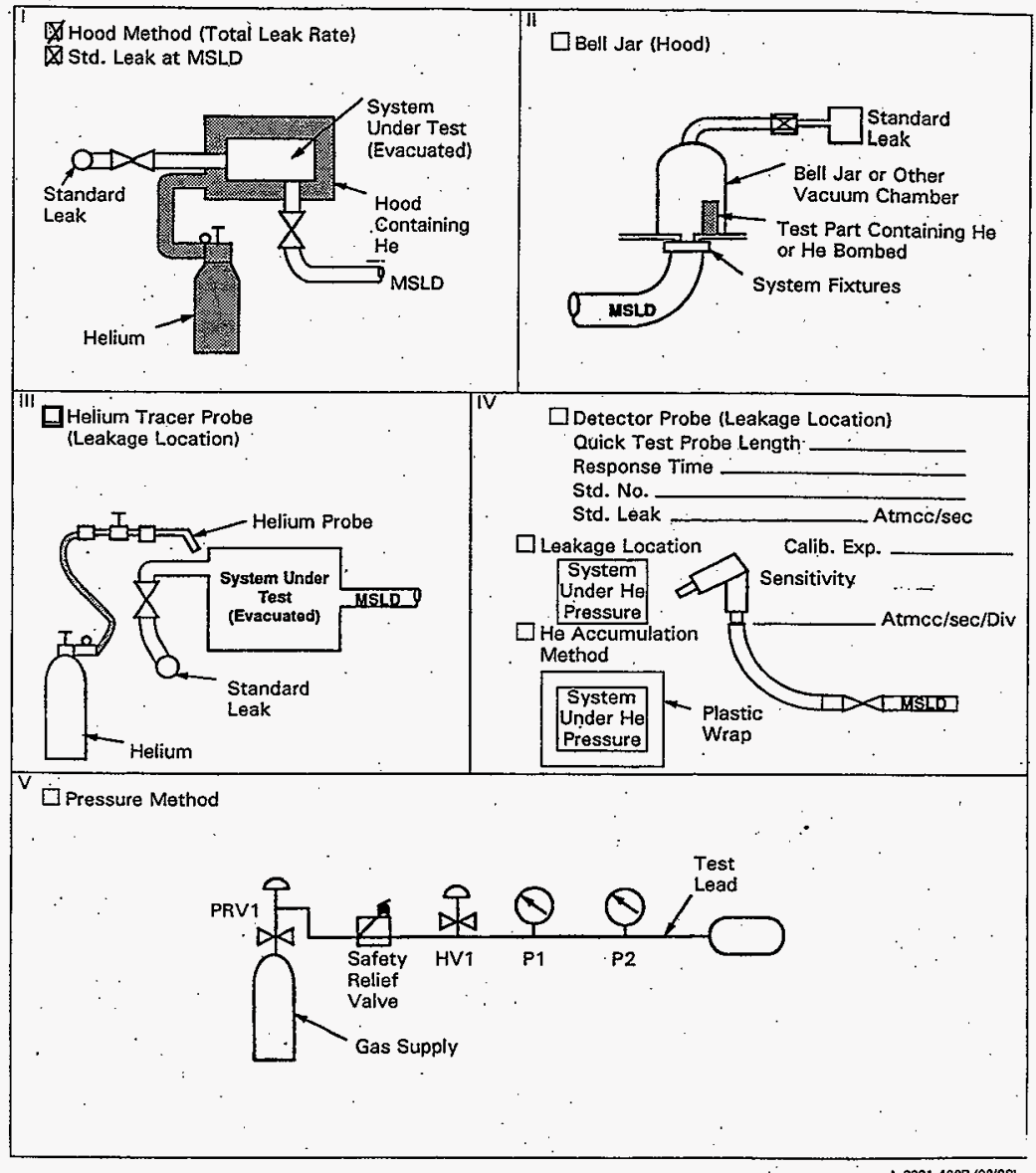

A.6001.492R (02/98) 


\section{DOCUMENT APPROVAL/TRANSMITTAL RECORD}

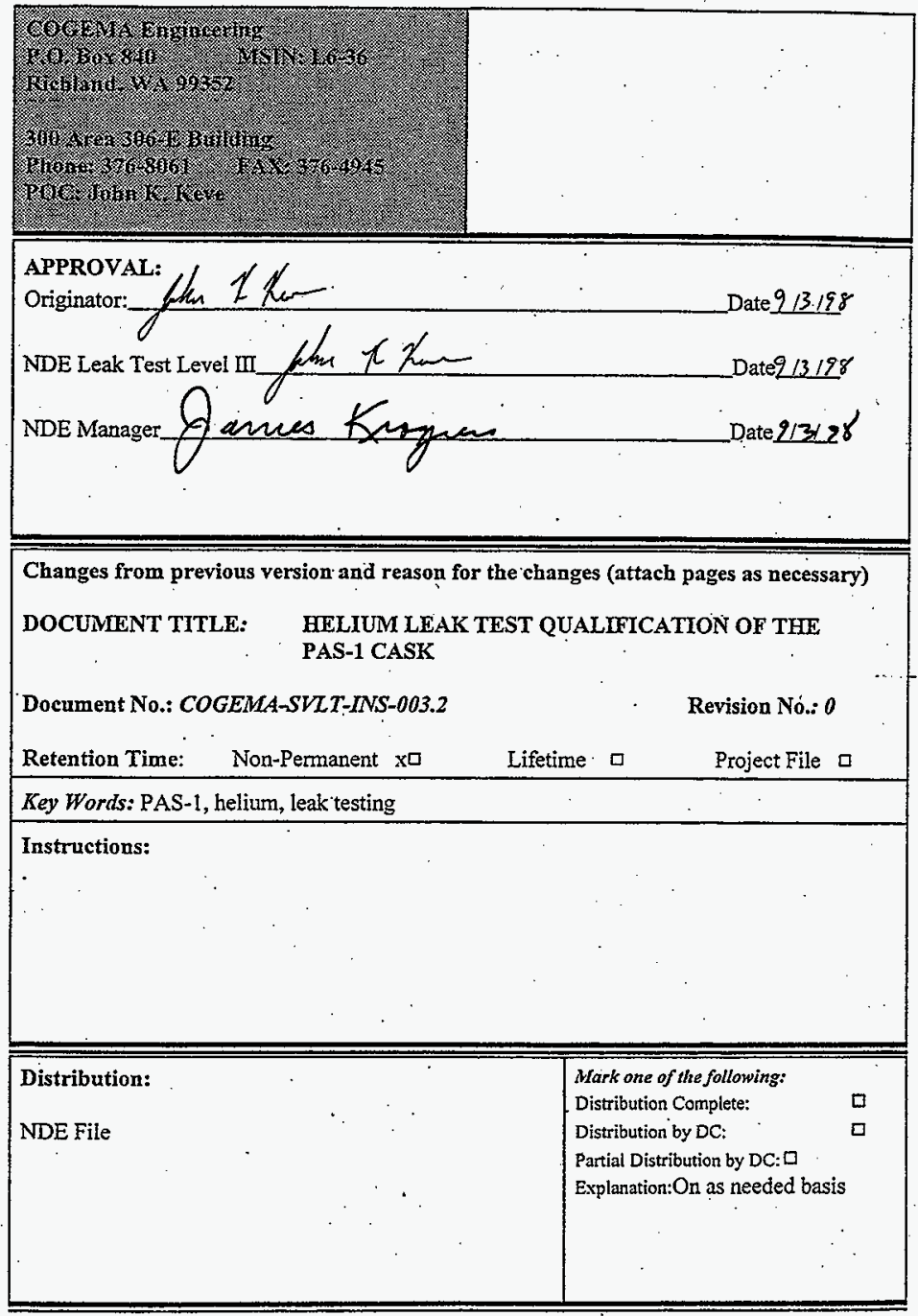


HNF-3516, Rev. 0

PAS-1 Cask Serial Number 2162-027 Post Pressure Test

Date $9 / 16 / 98$

\subsection{SCOPE}

This specific procedure addresses the helium leak testing of the vessel, outer O-ring seal, and the stat-o-seal in the primary and secondary PAS-1 cask. This technique shall be used in conjunction with NDT-LT-6000, General Leak Test Examination Procedure.

\subsection{INSTRUCTIONS}

Helium Mass Spectrometer Leak Detector (MSLD)

1. Operate the MSLD according to the manufacturer's operating manual.

2. Calibrate the MSLD using a $\times 10^{-8}$ atm-cc/sec calibrated standard. $W C 48869$

Helium Standard Identification

$584-400-03-017$

Helium Standard $1.9 \times 10^{-8} \mathrm{~atm}-\mathrm{cc} / \mathrm{sec}$

Helium Standard Calibration Expiration $9-23-98$

3. The MSLD shall have a machine sensitivity of at least $1 \times 10^{-9} \mathrm{~atm}-\mathrm{cc} / \mathrm{sec} / \mathrm{div}$.

Date and Time $9 / 16 / 98 \quad 9: 40$ AM

MSLD Reading $\mathbf{3 . 6} \times$ Range Factor $\mathbf{5 0 0}=$ MSLD Div.

Background 4 X Range Factor $\underline{5}=$ Backgnd Div.

MSLD Div. 1800 - Backgnd Div. $20=$ Net Div.

Helium Std $1.9 \times 10^{-8} \div$ Net Div. $1780=$

MSLD Sensitivity $1.1 \times 10^{-1 !}$ atm-cc/sec/div 


\section{HELIUM LEAK TEST QUALIFICATION OF THE PAS-1 CASK}

\section{Primary Containment Vessel and Lid Seal}

1. Clean and lightly apply a thin coating of Apiezon vacuum grease on the outer O-ring seal.

2. Install the outer O-ring onto the lid and insert the lid onto the body of the Primary Containment Vessel (PCV).

3. Torque the boits in a star pattern to $16-18 \mathrm{ft}-1 \mathrm{bs}$.

4. Remove the lid test plug(s) and stat-o-seal. Connect the test equipment as depicted in Figure 1.

5. Evacuate the PCV with the MSLD. When the MSLD reaches testing conditions check for leaks around the test fittings. To test the PCV place helium inside the plastic hood surrounding the body of the cask. Be sure to cut and tape the plastic so the leak test fitting remains outside of the plastic hood. The test duration should be approximately 2 minutes.

6. Determine the vessel and outer $\mathrm{O}$-ring seal leakage rate for the primary containment vessel.

Date and Time $9116 / 98 \quad 9: 50 \mathrm{AM}$

MSLD Reading 3.2 X Range Factor $500=$ MSLD Div.

Background $3.2 \times$ Range Factor $500=$ Backgnd Div.

MSLD Div. $1600-$ Backgnd Div. $1600=$ Net Div.

MSLD Sensitivity. $\longrightarrow$ Net Div. $\mathrm{O}=$

Primary Vessel and O-ring leakage Rate No Detectable Leak 


\section{HELIUM LEAK TEST QUALIFICATION OF THE PAS-1 CASK}

\section{Primary Containment Vessel Stat-O-Seal}

1. Connect the test equipment as depicted in Figure 2. Note the atmospheric pressure on the gage.

Gage Calibration Identiffcation

Gage Range

Gage Calibration Expiration

Gage Reading

$$
584-31-04-003
$$$$
0-100 \text { PSIA }
$$

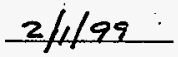

$14: 5 \quad$ PSIA

2. Evacuate the PCV with the vacuum pump to less than 0.5 PSLA. Record the gage reading.

Gage Reading

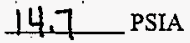

3. Valve the vacuum pump out of the system and backfill the PCV with helium to atmospheric pressure gage reading in step 1 .

4. Remove the manifold. Install the stat-o-seal and tighten to the closed position with the test port tool. Reconnect the MSLD to the cask test port.

5. Evacuate the stat-o-seal area with the MSLD.

6. When the MSLD switches to the test mode a large helium signal may be present. Ideally, the high helium background should decrease steadily to the background level established during the PCV test. However, experience has shown that the background level will settle out higher but to an acceptable level. The test duration should be long enough to establish a stable MSLD reading. To be conservative in calculating the leak rate of the vessel the background level established during the PCV test will be subtracted from the MSLD reading. Therefore, the stat-o-seal will probably have a leak rate associated with it, however, the leak rate should be smaller than the acceptance standard. 
HNF-3516, Rev. 0

\section{HELIUM LEAK TEST QUALIFICATION OF THE PAS-1 CASK}

\begin{tabular}{|l|l|}
\hline \multicolumn{1}{|c|}{ TIME } & \multicolumn{1}{|c|}{ MSLD READING } \\
\hline $\begin{array}{l}\text { Only use the time necessary to establish a } \\
\text { stable reading }\end{array}$ & MSLD Crossover Into Test Mode \\
\hline 30 Seconds & $1.6 \times 10^{-7}$ \\
\hline 1 Minute & $2.8 \times 10^{-8}$ \\
\hline 2 Minutes & $4.4 \times 10^{-8}$ \\
\hline 3 Minutes & $4.2 \times 10^{-8}$ \\
\hline 4 Minutes & \\
\hline 5 Minutes & \\
\hline 6 Minutes & \\
\hline 7 Minutes & \\
\hline 8 Minutes & \\
\hline 9 Minutes & \\
\hline 10 Minutes & \\
\hline
\end{tabular}

Date and Time $9116198 \quad 1040$

MSLD Reading $4.2 \times 10^{-8}$ X Range Factor $500=$ MSLD Div.

Background $5.2 \times 10$ X Range Factor $50=$ Backgnd Div.

MSLD Div. 2100 - Backgnd Div. $260=$ Net Div.

Net Div. $\left.1.0 \times 10^{-11}\right)$ MSLD Sensitivity $1840 \mathrm{~atm}-\mathrm{cc} / \mathrm{sec} / \mathrm{div}=$

Primary Stat-O-Seal Leak Rate $1.8 \times 10^{-8}$ atm-cc/sec 


\section{HELIUM LEAK TEST QUALIFICATION OF THE PAS-1 CASK}

\section{Secondary Containment Vessel and Lid Seal}

1. Clean and lightly apply a thin coating of Apiezon vacuum grease on the outer O-ring seal.

2. Install the outer $\mathrm{O}$-ring onto the lid and insert the lid onto the body of the Secondary Containinent Vessel (SCV).

3. Torque the bolts in a star pattern to $100-150 \mathrm{ft}-\mathrm{lbs}$. Repeat the sequence at $300-350 \mathrm{ft}$ lbs with the final torquing being $450-500 \mathrm{ft}-\mathrm{lbs}$.

4. Remove the lid test plug(s) and stat-o-seal. Connect the test equipment as depicted in Figure 1 .

5. Evacuate the SCV with the MSLD. When the MSLD reaches testing conditions check for leaks around the test fittings. Fo test the SCV place helium inside the plastic hood surrounding the body of the vessel. Be sure to cut and tape the plastic so the leak test fitting remains outside of the plastic hood. The fest duration should be approximately 2 minutes.

6. Determine the vessel and the $\mathrm{O}$-ring seal leakage rate for the secondary containment vessel.

Date and Time

MSLD Reading

Background

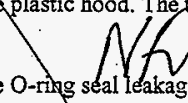

MSLD Div, $X$ Range Factor $=$ MSLD Div.

MSLD Sensitivity - Backgnd Div. $=$ Aackgnd Div.

Secondary vessel and O-ring leakage Rate $=$ Net Riv. 


\section{HELIUM LEAK TEST QUALIFICATION OF THE PAS-I CASK}

\section{Secondary Containment Vessel Stat-O-Seal}

1. Gonnect the test equipment as depicted in Figure 3: Note the atmospheric pressure on the gage?

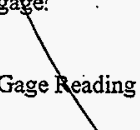

2. Evacuate thdSCV with the vacuum pump to less than 0.5 PSIA. Record the gage reading.

Gage Reading

PSIA

3. Valve the vacuum putp out of the systempand backfill the SCV with helium to the atmospheric pressure gage reading in step 1 .

4. Remove the manifold. Install an thbfenthe stat-o-seal to the closed position with the test port tool. Reconnect the MSLD to the cask test port.

5. Evacuate the stat-o-seal area with the MSLD.

6. When the MSLD switches to the test mode a large helium signal may be.present. Ideally, the high helium background should decrease steadily to the background established during the SCV seal test. However, experience has shown that the background level will settle out higher but to an acceptable level. The test duration should be long enough to establish a stable MSLD reading. To be conservative in calculating the leak rate of the vessel the background level established during the SCV test will be subtracted from the MSLD reading. Therefore, the stat-o-seal wili probably have a leak rate associated with it, however, the leak rate should be smaller than the acceptance standard.

\begin{tabular}{|l|l|}
\hline \multicolumn{1}{|c|}{ TIME } & MSLD READING \\
\hline $\begin{array}{l}\text { Only use the time necessary to establish a } \\
\text { stable reading }\end{array}$ & MSLD Crosspver Into Test Mode \\
\hline 30 Seconds & \\
\hline 1 Minute & \\
\hline 2 Minutes & \\
\hline 3 Minutes & \\
\hline
\end{tabular}


HELIUM LEAK TEST QUALIFICATION OF THE PAS-1 CASK

\begin{tabular}{|l|l|}
\hline 4 Minutes & \\
\hline 5 Minutes & \\
\hline 9 Minutes & \\
\hline 7 Minutes & \\
\hline 8 Minutes & \\
\hline 9 Minutes & \\
\hline 10 Minutss & \\
\hline
\end{tabular}

Date and Time

MSLD Reading $\mathrm{X}$ Range Factor $=$ MSLD Div.

Background

MSL̇D Div. - Backghd Div. A Range Factor $=$ Backgnd Div.

Net Div. __ XMSLD Sensitjvit
Secondary Stat-O Seal Leak Rate $\mathrm{atm}-\mathrm{cc} / \mathrm{sec} / \mathrm{div}=$

Seal Leak Rate<smiles>C1CCCCC1</smiles>
atm-cc/sec

7. The MSLD shall have a MSLD sensitivity at the end of the test shall be at least $1 \times 10^{-9}$ atm-cc/sec/div.

Date and Time

MSLD Reading

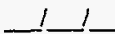

Background $\mathrm{X}$ Range Factor MSLD Div.

MSLD Div. Range Factor $=$ Backgad Div.

Helium Std - Backgnd Div. $=$ Net Div.

MSLD Sensitivity $\div$ Net Div. $\mathrm{atm}-\mathrm{cc} / \mathrm{sec} / \mathrm{div}$

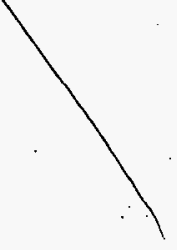


HNF-3516, Rev. 0

\section{HELIUM LEAK TEST QUALIFICATION OF THE PAS-1 CASK}

8. If the MSLD sensitivity has decreased 35 percent (less sensitive) during a calibration period the seal(s) examined since the last valid calibration period shall be retested:

9. Intermediate calibrations, if necessary.

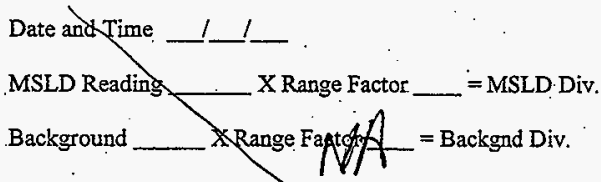

MSLD Div. ___ _ BackgndDiv. _____ Net Div.

Helium Std $\div$ Net Div.

MSLD Sensitivity atm-ce/sec/div

Date and Time $91 / 61981050$ closeont

MSLD Reading $4.0 \times 10^{8} \times$ Range Factor $500=$ MSLD Div.

Background $3 \times 10^{-1} \times$ Range Factor $s=$ Backgnd Div.

MSLD Div 2000 - Backgnd Div. $15=$ Net Div.

Helium Std $\underline{1.9 \times 10^{-8}} \div$ Net Div. $1985=$

MISLD Sensitivity $9.6 \times 10^{-12} \mathrm{~atm}-\mathrm{cc} / \mathrm{sec} / \mathrm{div}$

\section{Acceptance Criteria}

Each of the seals leakage rate shall be less than $1 \times 10^{-7} \mathrm{~atm}-\mathrm{cc} / \mathrm{sec}$ (air) or $2.6 \times 10^{-7} \mathrm{~atm}-\mathrm{cc} / \mathrm{sec}$ (helium). 
HNF-3516, Rev. 0

Figure 1

Primary Vessel and O-ring Seal

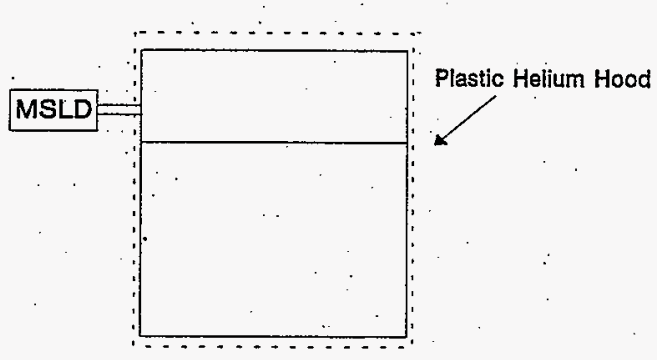

Secondary Vessel and O-ring Seal

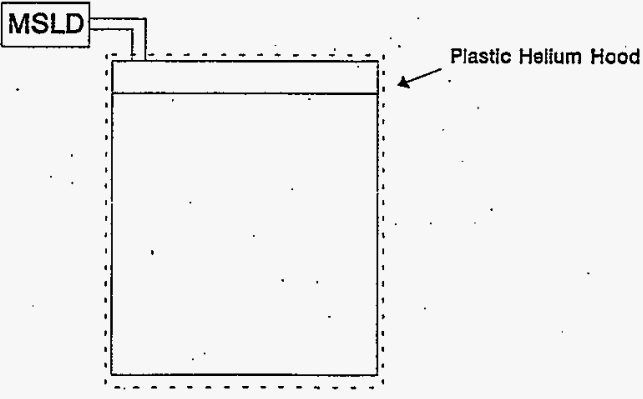


HNF-3516, Rev. 0

Figure 2

\section{Primary Stat-O-Seal}
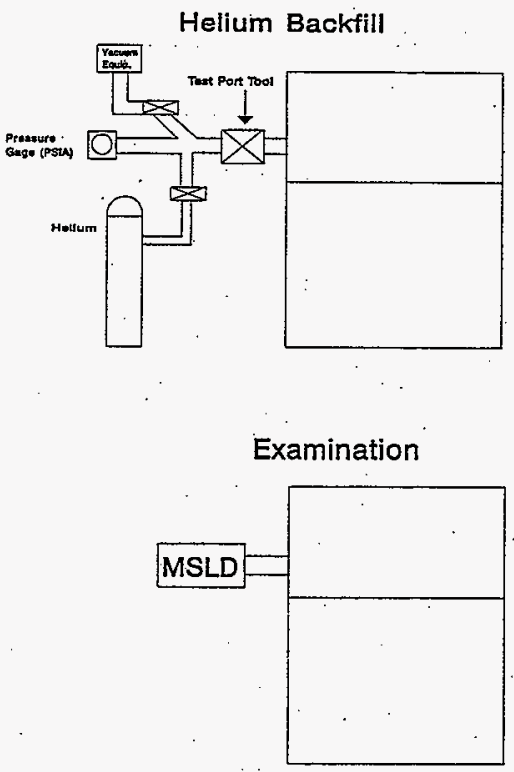
HNF-3516, Rev. 0

HELIUM LEAK TEST QUALIFICATION OF THE PAS-1 CASK

Figure 3

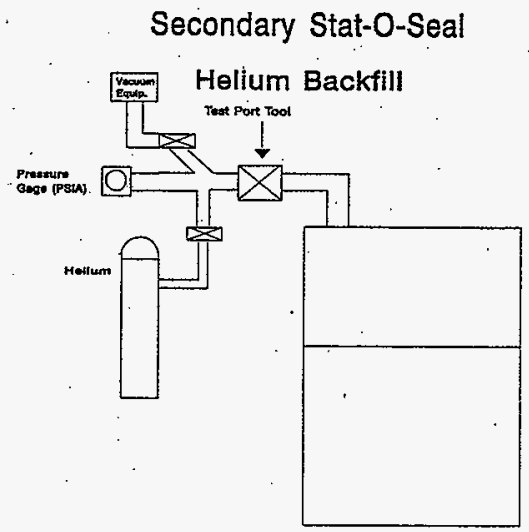

Examination

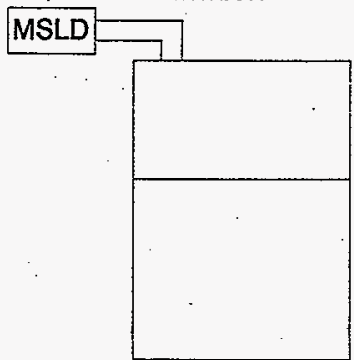


HNF-3516, Rev. 0

APPENDIX E

TEST REPORT FOR PRESSURE TESTING

E-i 
HNF-3516, Rev. 0

This page intentionally left blank.

E-ii 


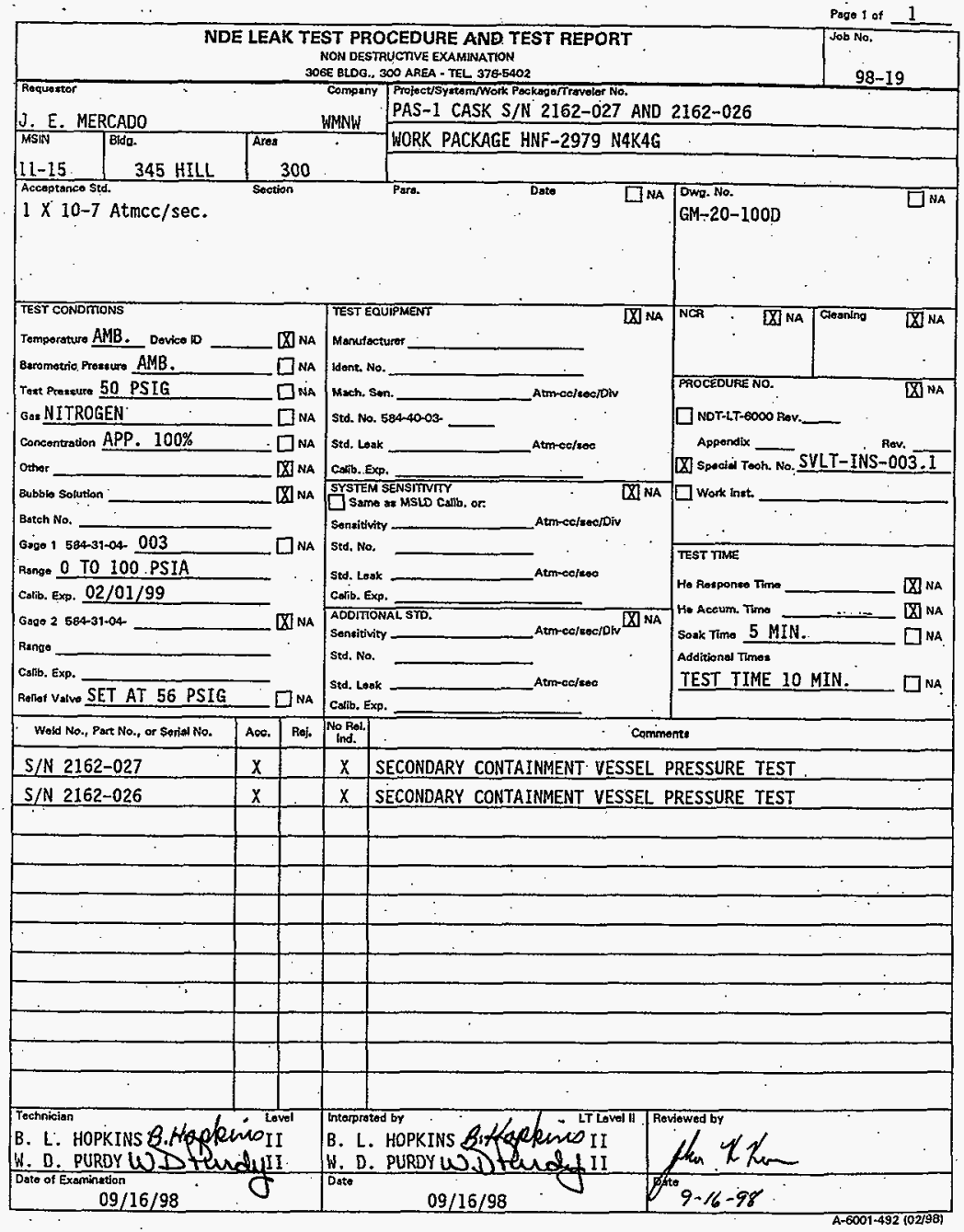


HNF-3516, Rev. 0

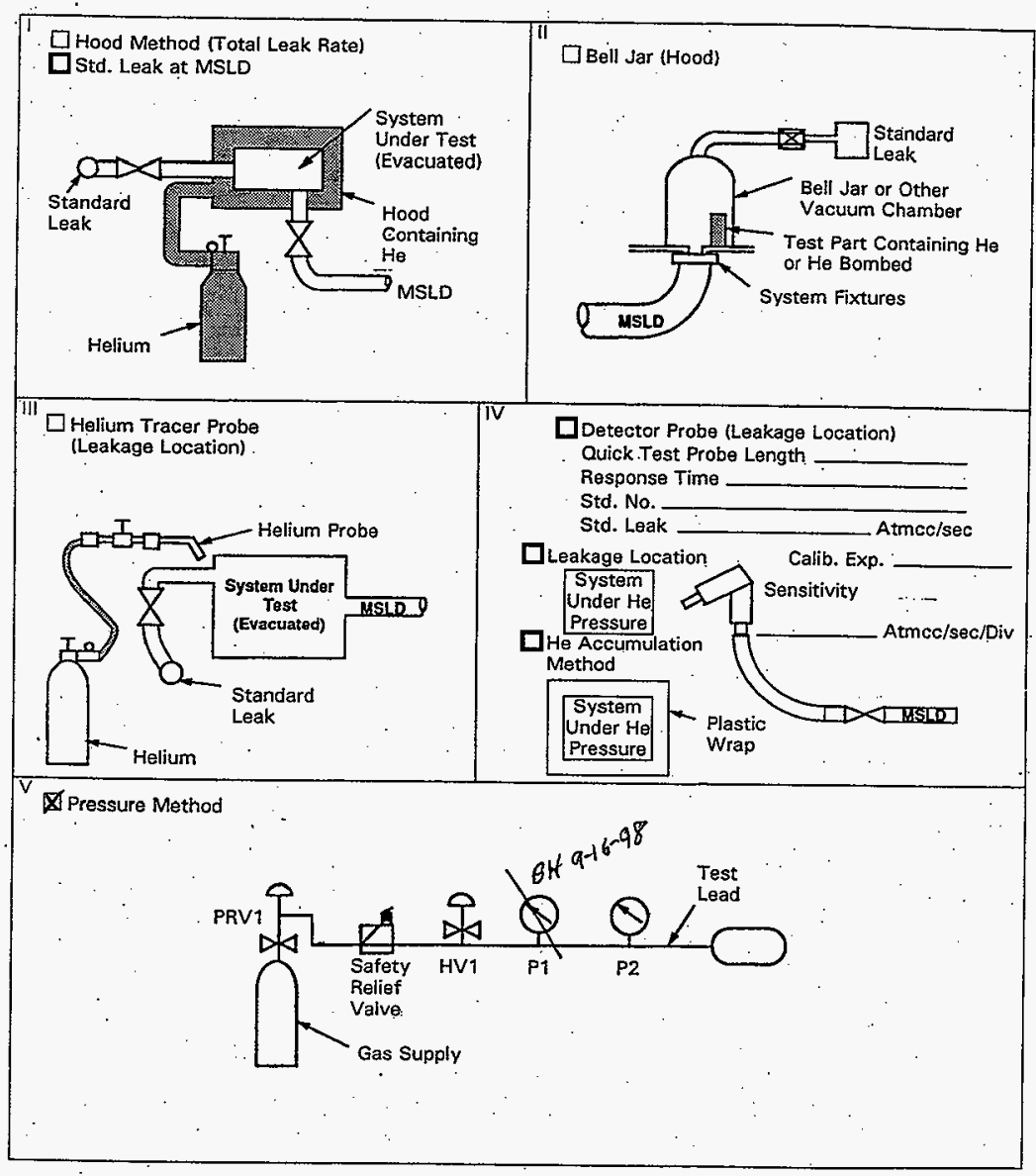

A-6001-4928 (02/98) 
DOCUMMENT APPROVAI/TRANSMTTAL RECORD

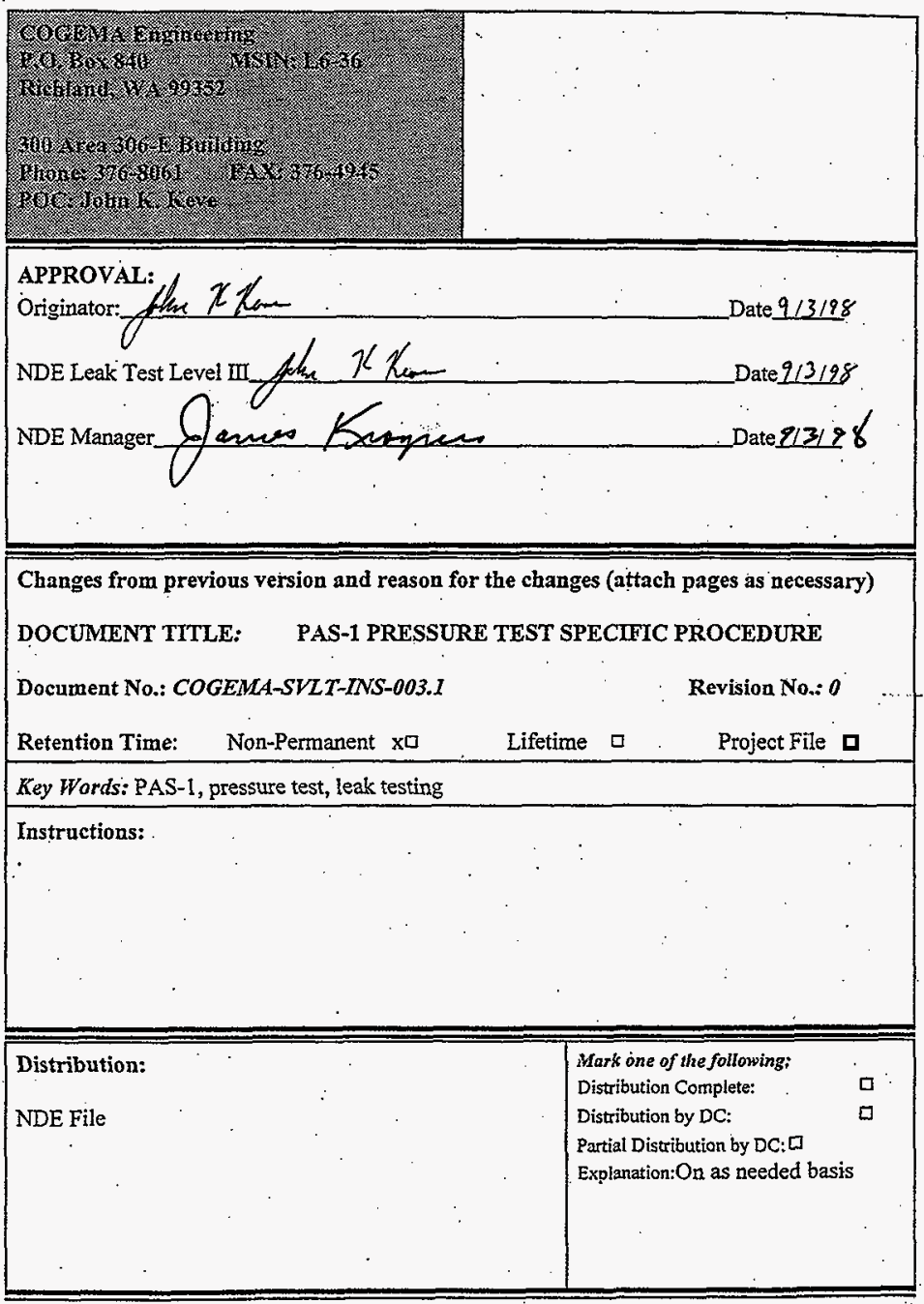




\section{PAS-1 PRESSURE TEST SPECIFIC PROCEDURE}

\subsection{SCOPE}

This specific procedure addresses the pressure test of the PAS-1 cask's secondary containment vessel (SCV) and the primary containment vessel (PCV). This procedure shall be used in conjunction with NDT-LT-6000 General Leak Test Examination Procedure.

\subsection{INSTRUCTIONS}

\subsection{Pressure Test Prerequisites}

- The gas used as the test gas shall be bottled nitrogen or dry clean air.

- The gages used in the examination shall be in current calibration. The gages should have graduations over a range of about double the intended maximum range, but in no case shall the range be less than one and one-half nor more than four time that pressure.

- A stand-alone pressure relief valve shall be installed in the pressurizing system, however, after the pressurization is completed and during the testing phase the valve maybe valved out of the system. The pressure relief valve shall be actuated at a pressure that is approximately 10 percent greater than .... the required pressure test.

- The ambient temperature shall be monitored, however the examination will be done in a controlled environment and the test duration is only 10 minutes. If the temperature increașes or decreases 5 degrees Fahrenheit contact the NDE Leak Test Level III for direction.

\subsection{Installing O-rings and Torquing the Bolts on the Primary Containment Vessel Lid}

- Clean, lightly apply Apiezon vacuum grease, and install the outer $O$-ring seal on the Primary Containment Vessel (PCV) lid.

- Install the lid onto the body of the PCV and assemble the cask with the closure bolts.

- 'The bolts shall be torqued to $16-18 \mathrm{ft}-\mathrm{lbs}$ with a calibrated torque wrench. using a star pattern.

\subsection{Pressure Test of the Primary Containment Vessel}

- Connect the pressure test equipment to the test port as depicted in Figure 1.

- With the test port tool verify that the stat-o-seal is in the open position.

- Verify the valve to the pressure relief valve (PRV) is open.

- Verify the pressure regulator control valve is at its minimum pressure setting. 


\section{PAS-1 PRESSURE TEST SPECIFIC PROCEDURE}

- Verify the vent valve is closed.

- Pressurize the PCV with nitrogen or dry bottled air to $39.7 \mathrm{psia}$ (25 psi). The pressure shall be increased in steps of 5 psi until the final test pressure of 64.7 psia (50 psi) $\pm 0.5 \mathrm{psi}$ is reached.

- The system pressure shall be stable on the test gages before proceeding.

- Just prior to the start of the examination the PRV valve may be closed.

- The pressure test shall last a minimum of 10 minutes with no evidence of pressure loss.

- Vent the system and remove the test equipment.

2.4 Installing O-rings and Torquing the Bolts on the Secondary Containment Vessel Lid

- Clean, lightly apply Apiezon vacuum grease, and install the outer O-ring seal on the Secondary Containment Vessel (SCV) lid.

- Install the lid onto the body of the SCV and assemble the cask with the closure bolts.

- The bolts shall be torqued to 100 to $150 \mathrm{ft}-\mathrm{lbs}$ with a calibrated torque wrench using a star pattern. The sequence shall be repeated for 300 to $350 \mathrm{ft}$-los with the final torque being 450 to $500 \mathrm{f}$-ibs.

\subsection{Pressure Test of the Secondary Containment Vessel}

- Connect the pressure test equipment to the test port as depicted in Figure 1.

- With the test port tool verify that the stat-o-seal is in the open position.

- Verify the valve to the pressure relief valve (PRV) is open.

- Verify the pressure regulator control valve is at its minimum pressure setting.

- Verify the vent valve is closed.

- Pressurize the SCV with nitrogen or dry bottled air to $39.7 \mathrm{psia}$ (25 psi). The pressure shall be increased in steps of 5 psi until the final test pressure of 64.7 psia ( 50 psi) \pm 0.5 psi is reached.

- The system pressure shall be stable on the test gages before proceeding.

- Just prior to the start of the examination the PRV valve may be closed.

- The pressure test shall last a minimum of 10 minutes with no evidence of pressure loss.

- Vent the system and remove the test equipment. 
HNF-3516, Rev. 0

PAS-1 PRESSURE TEST SPECIFIC PROCEDURE

Figure 1

Primary and Secondary

Containment Vessel

Pressure Test

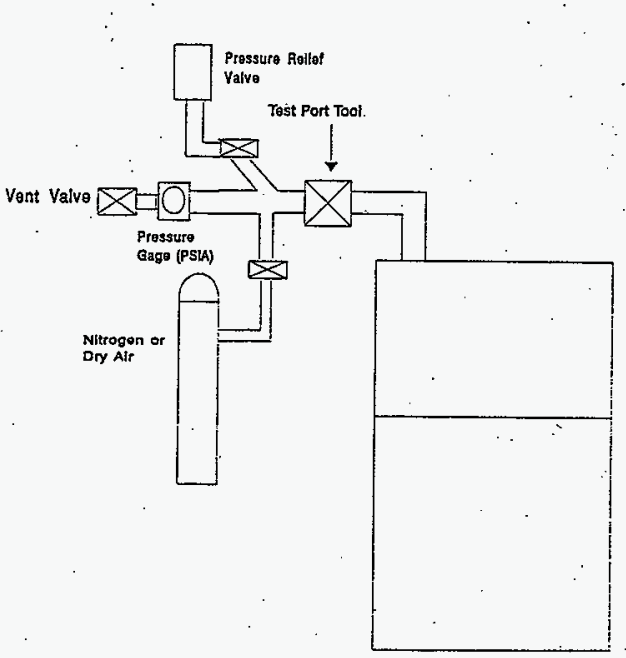




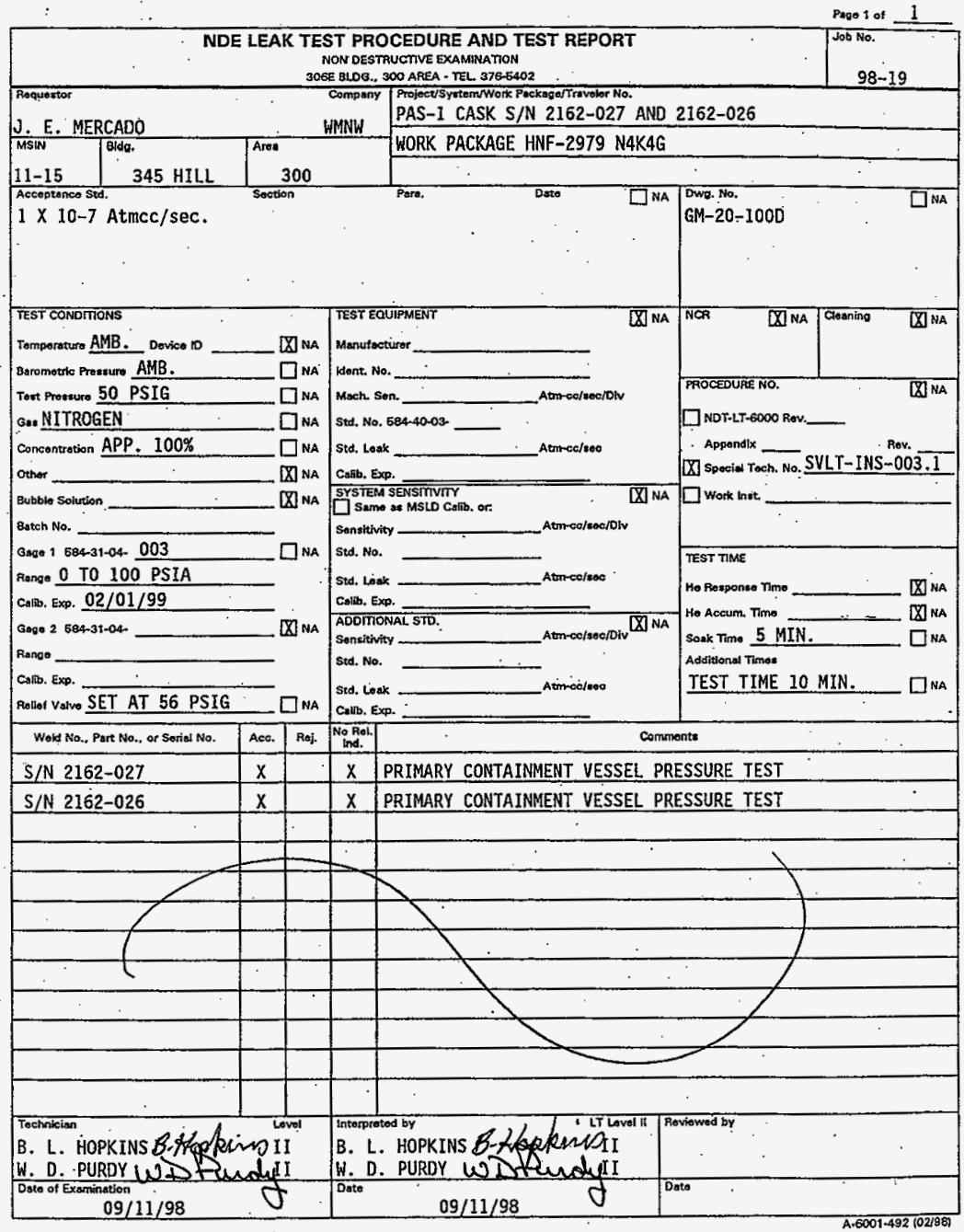


HNF-3516, Rev. 0

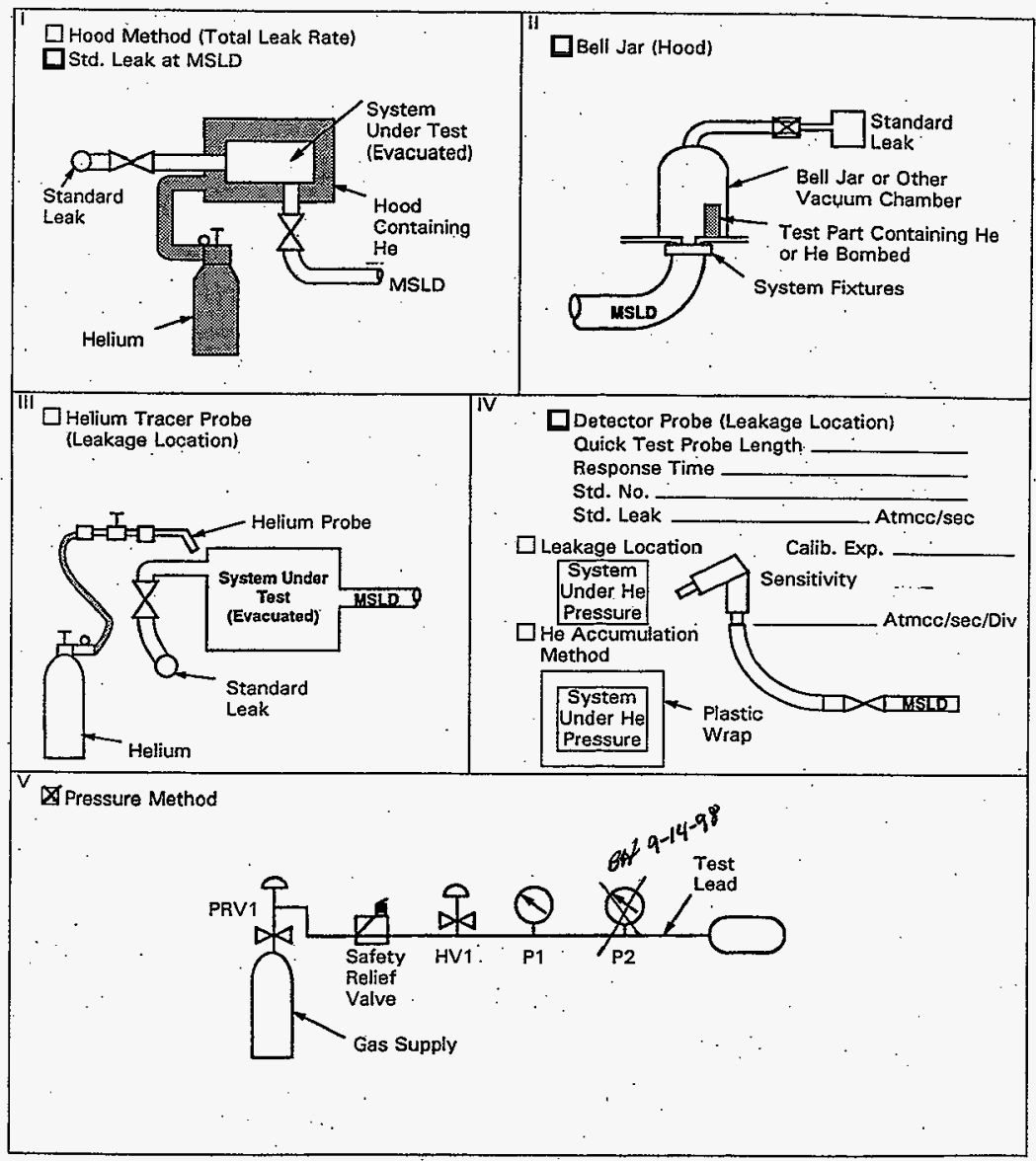




\section{DOCUMENT APPROVAI/TRANSMITTAL RECORD}
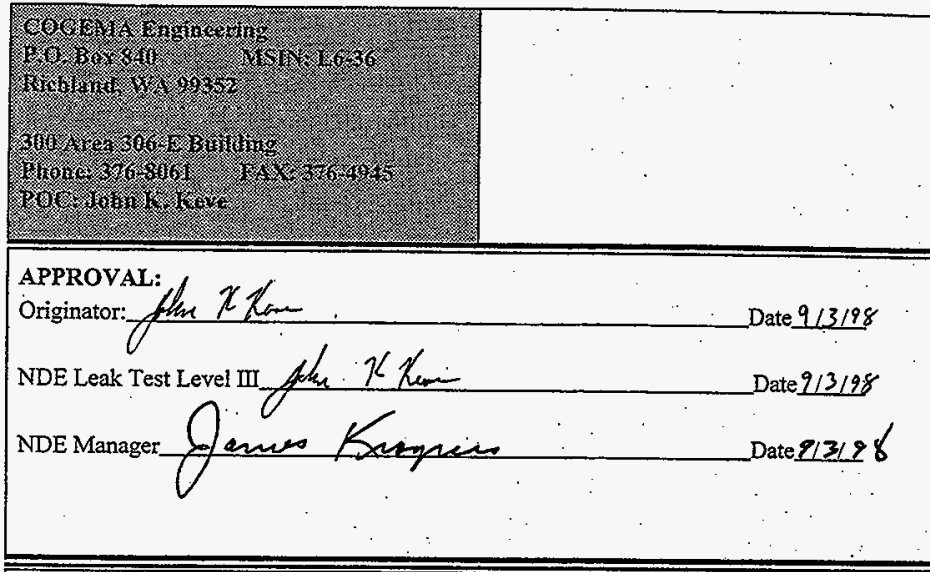

Changes from previous version and reason for the changes (attach pages as necessary) DOCỤMENT TITLE: PAS-1 PRESSURE TEST SPECIFIC PROCEDURE

Document No.: COGEMA-SVLT-INSS-003.1

Revision No.: 0

Retention Time: Non-Permanent $x \square . \quad$ Lifetime $\square \quad$ Project File $\square$

Key Words: PAS-1, pressure test, leak testing

Instructions:

Distribution:

Mark one of the following:

Distribution Complete:

ㅁ

NDE File

Distribution by DC:

Partial Distribution by DC: $\square$

Explanation: $O \mathrm{n}$ as needed basis 
HNF-3516, Rev. 0

\section{PAS-1 PRESSURE TEST SPECIFIC PROCEDURE}

\subsection{SCOPE}

This specific procedure addresses the pressure test of the PAS-1 cask's secondary containment vessel (SCV) and the primary containment vessel (PCV). This procedure shall be used in conjunction with NDT-LT-6000 General Leak Test Examination Procedure.

\subsection{INSTRUCTIONS}

\subsection{Pressure Test Prerequisites}

- The gas used as the test gas shall be bottled nitrogen or dry clean air.

- The gages used in the examination shall be in current calibration. The gages should have graduations over a range of about double the intended maximum range, but in no case shall the range be less than one and one-half nor more than four time that pressure.

- A stand-alone pressure relief valve shall be installed in the pressurizing system, however, after the pressurization is completed and during the testing phase the valve maybe valved out of the system. The pressure relief valve shall be actuated at a pressure that is approximately 10 percent greater than ..... the required pressure test.

- The ambient temperature shall be monitored, however the examination will be done in a controlled environment and the test duration is only 10 minutes. If the temperature increases or decreases 5 degrees Fahrenheit contact the NDE Leak Test Level III for direction.

2.2 Installing $\mathrm{O}$-rings and Torquing the Bolts on the Primary Containment Vessel Lid

- Clean, lightly apply Apiezon vacuum grease, and install the outer O-ring seal on the Primary Containment Vessel (PCV) lid.

- Install the lid onto the body of the PCV and assemble the cask with the closure bolts.

- The boits shall be torqued to $16-18 \mathrm{ft}-1 \mathrm{bs}$ with a calibrated torque wrench using a star pattern.

2.3 Pressure Test of the Primary Containment Vessel

- Connect the pressure test equipment to the test port as depicted in Figure 1.

- With the test port tool verify that the stat-o-seal is in the open position.

- Verify the valve to the pressure relief valve (PRV) is open.

- Verify the pressure regulator control valve is at its minimum pressure setting. 
HNF-3516, Rev. 0

\section{PAS-1 PRESSURE TEST SPECIFIC PROCEDURE}

- Verify the vent valve is closed.

- Pressurize the PCV with nitrogen or dry bottled air to $39.7 \mathrm{psia}$ (25 psi). The pressure shall be increased in steps of 5 psi until the final test pressure of 64.7 psia $(50 \mathrm{psi}) \pm 0.5 \mathrm{psi}$ is reached.

- The system pressure shall be stable on the test gages before proceeding.

- Just prior to the start of the examination the PRV valve may be closed.

- The pressure test shall last a minimum of 10 minutes with no evidence of pressure loss.

- Vent the system and remove the test equipment.

2.4 Installing O-rings and Torquing the Bolts on the Secondary Containment Vessel Lid

- Clean, lightly apply Apiezon vacuum grease, and install the outer O-ring seal on the Secondary Containment Vessel (SCV) lid.

- Install the lid onto the body of the SCV and assemble the cask with the closure bolts.

- The bolts shall be torqued to 100 to $150 \mathrm{ft}-\mathrm{lbs}$ with a calibrated torque wrench using a star pattern. The sequence shall be repeated for 300 to $350 \mathrm{ft}-1 \mathrm{bs}$ with the final torque being 450 to $500 \mathrm{ft}-1 \mathrm{bs}$.

\subsection{Pressure Test of the Secondary Containment Vessel}

- Connect the pressure test equipment to the test port as depicted in Figure 1 .

- With the test port tool verify that the stat-o-seal is in the open position.

- Verify the valve to the pressure relief valve (PRV) is open.

- Verify the pressure regulator control valve is at its minimum pressure setting.

- Verify the vent valve is closed.

- Pressurize the SCV with nitrogen or dry bottled air to $39.7 \mathrm{psia}$ (25 psi). The pressure shall be increased in steps of 5 psi until the final test pressure of 64.7 psia (50 psi) \pm 0.5 psi is reached.

- The system pressure shall be stable on the test gages before próceeding.

- Just prior to the start of the examination the PRV valve may be closed.

- The pressure test shall last a minimum of 10 minutes with no evidence of pressure loss.

- Vent the system and remove the test equipment. 
HNF-3516, Rev. 0

Figure 1

Primary and Secondary

Containment Vessel

Pressure Test

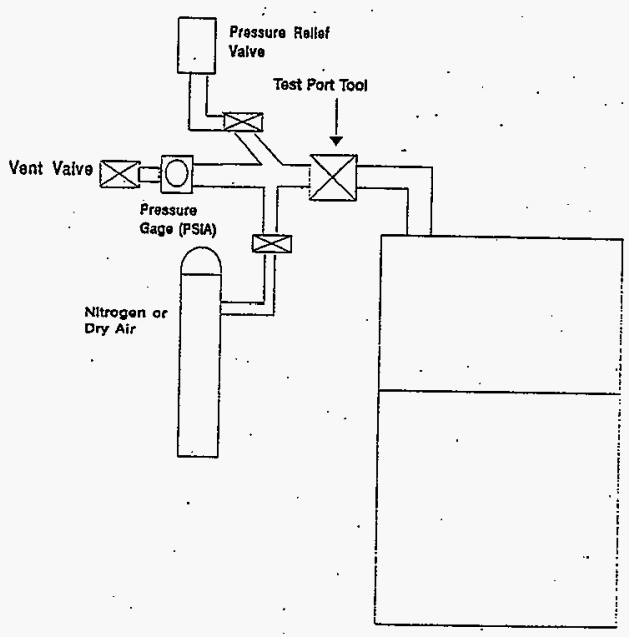


HNF-3516, Rev. 0

\section{DISTRIBUTION}

Number of copies

OFFSITE

U.S. Department of Energy-

Headquarters

Headquarters Certifying Official

Office of Site Operations, EM-70

19901 Germantown Road

Germantown, Maryland 20874

M. E. Wangler

1

Eagle Research Group

13241 Executive Park Terrace

Germantown, Maryland 20874

R. H. Towell

\section{ONSITE}

U.S. Department of Energy, Richland Operations Office

D. W. Claussen $\quad$ S7-55

Public Reading Room H2-53

1

Cogema Engineering Corporation

J. C. Krogness L6-38

2

Lockheed Martin Hanford Corporation

K. A. Gasper

A3-03

W. E. Ross

S7-84

1

Lockheed Martin Services, Inc.

Document Processing Center

A3-94

Distr-1 
HNF-3516, Rev. 0

\section{DISTRIBUTION, Cont.}

Number of copies

ONSITE, Cont.

1

Numatec Hanford Corporation

P. V. Meeuwsen

L6-13

Pacific Northwest National Laboratory

P. R. Bredt

P7-25

K. S. Webster

P7-75

Waste Management Federal Services

of Hanford, Inc.

C. M. Seidel

S3-30

D. D. Volkman

T3-05

4

Waste Management Federal Services, Inc. Northwest Operations

P. C. Ferrell

H1-15

J. E. Mercado

H1-15

R. J. Smith

$\mathrm{H} 1-15$

HNF-3516 File

$\mathrm{H} 1-15$

Distr-2 
DISTRIBUTION SHEET

\begin{tabular}{|c|c|c|c|c|c|}
\hline \multirow{2}{*}{$\begin{array}{l}\text { To } \\
\text { Distribution }\end{array}$} & \multirow{2}{*}{\multicolumn{3}{|c|}{$\begin{array}{l}\text { From } \\
\text { Packaging Engineering }\end{array}$}} & \multicolumn{2}{|l|}{ Page 1 of 1} \\
\hline & & & & \multicolumn{2}{|c|}{ Date 0 ct. 12,1998} \\
\hline \multirow{2}{*}{\multicolumn{4}{|c|}{$\begin{array}{l}\text { Project Title/Work Order } \\
\text { Test Report for PAS-1 Cask Certification for Shipping Payload B } \\
\text { (HNF-3516, Rev. 0) }\end{array}$}} & \multicolumn{2}{|c|}{ EDT No. 622969} \\
\hline & & & & \multicolumn{2}{|c|}{ ECN No. NA } \\
\hline \multicolumn{2}{|c|}{ Name } & $\begin{array}{l}\text { Text } \\
\text { With All } \\
\text { Attach. }\end{array}$ & Text Only & \begin{tabular}{|c} 
Attach./ \\
Appendix \\
Only
\end{tabular} & $\begin{array}{l}\text { EDT/ECN } \\
\text { Only }\end{array}$ \\
\hline $\begin{array}{l}\text { P. R. Bredt } \\
\text { D. W. Claussen } \\
\text { P. C. Ferrell } \\
\text { K. A. Gasper } \\
\text { J. C. Krogness } \\
\text { P. V. Meeuwsen } \\
\text { J. E. Mercado (3) } \\
\text { W. E. Ross } \\
\text { C. M. Seide] } \\
\text { R. J. Smith } \\
\text { D. D. Volkman } \\
\text { K. S. Webster }\end{array}$ & $\begin{array}{l}P 7-25 \\
S 7-55 \\
H 1-15 \\
A 3-03 \\
L 6-38 \\
\text { L6-13 } \\
H 1-15 \\
\text { S7-84 } \\
\text { S3-30 } \\
H 1-15 \\
T 3-05 \\
\text { P7-75 }\end{array}$ & $\begin{array}{l}x \\
x \\
x \\
x \\
x \\
x \\
x \\
x \\
x \\
x \\
x \\
x \\
x \\
x\end{array}$ & & & \\
\hline $\begin{array}{l}\text { RL Reading Room } \\
\text { HNF- } 3516 \text { File } \\
\text { Work Control (D. Kelly }\end{array}$ & $\begin{array}{l}\mathrm{H} 2-53 \\
\mathrm{H} 1-15 \\
\mathrm{H} 1-15\end{array}$ & $\begin{array}{l}x \\
x\end{array}$ & & & $\mathrm{x}$ \\
\hline Central Files & $\mathrm{Bl}-07$ & $x$ & & & \\
\hline
\end{tabular}

